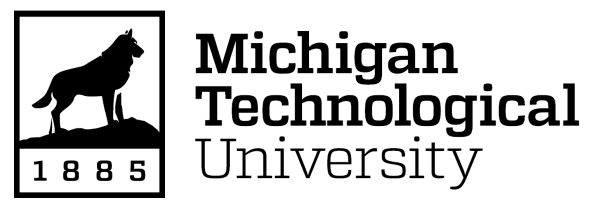

Michigan Technological University Digital Commons @ Michigan Tech

\title{
HOW DO ANGRY DRIVERS RESPOND TO EMOTIONAL MUSIC? A COMPREHENSIVE PERSPECTIVE ON ASSESSING EMOTION
}

Seyedeh Maryam Fakhr Hosseini

Michigan Technological University, sfakhrho@mtu.edu

Copyright 2018 Seyedeh Maryam Fakhr Hosseini

\section{Recommended Citation}

Fakhr Hosseini, Seyedeh Maryam, "HOW DO ANGRY DRIVERS RESPOND TO EMOTIONAL MUSIC? A COMPREHENSIVE PERSPECTIVE ON ASSESSING EMOTION", Open Access Dissertation, Michigan Technological University, 2018.

https://doi.org/10.37099/mtu.dc.etdr/725

Follow this and additional works at: https://digitalcommons.mtu.edu/etdr

Part of the Applied Behavior Analysis Commons, Cognition and Perception Commons, Cognitive Psychology Commons, Experimental Analysis of Behavior Commons, and the Human Factors Psychology Commons 
HOW DO ANGRY DRIVERS RESPOND TO EMOTIONAL MUSIC? A COMPREHENSIVE PERSPECTIVE ON ASSESSING EMOTION

By

Seyedeh Maryam Fakhr Hosseini

\begin{abstract}
A DISSERTATION
Submitted in partial fulfillment of the requirements for the degree of DOCTOR OF PHILOSOPHY
\end{abstract}

In Applied Cognitive Science and Human Factors

MICHIGAN TECHNOLOGICAL UNIVERSITY

2018

(C) 2018 S. Maryam Fakhr Hosseini 
This dissertation has been approved in partial fulfillment of the requirements for the Degree of DOCTOR OF PHILOSOPHY in Applied Cognitive Science and Human Factors.

Department of Cognitive and Learning Sciences

Dissertation Advisor: Myounghoon Jeon

Committee Member: Kelly Steelman

Committee Member: $\quad$ Shane Mueller

Committee Member: $\quad$ Dongyuan Debbie Wang

Department Chair: Susan Amato-Henderson 


\section{Table of Contents}

Acknowledgements .............................................................................................. vi

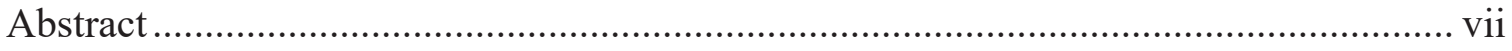

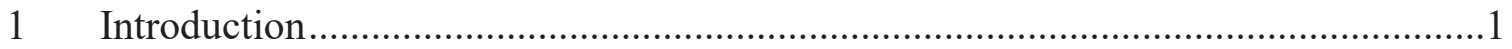

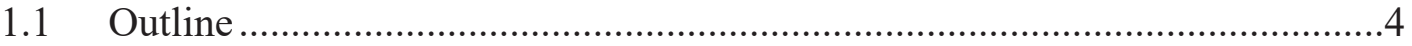

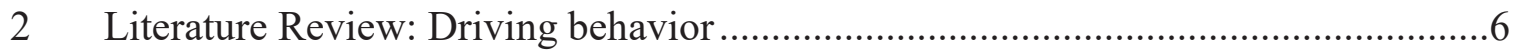

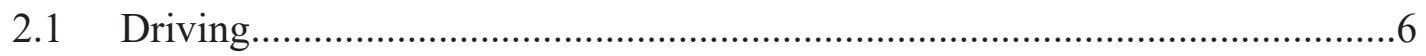

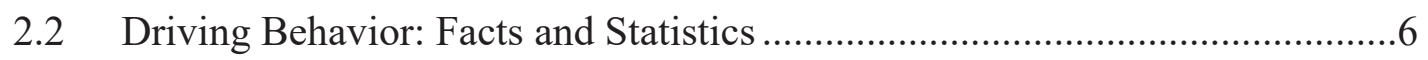

2.3 Distracted Driving .....................................................................................

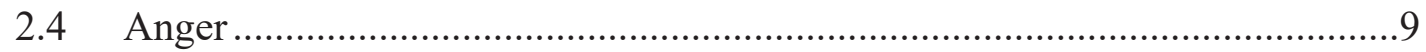

2.5 Driver Personality and Aggressive Driving ……………...........................12

2.6 What Causes Aggressive Driving? ..............................................................15

3 Literature Review: Music and Driving .............................................................16

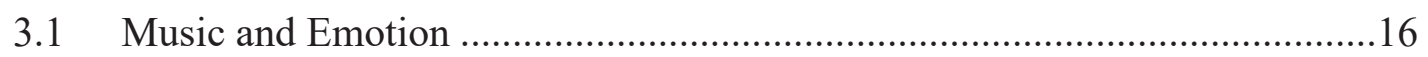

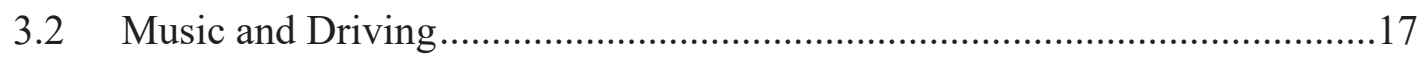

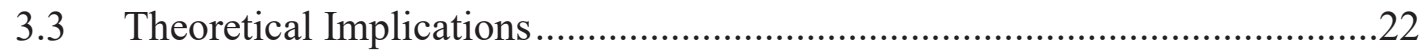

$4 \quad$ How Can Anger Be Measured? .................................................................................2

4.1 Heart Rate Variability (HRV) and Methods to Measure HRV …………........30

4.2 Hemodynamic Changes of Pre-frontal Cortex .................................................31

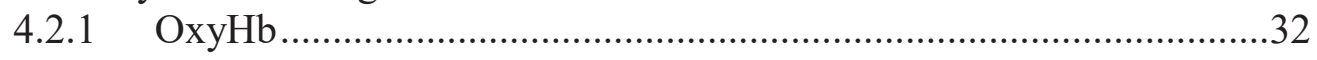

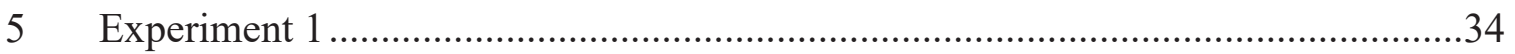

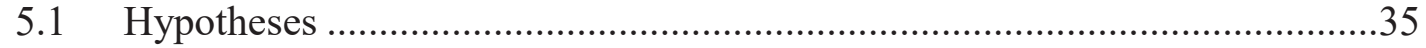

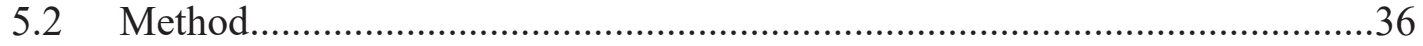

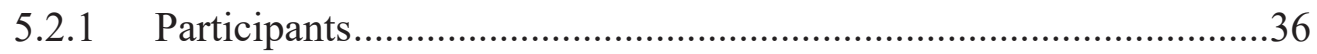

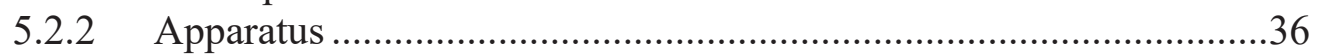

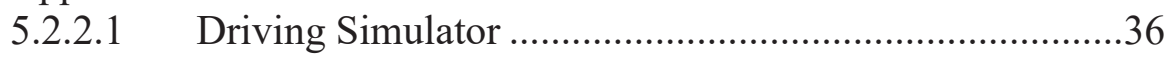

5.2.2.2 Electrocardiogram (ECG) ……………………...............37

5.2.2.3 Functional Near-Infrared Spectroscopy (fNIRS) .............37

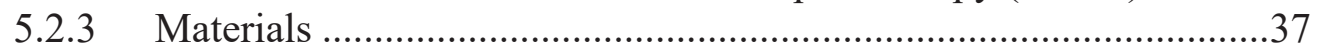

5.2.3.1 Differential Emotions Scale (DES) .................................37

5.2.3.2 Answer-Alternative Questionnaire …………..................38

5.2.3.3 Cognitive-Affective Response Test-Music (CART-M)..38 
5.2.3.4 Driving Anger Scale ........................................................38

5.2.3.5 Driving Behavior Questionnaire .......................................39

5.2.3.6 State-Trait Anger Expression Inventory-2 (STAXI-2) ...39

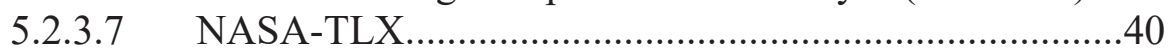

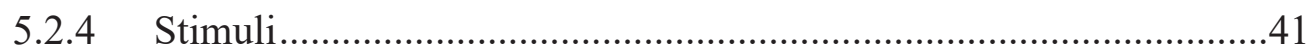

5.2.4.1 Music....................................................................... 41

5.2.4.2 Driving Scenario ...........................................................41

5.2.5 Design and Procedure …………......................................................42

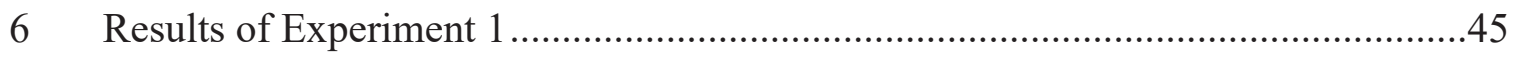

6.1 Subjective Results: Emotion Manipulation Check …………………….........45

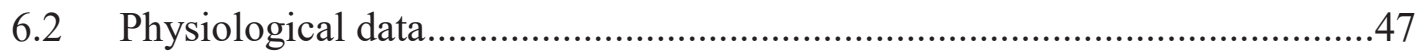

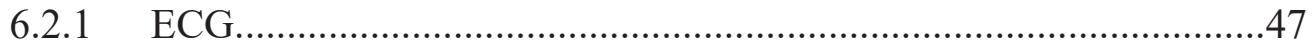

6.2.1.1 Between group comparisons ..........................................48

6.2.1.2 Within group comparisons ...............................................50

6.2.1.2.1 (ECG) HR ………………………….......50

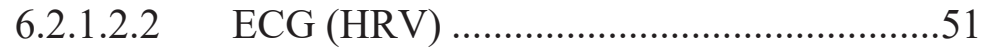

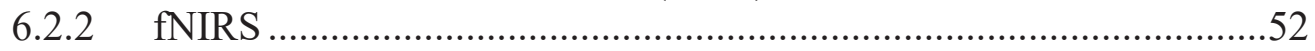

6.2.2.1 Between group comparisons ..........................................53

6.2.2.2 Within group comparisons ................................................53

6.3 Behavioral Data: Driving Errors ………………...................................5

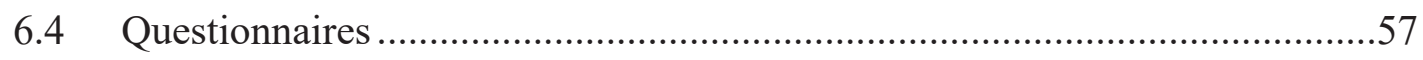

6.4.1 Workload................................................................................57

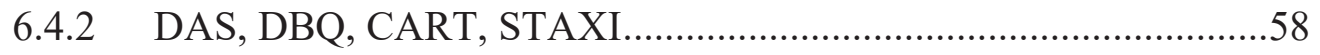

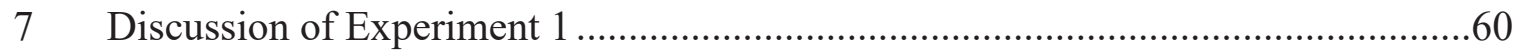

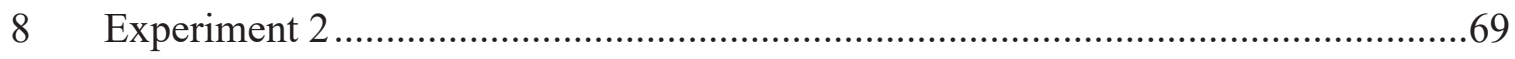

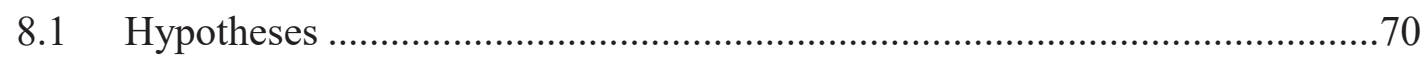

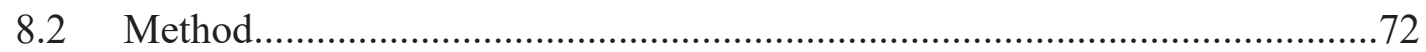

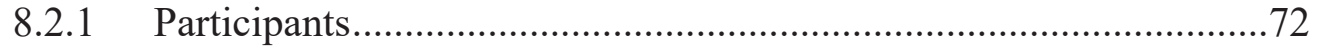

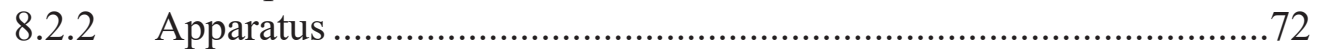

8.2.2.1 Driving simulator .........................................................72

8.2.2.2 Electrocardiogram (ECG) ..............................................73

8.2.2.3 Functional Near-Infrared Spectroscopy (fNIRS) .............73

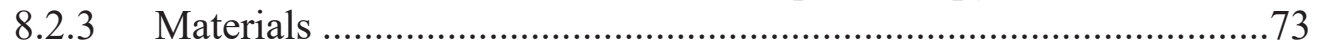

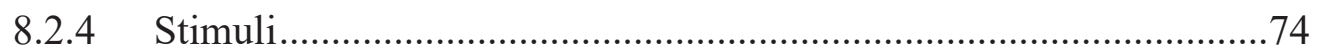

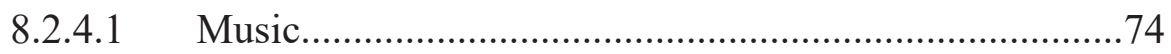

8.2.4.2 Driving Scenario ...........................................................74

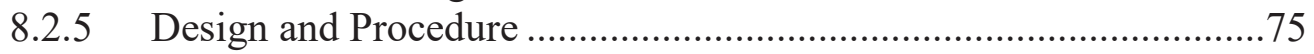

77 


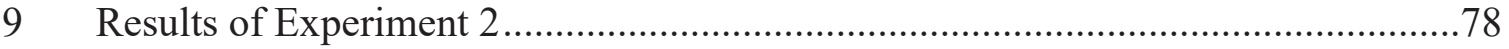

9.1 Subjective Results: Emotion Manipulation Check ............................................78

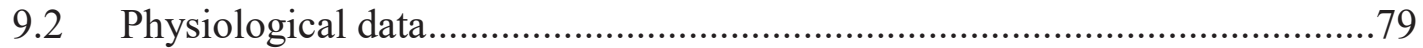

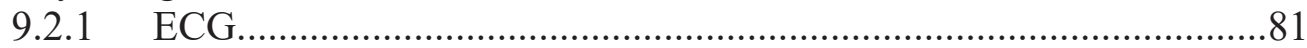

9.2.1.1 Between Group Comparisons ..........................................81

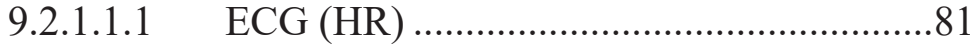

9.2.1.1.2 ECG (HRV) .......................................... 83

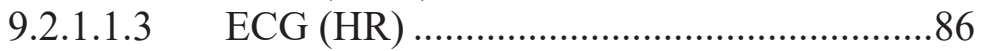

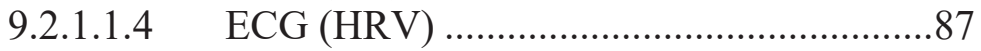

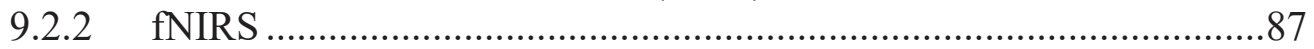

9.2.2.1 Between Group Comparisons ……………………….......87

9.2.2.2 Within Group Comparisons ..............................................88

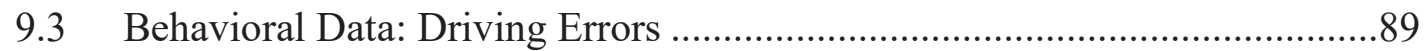

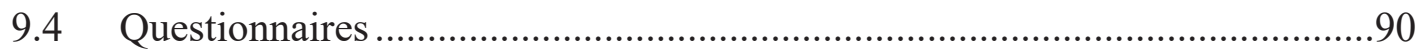

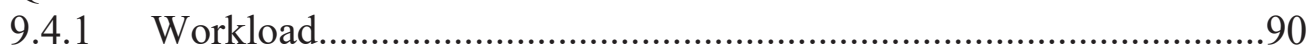

9.4.2 DAS, DBQ, CART, STAXI..........................................................

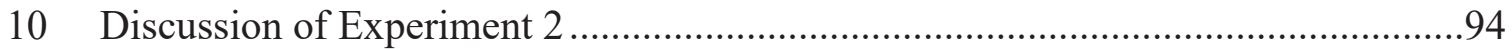

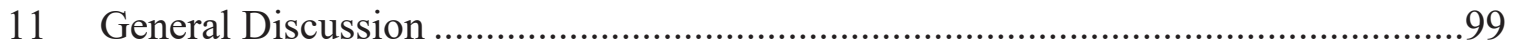

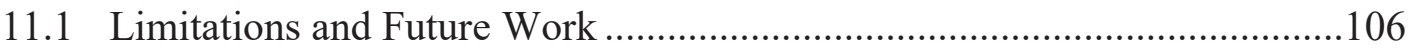

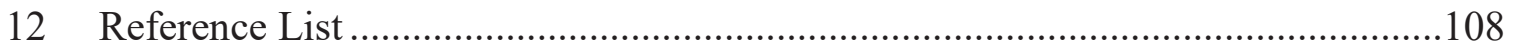

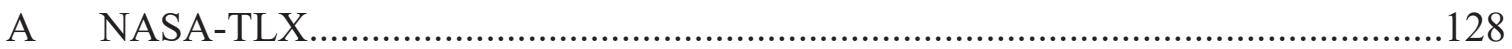




\section{Acknowledgements}

To my advisor Dr. Jeon, I couldn’t have done this without you.

To my husband, thank you for all of your support along the way. 


\section{Abstract}

Driving is a complicated task that requires the coordination of visual and sensory-motor skills. Unsafe driving behavior and accidents can happen regardless of the level of drivers' experience. The main cause of the most of these accidents is human error. Emotions influence the way drivers process and react to internal or environmental factors. Specifically, anger elicited either from traffic or personal issues, is a serious threat on the road. Therefore, having an affective intelligent system in the car that can estimate drivers' anger and respond to it appropriately can help drivers adapt to momentto-moment changes in driving situations. To this end, the present dissertation uses an integrated approach to monitoring drivers' affective states in various driving contexts to address the question: "What types of music can mitigate the effects of anger on driving performance?" Three sources of information (behavioral, physiological, and subjective data) were considered in two experiments. In Experiment 1, three groups of participants were compared based on their emotional reactions and driving behaviors. Results showed that angry drivers who did not listen to music had riskier driving behavior than emotionneutral drivers. Results from heart rate, oxygenation level in prefrontal cortex, and selfreport questionnaires showed that music could help angry drivers react at the similar level to emotion-neutral drivers both internally and behaviorally. In Experiment 2, types of music emotion and familiarity of music were addressed to identify what kind of music an in-vehicle auditory system should play when it recognizes drivers' anger. Results showed that different kinds of music did not effect driving performance. However, drivers experienced less frustration and effort when listening to music in general and less 
frustration when listening to self-selected music specifically. Regarding personality characteristics, drivers who had anger-expression out style had riskier driving behavior just as in Experiment 1. In conclusion, this research showed the benefits of music as a possible strategy to help angry drivers. In addition, important patterns were uncovered relating to assessing driver anger for possible affective intelligent systems in cars. 


\section{Introduction}

Automobiles and in-vehicle safety systems have been improved over the past several decades (Lee, 2008). Researchers classify driving safety strategies into two categories: Passive and Active/Primary safety applications. Passive strategies, such as airbags, help people stay alive and uninjured in the accidents (Lee, 2008), while active strategies, such as collision warnings and electronic stability controls, aid in the prevention of car crashes and improve drivers' performance (Jarašūniene \& Jakubauskas, 2007; Schoeneburg \& Breitling, 2005). Although vehicle technologies have been improved greatly to protect their users, National Safety Council estimated around 40,100 driving fatalities in the United States in 2017.

The National Highway Traffic Safety Administration (NHTSA) estimates that around $25 \%$ of traffic accidents in the U.S. are due to a distracted driver (Dibben, \& Williamson, 2007). Driving requires a high level of attention and information processing. Any competing stimulus that holds a drivers' attention to something other than driving, may lead to dangerous consequences (Brodsky, 2015). Among these stimuli, emotional events, related or unrelated to the driving, have been identified as potential problems. Emotions distract driver attention, cause loss of situation awareness and lack of coordination, and consequently, lead to unsafe driving (Jansen, Westphal, Jeon, \& Riener, 2013; Jeon, Yim, \& Walker, 2011; Lisetti \& Nasoz, 2005).

Given that the main cause of road accidents is human error (Lajunen, Parker, \& Summala, 2004), monitoring drivers via in-vehicle-systems and responding to the drivers in an appropriate manner is one method to increase driving safety. A study conducted by 
Lisetti and Nasoz (2005) focused on designing in-vehicle intelligent systems called "Multimodal Affective Intelligent Interfaces (MAUI)" to monitor and respond to drivers' emotional states. They suggested that their affective intelligent car interface system could enhance drivers' safety by helping them be better aware of themselves. To alert drivers, they successfully analyzed psychological data by an algorithmic process and devised an intervention interface with different strategies, such as turning on the radio, opening the car's window, or playing music; however, they did not discuss drivers' performance data.

Music, for its ability to successfully influence the mood and body (Haake, 2011;

Saarikallio, \& Erkkilä, 2007), has been considered a potential tool to regulate emotions of angry drivers (FakhrHosseini, Jeon, \& Bose, 2015). Research efforts have been made to find types of music and specific musical features to regulate emotion and improve driving performance (FakhrHosseini, Landry, Tan, Bhattarai, \& Jeon, 2014; Van der Zwaang et al., 2012). For example, Brodsky (2001) in a study on a driving simulator found that drivers sped more as the tempo of the background music increased. Disregarded red traffic-lights, lane crossings, and collisions were other errors found in his study as the influence of increased background music tempo. He discussed that music tempo can be a leading factor to risky driving by competing for attentional space. 
This dissertation aimed to investigate different types of music as a potential strategy to help angry drivers. Two experiments were designed to find the relationships of drivers' affective state (specifically, anger), driving performance, and the effects of music more systematically. To obtain an overall picture, I looked at three different types of measures: behavioral data, physiological data, and subjective experience data (Figure 1.1). In Experiment 1, I examined the influence of music on angry drivers' errors, while driving in low, medium, and high traffic conditions. The results of this experiment showed the type of errors angry drivers made and the differences among angry drivers' behavior when they listened to music and did not.

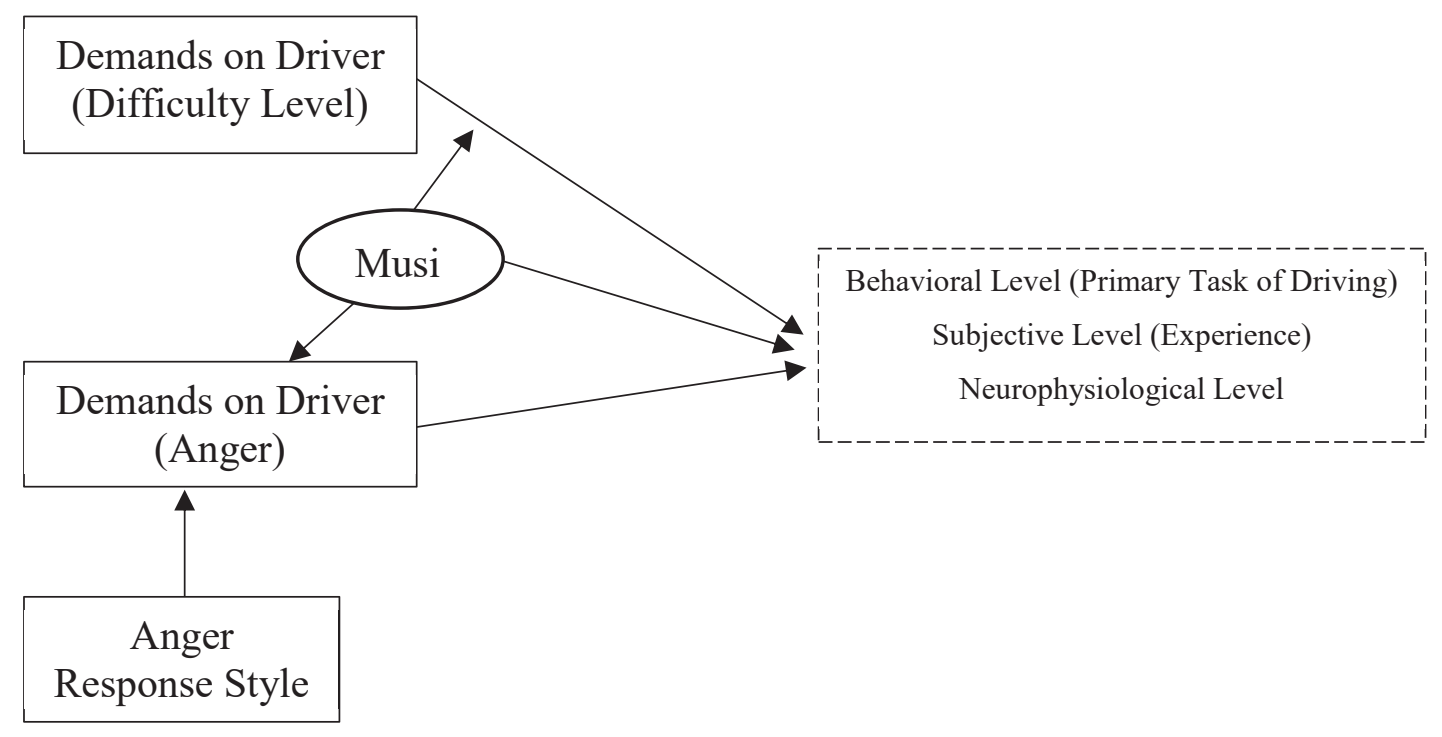

Figure 1.1. An overview of the mechanisms and factors involved in the drivers' emotional status.

In Experiment 2, various types of music pieces were used to mitigate the effects of drivers' anger on driving. The results provided the information about the relationships of 
drivers' emotional states and diverse types of music. The ultimate goal would be to design an affective intelligent car system that will facilitate the interaction between drivers and their vehicles by informing the drivers about their current emotional states and by regulating further their emotional states and actions.

\subsection{Outline}

In chapter 2, I provide the statistical report of injuries and fatalities of road accidents. The literature review covers the definitions of angry and aggressive drivers, research of such drivers in different situations, and knowledge gaps found in previous studies. Then, contradictory results about the impact of music on driving performance will be discussed and theories that assist the present study to assess emotional states will be introduced.

In Chapter 3, I cover a comprehensive overview of previous studies on the influence of music on mind and body. I review the results of the research that used music in naturalistic or simulated driving environments. Then, the gaps of previous studies and the theoretical considerations will be discussed as the necessity of this study. In addition, Chapter 4 is devoted to theories and models for assessing emotion. I describe the measurements for this study and how I approach them.

Experiments 1 and 2 will be explained in Chapters 5 and 8 respectively. Each chapter includes the goal of the study, hypotheses, participants, materials, design, and procedures.

In Chapters 6 and 7 results and discussions of Experiment 1 are explained in details. Results and discussions of Experiment 2 are brought in Chapters 9 and 10. Finally, in 
Chapter 11, I discuss the overall study, applications of the results, limitations, and future work. 


\section{Literature Review: Driving behavior}

\subsection{Driving}

In this chapter, I review previous studies of driver distraction. I provide some facts and statistics about road accidents, including how many of the injuries and fatalities are related to distracted (and emotional) drivers. The concentration is on the definitions of driving, angry drivers and types of driving styles. In addition, the research gaps that have not been addressed are highlighted.

\subsection{Driving Behavior: Facts and Statistics}

Driving is a complicated task that requires coordination of many subtasks. For example, in one mile, drivers have to apply almost 1500 sub-skills (e.g., checking speed, maintaining distances, estimating risks, etc.) and make around 20 decisions (Brodsky, 2015). Eyben et al. (2010) broke driving subtasks into three categories: primary tasks, secondary tasks, and tertiary tasks. Primary tasks are tasks necessary for safe vehicle control (e.g., accelerating, braking, etc.). Secondary tasks facilitate safe driving indirectly (e.g., turning on windscreen wipers, etc.). Tertiary tasks are irrelevant to safe driving (using air conditioner, radio, etc.) (Eyben, Wöllmer, Poitschke, Schuller, Blaschke, Färber, \& Nguyen-Thien, 2010). When drivers engage in secondary and tertiary tasks, they may miss driving-relevant information, which could result in unsafe driving (Brodsky, 2015).

Recently, vehicle technologies have been vastly improved to protect drivers. The annual number of vehicle crash fatalities has declined from an average of 42,000 from 1995- 
2007 to about 32,000 in 2010 (Tefft, 2012). Therefore, in 2011, for the third consecutive year, traffic collisions fell outside the top 10 causes of death in America. Despite the progress of technological advancement in automotive industry, motor vehicle crashes were still the 12th leading cause of death in the United States among all ages and the number one cause of death in youth (16-20), youth adults (21-24) and young adults (2124) in 2011 (NHTSA, 2015).

\subsection{Distracted Driving}

Distraction happens when the driver is engaging in another tertiary activity, such as talking on the phone or daydreaming. Distraction is defined as "the diversion of attention from activities critical for safe driving toward competing activities" (Lee, Young, \& Regan, 2009). The National Highway Traffic Safety Administration (NHTSA) estimates that distraction is the reason of almost 25 percent of traffic accidents in the United States, which is around 1.2 million incidents annually (Ranney, Mazzae, Garrott, \& Goodman, 2000).

Lee (2008) distinguished distraction from inattention in driving. He suggested that "inattention represents diminished attention to activities that are critical for safe driving in the absence of a competing activity"; for example, fatigue can influence drivers' capacity to attend to the road.

Young, Regan, and Hammer (2007) divided driver distraction into four classes: visual, auditory, biomechanical (physical), and cognitive distraction. Visual distraction occurs when drivers' visual attention is on another target instead of the road for a while. 
Auditory distraction happens when drivers focus their attention on driving-irrelevant auditory signals. Biomechanical or physical distraction occurs when drivers remove at least one hand from the steering wheel. Cognitive distraction includes any thoughts that grab drivers' attention from the road.

Recently, emotions have been considered another critical factor of driver distraction in driving safety research (Chan, \& Singhal, 2015; Cunningham, \& Regan, 2016; Deffenbacher, Filetti, Lynch, Dahlen, \& Oetting, 2002; FakhrHosseini, Kirby, \& Jeon, 2015; Jeon, Yim, \& Walker, 2011; Underwood, Chapman, Wright, \& Crundall, 1999; Van der Zwaag, Fairclough, Spiridon, \& Westerink, 2011). Emotions have a major impact on performance (Lazarus, 1982; Izard, 1992). Emotional drivers may fail to attend on the critical information at the right time due to occupied resources with emotions (Lee, 2008). Therefore, any changes in drivers' affective state can lead to performance errors (Hughes, Rudin-Brown, \& Young, 2012). Among all types of emotions, anger is relatively a common emotion while driving (Underwood, Chapman, Wright \& Crundall, 1999). Anger can be integral or incidental while driving. Integral affect describes anger which is related to the driving situations. Incidental affect comes from experiences that are not related to driving (Bodenhausen, 1993). Most of the previous research showed that angry drivers make more driving errors than non-angry drivers. (Deffenbacher, Filetti, Lynch, Dahlen, \& Oetting, 2002; Jeon, Yim, \& Walker, 2011; Underwood, Chapman, Wright, \& Crundall, 1999; Ünal, Steg, \& Epstude, 2012; Van der Zwaag, Fairclough, Spiridon, \& Westerink, 2011). 


\subsection{Anger}

Anger, like any other emotions, consists of components that vary in different situations. The components include patterns of peripheral physiological responses, brain activation, physical sensation, subjective feelings and experiences, cognition, and action tendencies (Scherer, 2005). The operational definition of anger refers to a negatively felt state associated with cognitive distortions and physiological changes in response to a negative stimulus that may result in maladaptive patterns of behavior (Cox, 2008). Lazarus (1991) suggested that anger has been associated with a sense that one has been treated unfairly by another entity paired with a certainty of unfairness (Potegal, \& Spielberger, 2010). Feeling angry usually creates a kind of belief that another person is responsible for the negative event and an expectation that the self has the ability to overcome the situation (Lerner \& Tiedens, 2006).

Based on appraisal theory of emotion, core cognitive dimensions of anger are (a) otherresponsibility for negative events, (b) individual control, and (c) a sense of certainty about what happened (Smith \& Ellsworth, 1985). Therefore, emotion influences the ongoing cognitive processes, judgment, memory, attention, etc. To understand the role of underlying appraisals on affect and judgment, Lerner and Keltner (2000) compared fear and anger by risk assessments made by fearful and angry individuals based on two different approaches: two-dimensional theory of emotion and appraisal-tendency framework. Based on two-dimensional theory of emotion, since anger and fear have similar arousal and valance levels, angry and fearful individuals will have similar risk assessment. In line with appraisal-tendency framework, angry and fearful individuals will 
have different perceptions of risky situations. Consistent with the appraisal-tendency view, fearful and angry participants showed different risk assessments. Participants who went through anger induction procedure predicted lower risk assessments in comparison to those who were induced fear. These results indicate that the systematic misperception of situations may lead to take more risks by angry people.

There is a great deal of evidence that suggests anger influences autonomic, sympathetic, and parasympathetic nervous systems. Scherer and Wallbott (1994) studied bodily changes of 2,921 samples from 37 countries and found that participants with induced anger was characterized by rapid heart rate, tension, fast breathing, and feeling hot. Studies on anger induction, mostly report that anger is associated with increased systolic blood pressure and heart rate (Cox, 2008; Potegal, \& Spielberger, 2010). Levenson et al. (1990), in the Directed Facial Action Task, observed higher heart rate, finger skin temperature, and skin conductance level when they instructed the participants to contract and hold several facial muscles. In another study, the average heart rate of drivers increased after anger induction (i.e., writing past angry experiences) as compared to the baseline i.e., before induction (Jansen, Westphal, Jeon, \& Riener, 2013).

Results of previous studies have found that the left hemisphere is associated with positive emotions (Suda, Morimoto, Obata, Koizumi, \& Maki, 2008) and the right with negative emotions (Harmon-Jones, \& Sigelman, 2001, Ehrlichman, 1987). The role of left and right hemispheres during anger is related to approach-withdrawal behavior (Hamon-Jones et al., 2003). Activation in the left prefrontal cortex (PFC) has been associated with anger-motivated approach but activation in the right PFC is associated with anger- 
motivated withdrawal. Hamon-Jones and colleagues also concluded that when there are opportunities to overcome the obstacle causing anger, there is increased activation in the left PFC.

To see the effects of anger on driving performance and safety, FakhrHosseini, Jeon, and Bose (2015) investigated angry drivers' oxygen concentration level of PFC using functional Near Infrared Spectroscopy (fNIRS), one of the physiological indicators of emotional changes. Ten participants drove in scenarios with and without anger where they encountered different hazards after anger induction. Drivers' oxygen concentration of PFC was recorded during the driving and the anger induction sessions (recall and writing). Cluster analysis and factor analysis of fNIRS data showed that oxygen concentration levels were higher in the angry driving period than in the neutral state. Specifically, the right hemisphere, which is responsible for negative emotions, showed consistently higher oxygen concentration levels than the left hemisphere during angry driving session. This study showed benefits of using fNIRS in the driving context where drivers' emotional states can be identified and distinguished from the neutral state based on fNIRS data. This method can be used to transit the physiological data to adaptive mitigation interfaces to provide real-time feedback to emotional drivers. (FakhrHosseini, Jeon, \& Bose, 2015).

Emotions with negative valance can decrease the available attentional resources. While processing negative emotions, mechanisms such as ruminations and internal thoughts do not let the attentional resources be used to perform the tasks (Ellis \& Ashbrook 1988). Moreover, high arousal level increases the duration of individual's concentration time on 
the arousing stimuli and distracts the person from other tasks, in other words, inattention (Jallais, Roge, Alexandra, \& Gabaude, 2013). Craft and Preslopsky (2009) defined inattention as: "when the driver's mind has wandered from the driving task for some noncompelling reason". In a complicated task like driving, these emotions and the internal thoughts influence drivers' information processing and performance. For example, participants who reported anger drove faster and exceeded the speed limit more often than those who did not report anger (Mesken, Hagenzieker, Rothengatter, \& de Waard, 2007).

Previous studies showed that anger significantly degrades driving performance (e.g., Deffenbacher, Deffenbacher, Lynch, \& Richards, 2003; Jeon, Yim, \& Walker, 2011; Roidl, Frehse \& Höger, 2013; Underwood, Chapman, Wright, \& Crundall, 1999). Research has shown that anger negatively influences various driving performance and risky behaviors such as lane deviations, speed, and collisions (Deffenbacher et al., 2003;

Jeon et al., 2011; Underwood et al., 1999). Since much research (e.g., Underwood et al., 1999) showed the frequency of experiencing anger while driving is high, it confirms the importance of investigating its mechanisms and possible solutions.

\subsection{Driver Personality and Aggressive Driving}

Individuals differ in the way they express anger. The State-Trait Anger Expression Inventory (STAXI; Spielberger, 1988) captures State and Trait Anger as well as the Anger Expression (AX) style of individuals. In STAXI, State Anger measures the intensity of individuals' angry feelings within a specific time frame, and Trait Anger 
measures individuals' general tendency to become angry. If people usually express their anger outwardly, it represents a style known as Anger Expression-Out. This style may lead to physical or verbal expressions of anger. Conversely, Anger Expression-In response style refers to individuals who suppress their behavioral expressions when they are angry (Spielberger, 1999; Vagg, \& Spielberger, 1979).

Deffenbacher's (2001) research on emotional driving has focused on personality, aggressiveness, and risk-taking characteristics of drivers with high trait-anger. His studies revealed that drivers with high trait-anger are more critical towards other drivers, compared to low-anger drivers. Drivers with high trait-anger also get angry more quickly, and behave more aggressively by doing things, such as yelling or honking their horns. High trait-anger drivers also report more near-accidents and receive more speeding tickets than low trait-anger drivers. Overall, drivers with higher trait anger demonstrate a lack of control of their vehicle as a result of their anger (Deffenbacher, Deffenbacher, Lynch, \& Richards, 2003; Deffenbacher, Huff, Lynch, Oetting, \& Salvatore, 2000; Deffenbacher, Lynch, Oetting, \& Yingling, 2001; Lynch, Deffenbacher, Filetti \& Dahlen, 1999).

Tasca (2000) suggested a driving behavior is aggressive if "it is deliberate, likely to increase the risk of collision and is motivated by impatience, annoyance, hostility and/or an attempt to save time" (p.2). In his article "A review of the literature on aggressive driving research", aggressive driving has generally been attributed to one or more of the following: speeding, being frustrated towards other drivers in congested traffic conditions, disobeying traffic signals and rules, disregarding other drivers' right-of-way, 
tailgating, weaving, changing lanes suddenly and without indication, improper passing, and racing.

In total, 106,727 fatal crashes during the years 2003 to 2007 involved at least one driver who committed a potentially-aggressive action (AAA, 2009). Results of AAA Foundation for Traffic Safety research (2016) showed that more than 78\% of drivers, mostly ages $25-39$, reported having engaged in at least one aggressive driving behaviors (e.g., tailgating, yelling at other drivers, blocking another driver from changing lane) in 2014. Another surprising result in this study was that around 5.7 million drivers in the US intentionally bumped or rammed another vehicle in 2014. Moreover, male drivers committed more aggressive driving behaviors than female drivers.

To identify social and psychological factors that would distinguish aggressive from nonaggressive drivers, Beck et al. (2006) measured some factors via a random digit dial telephone survey. Responses from 1715 non-aggressive and 305 aggressive drivers (selfreported) showed that aggressive drivers were more likely to be male and aged 45 and under. Aggressive drivers had significantly different opinions about aggressive behaviors. In this case they identified speeding and using a cell phone while driving as a less critical concern than non-aggressive drivers. Also, aggressive drivers reported more experiences of drowsiness, cell phone use while driving and tickets for traffic offenses. However, both groups had similar concerns about drunk driving, running red lights or stop signs, distracted or inattentive driving, road rage, and underage drinking. Aggressive drivers differed from non-aggressive drivers in their beliefs about the effectiveness of sobriety checks at reducing drunk driving and the fairness of higher penalties for drunk drivers 
with very high blood alcohol levels. Aggressive drivers (compared to non-aggressive drivers) described themselves as significantly more perturbed, frustrated and careless when they drive. However, in this study, they discriminated between aggressive and nonaggressive drivers based on several experimenter-made questionnaire instead of using a standard questionnaire.

\subsection{What Causes Aggressive Driving?}

Anyone may drive aggressively if expressing anger becomes more important than safe driving. Causes of driver anger vary depending on the situation. In a naturalistic driving situation, Hennessy and Wiesenthal (1999) showed that the driver's state stress was greater in high- than in low-congestion conditions. To find emotion eliciting situations in the driving context, Underwood, Chapman, Wright, and Crundall (1999) asked 100 drivers to keep a record of anger inducing driving situations. The diaries consisted of 293 near accidents and 383 traffic violations. More than $80 \%$ of the drivers experienced anger at least once during the two-week period, showing that anger is a common emotion in the driving context. Most of the reports were claimed in high congestion conditions but they were not related to the intensity of anger felt by the drivers. This study showed that near accidents provoked feelings of anger, especially when they believed that it was another driver's fault. Results from Driving Behavior Questionnaire and Driving Anger Scale were not correlated with the reports, which supports the notion that such anger is an inevitable consequence of involvement in near accidents (Lerner \& Tiedens, 2006). 


\section{Literature Review: Music and Driving}

In this chapter, I describe the influence of music on mind and body. For its ability to elicit emotion and change the mood, music has been used in different situations such as driving. Then, I discuss the elements of music and their relationship to emotions. The focus is on angry drivers. Following that, I introduce theories that can help measure emotions and predict their outcomes. In addition, the theories of emotion will facilitate the assessment process of emotions in the following chapter.

\subsection{Music and Emotion}

Listening to music leads to brain activity across multiple regions (Ryali, Supekar, Abrams, \& Menon, 2010). For its tremendous effects on thoughts and emotions, music has been used for different purposes. Music therapy in psychology is an effective tool in reducing anxiety, tension, blood pressure, and heart rate (Saarikallio \& Erkkilä, 2007; Sendelbach, Halm, Doran, Miller, \& Gaillard, 2006). Music helps people focus their attention in the workplace (Haake, 2011) or students at school (Lewis, 2002). Music also helps patients get them away from the experience of pain (Nguyen, Nilsson, Hellström, \& Bengtson, 2010). Other than reducing negative symptoms, it facilitates relaxation (Hennessy, 2000; Nilsson, 2009) and perceptions of situational control, and consequently, leads to better performance (Hennessy, 2000).

One of the most popular activities in the vehicle is listening to music and talk radio (Dalton \& Behm, 2007; Dibben \& Williamson, 2007; Sloboda, O’Neill \& Vivaldi, 2001). An observational study of American drivers showed that audio was playing in vehicles 72 
percent of the time while on the road (Stutts, 2003). In a survey of British drivers conducted by Dibben and Williamson (2007), two-thirds of drivers claimed that they usually listen to music while driving. Evidence suggests that people play music in cars because it provides a feeling of pleasure or excitement, prevents boredom, entertains and relaxes drivers, etc. (Dibben, \& Williamson, 2007). From this point of view, playing music while driving can be considered a strategy for individuals to alter their environment based on their needs.

\subsection{Music and Driving}

Research observing the influence of music on driving has shown contradictory results. In 1984, Hancock argued that there was not enough research to make a confident statement on the effects of various types of music on driving behavior. Today, after more than 30 years there is still no consensus and many contradictory results exist. Some studies found that the presence of music while completing a task may add cognitive load due to additional irrelevant stimuli and contribute to cognitive overload, especially when there are not enough available cognitive resources to attend all the demands of the task (North \& Hargreaves, 1999). For example, Ünal et al. (2013) showed that driving with loud music significantly increases self-reported mental effort regardless of driving conditions. Additionally, poorer driving game performance was found in the presence of music (Cassidy \& Macdonald, 2009; Yamada, 2002). In another study, high-intensity (loud) music was only associated with an increase in response time to peripheral signals under high-demand conditions (Beh, \& Hirst, 1999). Research suggests that the more a piece of music engages attention, the more likely it is to overlap with attentional requirements of 
the primary driving task, which will result in driving performance decrements. For example, music with high arousal ratings resulted in an increase of speeding and red-light violations during a simulated drive (Ünal, Steg, \& Epstude, 2012) and slower lap times compared to low arousing music which led to the faster lap times (North \& Hargreaves, 1999).

Not all evidence points in the same direction. It is also found that listening to music does not negatively influence driving performance (Dibben, \& Williamson, 2007), and can even facilitate safer driving (Beh \& Hirst, 1999; Brown, 1965; Matthews, Quinn, \& Mitchell, 1998). Results from a self-reported survey research project suggested that listening to music was not correlated with crashes (Dibben \& Williamson, 2007). It seems that the potential benefits of listening to music while driving are moderated by mental workload levels. If a driving task is very demanding, a secondary task music may deteriorate driving performance. However, in an unchallenging driving environment, a secondary task may not influence primary task performance at all or even enhance driving performance in some conditions (Beh \& Hirst, 1999; Consiglio, Driscoll, Witte, \& Berg, 2003; Oron-Gilad, Ronen, \& Shinar, 2008; Ünal, Steg, \& Epstude, 2012; Ünal, Platteel, Steg, and Epstude, 2013; Wang, Jimison, Richard, \& Chuan, 2015). Therefore, data suggest the effect of music on driving is partly determined by the primary task difficulty.

Music is just one of many potential strategies to regulate the arousal levels of drivers (Ünal, Steg, \& Epstude, 2012). Regarding the influential characteristics of music, Groene and Barrett (2012) showed that $83 \%$ of drivers had less stress while driving with music. 
In this study, drivers in the music group listened to an instrumental music piece taken from a $\mathrm{CD}$. The $\mathrm{CD}$ was created by a music therapist to reduce the anxiety of commuters for 13.5 minutes. In a similar study, Hennessy (2000) measured drivers' stress with a cellphone during a single commute in low and high congestion conditions. Drivers were classified into two groups: self-selected music and no music group. He found out that drivers in the high congestion conditions had higher level of stress and listening to selfselected music helped drivers to reduce their tension in only the highly frustrating condition. Drivers' time estimation in another study showed that drivers overestimated time in self-selected music and underestimated time in experimenter-selected music (Cassidy \& MacDonald, 2010). In this study, participants completed a driving game while listening to different sounds (silence, car sounds, car sounds with self-selected music, and car sounds with experimenter-selected music, high-arousal (70 bpm), higharousal (130 bpm), low-arousal (70 bpm), and low-arousal (130 bpm) music). Cassidy and MacDonald (2010) explained this by the impact of the new stimulus (i.e., experimenter-selected music), which required more information to be processed. However, they did not discuss the mechanisms that can justify why new or old information can influence the time estimation in any directions. Regarding drivers' performance in this study, an opposite pattern was shown. Participants showed more speeding during listening to experimenter-selected music, and the best performance when listened to self-selected music.

Psychophysiological effects of emotional properties of music (arousal and valence) on angry drivers were investigated by Van der Zwaag et al. (2011). They asked five groups 
of participants to complete a driving route under time pressure. The data suggest that high arousal, positive valence music mitigates the negative influences of anger by redirecting driver attention. Conversely, music with high arousal and negative valence increases selfreported anger levels. Low energy music with either positive or negative valence does not influence anger. This finding showed that music with positive valance can mitigate or change drivers' emotional states.

There are several factors that determine whether music has high or low arousal, such as tempo (fast versus slow), complexity, emotion (exciting versus calming) and liking (Cassidy \& Macdonald, 2009). North and Hargreaves (1999) investigated the effects of high or low arousing music on driving game performance. Results showed during high arousal music (140bpm; 80dBA), lap times were slowest and the task was perceived to be the most difficult in comparison to low arousal music (80bpm; 60dBA) and the no-music condition. This might work through occupying some parts of working memory (Salamé, \& Baddeley, 1989). Berz (1995) in the introduction of his article "Working memory in music" discussed the size and nature of short-term memory in music and suggested that people can process 11 to 15 pitches at one time. This indicates that a combination of a highly complex task and high arousal music requires more cognitive processing. Thus, performance would be best with the low demand and low arousal condition. Moreover, participants showed better performance when they liked the music, which also shows that familiarity matters.

Wiesenthal et al. (2000) showed that one's favorite music alleviates stress during high congestion drives compared to no-music drives. They proposed that favorite music can 
regulate driver aggression in high demanding rides (Wiesenthal et al. 2003). Moreover, previous studies have shown that drivers' behaviors are more efficient in the self-selected music group than the experimenter-selected group. In addition, people who listened to self-selected music reported lower distraction, higher enjoyment, and less anxiety (Cassidy, \& Macdonald, 2009). Van der Zwaag et al. (2012) investigated the influence of music valance on driving behavior. They compared personally selected positive and negative music on mood, driving performance, and physiological changes and found a significantly lower respiration rate during the negative music condition, compared to the no music condition, irrespective of driving demand. Regarding driving performance, higher speed was observed during the no-music condition compared to the positive music condition. Other than arousal and valance, some researchers consider the influence of discrete emotions of music on drivers' performance. Pêcher et al. (2009) interviewed their participants after the experiment. They reported that most of the drivers found happy music the most disrupting. This notion was supported by drivers' behavioral data which showed that happy music resulted in deteriorated driving performance. Happy music distracts drivers, reduces speed, and improves lane deviation. In contrast, sad music was related to less lane deviation and reduction in speed. Drivers in the sad music condition tried to have more trajectory controls and drove based on speed limit (Hughes, RudinBrown, \& Young, 2012). Note that because music can occupy any of the quadrants of the valence and arousal dimensional coordinate system, a low energetic-positive valence state is the most opposite state from anger (a high energetic-negative valence state). Therefore, affect in low arousal and positive valence might be perceived as incongruent 
with the situation and thereby, seen as an incongruent stimulus (Van der Zwaag, Fairclough, Spiridon, \& Westerink, 2011).

\subsection{Theoretical Implications}

The impacts of music on people's emotional states while performing complex tasks (like driving) can be explained by different theories. Based on the results of previous studies, angry drivers are considered unsafe drivers (e.g. Deffenbacher, Deffenbacher, Lynch, \& Richards, 2003). Driver spare capacity (a continuous monitoring of surroundings) decreases, whenever the individual's attention is paid to a specific process like emotion (Kahneman, 1973). According to multiple resource theory (Wickens, 2002), each task has a vector that shows the number and qualitative level of the resources. If driving requires

visual, spatial, and manual resources, the amount of load within each resource depends on the tasks' demands and whether the tasks compete for overlapping resources. For example, in an icy road, manual resource demands will increase versus a foggy road that requires visual attention. Based on this theory, if two tasks have equal priority, performance on both tasks will be degraded equally (Wickens, 2002). This theory is helpful to understand people's performance in a multitasking situation like driving.

Research on the effects of emotions in general, and anger specifically on information processing and cognitive states, suggests that emotional states have impacts on both what and how people think (Wang \& Lang, 2012). Lerner and Tiedens (2006) in their Appraisal-Tendency Framework (ATF) distinguished the effects specific emotions have on judgment and decision making. The ATF assumes that specific emotions create 
specific cognitive properties that may manifest at the biological and behavioral level. Their research showed that angry people tend to blame others more, for negative outcomes and are more optimistic when negative outcomes are not highlighted (Lerner \& Tiedens, 2006). This offers a potential explanation for the driving errors of angry and aggressive drivers.

Since human information processing capacity is limited, it can be engaged in a few tasks at a particular time (Kahneman, 1973). Ünal, Platteel, Steg, and Epstude (2013) discussed that drivers' performance may deteriorate by the emotion independently or by influencing on cognitive process due to fewer available resources for driving.

Teigen (1994) discussed the effect of arousal on performance. He explained with increased arousal, the number of cues that can be processed by the individual will decrease at the cost of ignoring the unnecessary information. This procedure does not guarantee that the relevant information will not be eliminated. He added that optimal arousal will vary from task to task. Easterbrook's cue-utilization theory (1959) has explained the inverted U-shape relationship between emotional arousal and performance. This theory assumes that at the medium level of emotional arousal, performance is optimal and individual can process a large number of cues. If the arousal increases more, it negatively impacts individuals' ability to process the number of cues (Hanoch \& Vitouch, 2004).

Although a lot of research has been conducted on the effect of emotion on information processing, little research has investigated the role of emotion and its impact on 
multitasking. Researchers found that negative information in comparison to positive information usually receives quicker allocation of resources (Cooper, 2013). This process can be explained as an adaptive response to potential threats (Pratto, \& John, 1991). Lang, Park, Sanders-Jackson, Wilson, and Wang, (2007) suggested if the stimuli is too arousing, the individual exceeds the available resources (cognitive overload). Cognitive overload happens quicker with negative information compared to positive information (Cooper, 2013). When a driver is angry, depending on the personal, motivational, and situational (related to driving) factors, some of resources will be allocated to process the emotional stimuli. If the anger is too arousing, drivers may not have enough resources to attend on the road safely.

In a study by FakhrHosseini, Kirby, and Jeon (2015), we suggested that anger or frustration in a person can be mitigated or eliminated by presenting a different emotional stimulus. The new emotional stimuli can create a different mental model by forcing a reappraisal. According to the appraisal theory of emotion, emotions arise from the perceptions of environmental changes and circumstances. This perception is influenced by personality characteristics, physiology, culture, and current goals. The construction of the evaluation i.e., mental model (based on novelty, valence, certainty, goal conduciveness, agency, and control) specifies the types of emotion that a person feels (Ellsworth, 2013). To change the mental model of angry drivers (others' responsibility), music for its strong ability to induce emotion and/or mediate or regulate people's emotional states can be a possible in-vehicle intervention strategy (FakhrHosseini, Kirby, \& Jeon, 2015). 
The contradictory results of previous studies show that the effects of music on the primary task, e.g., driving, depend on the type of music and the demands of the primary task e.g., traffic condition. If the driving situation is not demanding, music does not distract drivers (e.g., Dibben, \& Williamson, 2007), and it may also facilitate driving performance (e.g., Beh \& Hirst, 1999). In this situation, music can be interpreted as a "positive" distractor in that it occupies a small portion of cognitive resources all of which were busy with the emotional information. This notion is close to the third stage of emotion regulation procedure, which is called attentional deployment (Johnson, 2009). Likewise, Jeon (2012) showed that simple speech-based interventions helped angry drivers divert their attention from their anger to the driving information (attention deployment). Factors such as music genres, instruments, musical elements, and familiarity to the song can impact drivers in different ways (Jeon, 2012). For example, Pembrook (1987) suggested that processing unfamiliar melodies are much more demanding than familiar melodies. This notion can explain some of the results of studies that used either self-selected or experimenter-selected music. Results also showed that listening to music can reduce driving performance degradation associated with negative emotion by redirecting drivers' attention (FakhrHosseini, Landry, Tan, Bhattarai, \& Jeon, 2014; Hennessy, 2000).

Feeling angry on the road has been reported a common phenomenon (AAA Foundation for Traffic Safety, 2016). In a diary study by Neighbors, Vietor, and Knee (2002), participants showed often behavioral responses when becoming angry which was 
observed even when they claimed a mild anger level. These findings show the critical role of anger and its prevocational role on the roads. Although there has been a great deal of research to explain the influence of music in the driving context, there is less effort to investigate using music as an in-vehicle intervention strategy to help angry drivers with a wholistic approach. This study aims at finding factors that can be used as predictive value for in-vehicle systems to understand drivers' anger and respond to them appropriately. Therefore, in the frame of MRT and appraisal theory of emotion, possible effects are discussed. 


\section{How Can Anger Be Measured?}

In this chapter, I introduce Scherer's componential theory of emotion, Stemmler's anger response style model, and Thayer's super system. The relevant details of these three approaches and theories, and their relationships to this research are discussed. The information from these concepts helped in the measurement of emotion and interpretation of the study results.

Scherer in his paper (2005) defines emotion as "an episode of interrelated, synchronized changes in the states of all or most of the five organismic subsystems in response to the evaluation of an external or internal stimulus event as relevant to major concerns of the organism" (p. 697) (Scherer, 1987, 2001, 2005). The components of an emotion represent the five subsystems that have roles in creating an emotion and the related process over time. Table 4.1 shows the relationship between components and subsystems as well as related functions (Scherer, 2005).

Scherer (2005) stated that since there is no single standard method for measuring emotion, comprehensive assessments of all the changes are required. Based on Scherer's componential theory of emotion, to assess emotion, we need to measure (1) appraisal processes, (2) the response patterns generated in the neuroendocrine, autonomic, and somatic nervous systems, (3) the motivational changes produced by the appraisal results, (4) the patterns of facial and vocal expression as well as body movements, and (5) the nature of the subjectively experienced feeling state that reflects all of these component changes. 
In an emotional situation, all the components work together. After processing information, autonomic nervous system (ANS) distributes some specific signal from central nervous system (CNS) to the end organs to achieve an optimal state of homeostasis. If an action is necessary to happen, the endocrine system and ANS will support the motor system. All the systems (motor and endocrine as well as autonomic homeostatic regulations) are under the control of the forebrain and they are integrated with representations of the perceptual world. The CNS signals can be modified within ganglia, which allow for self-regulation at various system levels (Potegal, \& Spielberger, 2010).

Stemmler et al. (1993) in their anger response style model claim that components of anger (physiology, experience, and behavior) vary somewhat independently across angry people. The possible combinations of three components with each two classes, "strong", or "weak" reactivity, result in eight response style categories.

1. High vs. low anger intensity

High intensity is characterized by high physiological, experiential, and behavioral reactivity. Also, people with low intensity have low intensity in all three components.

\section{High vs. low anger suppression}

People with high suppression style have strong physiological and experiential reactivity but weak behavioral reactivity. Low suppression is characterized by weak experiential and physiological signs of anger but express their anger instrumentally. 
3. High vs. low anger denial

High anger denial refers to strong physiological and behavioral anger reactivity without a consciousness experience of the feeling (like people with alexithymia).

However, low denial is characterized by only an experiential reaction. This might happen when a person pretends to be angry.

4. High vs. low anger repression: High repression style people have a strong physiological and weak behavioral reactivity without a consciousness experience of the feeling; Low repression is related to strong anger expression in the experiential and behavioral manner while the physiological changes are weak (Böddeker, \& Stemmler, 2000).

Note that anger responses cannot be predicted just with one of the anger components (based on Scherer and Stemmler approaches). Therefore, all aspects of emotion using different measurements is assessed and discussed in the follows. For the physiological components, monitoring heartrate and hemodynamic changes have been considered (FakhrHosseini, Jeon, \& Bose, 2015). Drivers' performance has been recognized as the indicator of emotion's motivational components in this study (action tendencies). For the subjective feeling component, drivers' self-report of emotion shows their emotional experiences through the phases.

Like Scherer (2005), Thayer, Åhs, Fredrikson, Sollers, and Wager (2012) also considered emotion as a multidimensional process. In their "super system", they introduced 
autonomic nervous system (ANS) and heartrate variability (HRV) as two important systems that interact with each other to integrate physiological responses in the context of emotion with the consideration of environmental demands and individuals' goals. Next section explains HRV and hemodynamic changes of prefrontal cortex (PFC) as important indicators in emotional changes.

\subsection{Heart Rate Variability (HRV) and Methods to Measure HRV}

HRV refers to the variance between heart beats which varies from person to person and depending on the situation people are experiencing (Callahan, 2001). "Normal-toNormal" (NN) intervals are another name for HRV since HRV means the temporal distance between Rspikes generated by sinoatrial depolarizations (Appelhans, \& Luecken, 2006). To measure HRV, there are different strategies: statistical, geometrical, and frequency-based analysis.

The geometrical class of analyses: this method is based on the estimation of "HRV from the geometric properties of the sample density distributions of either the interbeat intervals or the differences between consecutive interbeat intervals" (see Malik, 1995; Appelhans, \& Luecken, 2006).

Power spectral analysis: it is under the frequency class of analyses that divides the amount of variance within a certain frequency (Appelhans, \& Luecken, 2006). Fast Fourier transform and autoregressive modeling techniques are two methods in this category. High frequency HRV represents parasympathetic influences and lower 
frequencies (below about $0.15 \mathrm{~Hz}$ ) show a mixture of sympathetic and parasympathetic autonomic influences (Thayer, Åhs, Fredrikson, Sollers, \& Wager, 2012).

Time domain variables: this method is under the statistical class of analyses and aims at measuring the variation of beat-to-beat intervals of the heart (Appelhans, \& Luecken, 2006; Kleiger, Bosner, \& Rottman, 1995; Thayer, Åhs, Fredrikson, Sollers, \& Wager, 2012). There are different measures in this category such as mean RR interval (mRR), mean heart rate (mHR), standard deviation of RR interval (SDRR), standard deviation of heart rate (SDHR), coefficient of variance of RR intervals (CVRR), root mean square successive difference (RMSSD), number of pairs of adjacent RR intervals differing by more than $20 \mathrm{~ms}$ to all RR intervals (pRR20), and number of pairs of adjacent RR intervals differing by more than $50 \mathrm{~ms}$ to all RR intervals (pRR50) (Costin, Rotariu, \& Pasarica, 2012).

Based on the tool that I measured HRV, time domain under statistical class was appropriate. As it is shown in the previous literature, I analyzed the SD of beat to beat interval to find HRV.

\subsection{Hemodynamic Changes of Pre-frontal Cortex}

In this study, fNIRS is used to monitor prefrontal cortex (PFC), which is an important region in emotional processing (Balconi, Grippa, Vanutelli, 2015). The PFC role in emotion has been the topic of many studies. Results showed a significant PFC lateralization effect to emotional stimuli with different valance (positive and negative) which means that negative emotions are mostly processed by right and positive emotions 
are processed by the left hemisphere (Balconi, Grippa, Vanutelli, 2015; Balconi \& Mazza, 2010).

\subsubsection{OxyHb}

To activate any region in brain and produce action potentials in neurons, blood flow should provide oxygen and other necessary substances. Therefore, changes in blood oxygenation can be an index of brain activity. During activation, metabolic rate of oxygen increases. As much as neurons consume more oxygen, a decrease in tissue oxygenation will happen. If that part of the brain is still activated with a lasting stimulus, an increment in blood flow keeps glucose and oxygen constant in neurons (Figure 4.1). Therefore, there are two variables that represent the above procedure:

1. Oxyhemoglobin (oxyHb): when hemoglobin transports oxygen

2. Deoxyhemoglobin (deoxyHb): when hemoglobin releases oxygen by increment in oxygen consumption

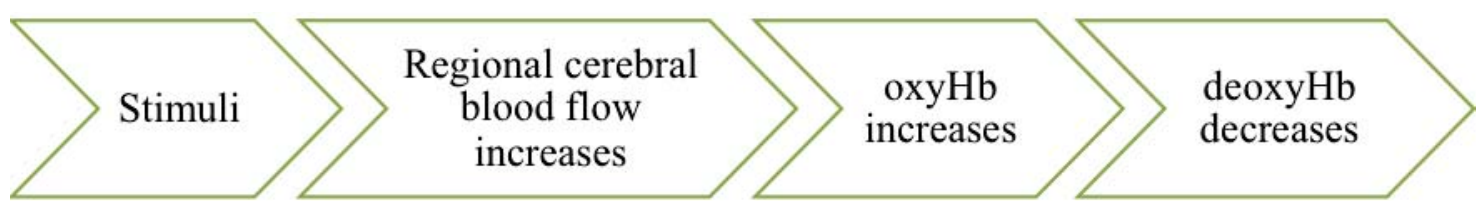

Figure 4.1. A brief summary of activation in cerebral region

Models and theories discussed in this chapter will be used to understand the data from Experiments 1 and 2 of this dissertation. Experiment 1 is designed to understand angry 
drivers' emotional responses to music and driving conditions. Experiment 2 will uncover drivers' reactions to different emotional music. Therefore, to understand the relationships and plausible causal factors among the behavioral, subjective, and physiological data, Sherer's componential theory of emotion has provided a framework for our analysis. 


\section{Experiment 1}

In Experiment 1, differences between angry and non-angry drivers' performance were examined. Besides their driving errors, their physiological responses were evaluated based on their anger response style and other variables such as workload were compared among the groups. Self-selected music pieces were used to identify how much music can change emotional reactions, driving behavior, and perceived experience. Other personality characteristics, including participants' answers to Driving Anger Scale, their driving experiences, and their anger expression style were also investigated. Anger expression style refers to the way that people convey their emotion. Spielberger (1988) classified individuals based on the way that they express their emotion. He suggested that people with anger-expression-out response style are in the habit of expressing their anger outwardly which may lead to some types of aggressive actions either behaviorally or verbally (Spielberger, 1999; Vagg, \& Spielberger, 1979). Therefore, based on Spielberger's notion, people with anger-expression-out response style may make more errors than others. Observation of drivers in naturalistic or simulated driving environment showed that high-trait and aggressive drivers make more errors (Deffenbacher, Lynch, Oetting, \& Yingling, 2001; Hennessy, \& Wiesenthal 1999; Lynch, Deffenbacher, Filetti \& Dahlen, 1999). In addition, based on anger response style model of Stemmler (1993), people with higher score in anger-expression-out subscale strongly experience emotion in all three levels: behavioral, physiological and subjective level. According to Stemmler's model of anger expression style (1993) and component process model of Scherer (2005) 
that were discussed in Chapter 4, a comprehensive measurement was framed to check multiple aspects of emotion and all the possible interactions among the variables.

\subsection{Hypotheses}

This is a list of the hypotheses that will be tested in Experiment 1:

Hypothesis 1: Angry drivers will commit more errors than non-angry drivers.

Results of previous studies indicate that angry drivers make more errors than non-angry drivers (e.g., Deffenbacher, Deffenbacher, Lynch, \& Richards, 2003; Lynch, Deffenbacher, Filetti \& Dahlen, 1999).

Hypothesis 2: Angry drivers in the music group will commit fewer errors than angry drivers in the no music group.

Hypothesis 3: Angry drivers in the music group will report less anger after the experiment than those in the no music group.

Hypothesis 4: Angry drivers in the music group will show a different pattern in their physiological data than those in the no music group.

Hypothesis 5: Drivers with higher scores in the anger-expression-out subscale and driving anger scale will show worse driving performance (behavioral level) than other drivers. 


\subsection{Method}

Before conducting the experiment, I submitted the study protocol to the Michigan Technological University Human Subjects review board for the approval. There was no more than minimal risk associated with participating in this study.

\subsubsection{Participants}

All participants in this experiment were recruited from the MTU community population and the introductory psychology subject pool. I recruited 52 participants (male $=43$, female $=9$, mean age $=21.82$, SD of age $=2.42$ ) in the MTU laboratory at Meese building. Participants received one credit for each half-hour of participation time, as an optional part of their class requirements. The entire experiment took one hour. The number of participants is shown in Table 5.1.

Table 5.1. Number of participants in each group.

\begin{tabular}{ll}
\hline Groups & N \\
\hline Neutral without music & 17 \\
\hline Anger with music & 18 \\
\hline Anger without music & 17 \\
\hline
\end{tabular}

\subsubsection{Apparatus}

\subsubsection{Driving Simulator}

The driving simulator consists of SimuRide software running on a Dell Optiplex 960 using Windows 7 operating system. The monitor is a 39” Samsung LED TV placed on a desk in front of the participant. SimuRide's driving simulator sounds are from a speaker behind the monitor averaging around 75 decibels from 2 feet away from the participant. 
A Thrustmaster universal USB steering wheel and gas/brake pedals were used to better simulate real world driving.

\subsubsection{Electrocardiogram (ECG)}

To measure heart rate and heart rate variability, I used a Polar H7 heart rate sensor. It is a belt that can be connected to an HRV Logger app via Bluetooth and transmit live heart data to a smartphone.

\subsubsection{Functional Near-Infrared Spectroscopy (fNIRS)}

Hamamatsu NIRO-200NX is a non-invasive, lightweight tool which is designed to record changes in concentration of oxygenated and deoxygenated hemoglobin and the degree of oxygenation of human tissues. To monitor the changes, it uses optical methods. It has one detection and one emission probes in each channel (two left, two right) with a hairband. The hemodynamic changes can be seen in its monitor.

\subsubsection{Materials}

\subsubsection{Differential Emotions Scale (DES)}

To assess discrete emotional dimensions, I used self-report scales of discrete emotional feelings. This questionnaire contains 16 items and participants rated each item using a 7point Likert-type scale from 1 (not at all) to 7 (very much) (Schaefer, Nils, Sanchez, \& Philippot, 2010). 


\subsubsection{Answer-Alternative Questionnaire}

In 1989, Scherer created this questionnaire to illustrate the importance of using questionnaires for assessing and evaluating emotions. The 15 questions assess the characteristics of the emotion-arousing situation, experiencing person, subjective experience of emotion, verbal, expressive and physiological reaction and regulation attempts of subjects.

\subsubsection{Cognitive-Affective Response Test-Music (CART-M)}

Bartel (1992) claimed that cognitive and affective phases can be distinguished on the basis of two dimensions: formal-intellectual and emotional-expressive. This questionnaire consists of nine semantic scales for each of formal-intellectual and emotional-expressive response dimensions (Bartel, 1992; Perlmutter \& Perkins, 1982). Results from this questionnaire will help us to understand how drivers processed the music and how different music perception may influence their performance. In other words, the way drivers process music is another piece (the cognitive component of emotion) that we need to consider based on componential theory of emotion.

\subsubsection{Driving Anger Scale}

This questionnaire measures driving anger for several hypothetical anger-provoking driving scenarios. I used the 14-item short form that is highly correlated with scores on the long form (Deffenbacher, Getting, \& Lynch, 1994). 


\subsubsection{Driving Behavior Questionnaire}

This 27-item questionnaire was developed to measure how frequently drivers show highway code violations (e.g., speeding), aggressive violations, and errors. In this subjective scale, items describe aberrant driving and respondents should rate the answers on a never to nearly all the time scale (Harrison, 2009).

\subsubsection{State-Trait Anger Expression Inventory-2 (STAXI-2)}

This questionnaire consists of 57 items to assess 5 subscales: State Anger (S-Ang), Trait Anger (T-Ang), Anger Expression-Out, Anger Expression-in and Anger Control (Spielberger, 1999). Spielberger (1999) explained each scale as follows: State Anger refers to the intensity of the individual's angry feelings. Trait Anger evaluates a person's general predisposition to become angry. The Anger Expression-Out scale describes the extent to which a person expresses her emotional experience of anger in an outwardly negative and poorly controlled manner. People with Anger Expression-in hold things in or suppress anger when they are angry. Anger Control-Out involves the expenditure of energy to monitor and control the physical or verbal expressions of anger. Anger Controlin measures how often people attempt to relax, calm down, and reduce angry feelings before they get out of control. The AX Index provides an overall estimate of the person's tendencies to express anger either outwardly toward other people, or inwardly toward herself. 


\subsubsection{NASA-TLX}

NASA-TLX is a multi-dimensional scale that identifies factors associated with variations in subjective workload while or after performing a task (Hart, 2006). It has six workload measures (Appendix A):

Mental demand: how much mental and perceptual activity, was required (e.g., thinking. deciding, calculating, remembering. looking, searching, etc.)? Was the task easy or demanding, simple or complex, exacting or forgiving?

Physical demand: how much physical activity was required (e.g., pushing, pulling, turning. controlling, activating, etc.)? Was the task easy or demanding, slow or brisk, slack or strenuous restful or laborious?

Temporal demand: how much time pressure was felt due to the rate or pace at which the tasks or task elements occurred? Was the pace slow and leisurely or rapid and frantic?

Performance: was the task accomplished successfully based on the goals of the task set by the experimenter (or yourself)? How much?

Effort: how much work was required to accomplish your level of performance (mentally and physically)?

Frustration: How insecure, discouraged, irritated. stressed and annoyed versus secure, gratified, content, relaxed and complacent did the person feel during the task? 


\subsubsection{Stimuli}

\subsubsection{Music}

Drivers in Anger with music group listened to one music piece for the entire time of driving session. They selected that music after the anger induction procedure. They were asked to "select a music piece that you want to listen while your drive. It should not be necessarily your favorite music. Pick a song that you want to listen now based on your current mood." This instruction was chosen to represent a real-world situation. We were curious to know in real world if a driver gets angry and wants to listen to music, how much does self-selected music help angry drivers? And consequently, how much should an in-vehicle auditory display rely on drivers' library and their browsing history?

\subsubsection{Driving Scenario}

For the driving scenario, I picked three different scenarios that represent various driving conditions. These scenarios were: highway (easy condition), a rural road with unexpected hazards like rolling rocks on the road (medium scenario), and foggy and snowy road (hard condition). Each scenario took five minutes.

During the drive, the experimenter recorded the number of all driving errors. Driving errors included: lane deviation, speeding, rolling through stop signs, disobeying traffic lights, collisions, and poor fuel-efficient driving behavior. Fuel-efficient driving behavior was recognized by the driving simulator which is an indicator of risky driving behavior (Jeon, 2016). To measure fuel-efficient driving behavior, the experimenter timed the period the simulator eco-driving icon changed to red. While the simulator is on and the 
driver is driving in a scenario, there is an icon on the top center of the monitor that says EcoDrive. This icon is normally green until the driver floors gas or brake pedal which changes the icon color to orange, brown, and red. Red indicates the poorest fuel-efficient driving behavior and only red was timed as the indicator of poor fuel-efficient driving behavior.

Table 5.2. Driving errors.

\begin{tabular}{ll}
\hline Driving Errors & Definition \\
\hline Lane Deviation & $\begin{array}{l}\text { Crossing the center line and sideline of } \\
\text { the road with outside tire }\end{array}$ \\
\hline Speeding & $\begin{array}{l}\text { Total time drivers drove more than 2 } \\
\text { mph over the speed limit }\end{array}$ \\
\hline Rolling through stop signs & Count of incomplete stops at stop signs \\
\hline Disobeying traffic lights & $\begin{array}{l}\text { Count of incomplete stops at traffic } \\
\text { lights }\end{array}$ \\
\hline Collisions & $\begin{array}{l}\text { Count of collisions with objects, } \\
\text { vehicles, and driver vehicle roll overs }\end{array}$ \\
\hline Poor fuel-efficient driving behavior & $\begin{array}{l}\text { Total time drivers floored gas and/or } \\
\text { brake pedal }\end{array}$ \\
\hline
\end{tabular}

\subsubsection{Design and Procedure}

I had three between-subjects conditions: angry drivers who drove with self-selected music (Anger with music), angry drivers who drove without music (Anger without music), and neutral drivers who drove without music (Neutral without music). After completing the consent procedure, I asked participants to rate their current emotional state using the Differential Emotions Scale (DES) and fill out the state-trait anger expression inventory (STAXI-2). Before driving in the experimental scenario, participants practiced for 5 minutes in a different scenario. This helped them feel comfortable and control over the simulator. This practice session could also change their perception of music. The previous study showed that when people are completing a novel 
task, they may not perceive music simultaneously as much (Ünal, Platteel, Steg, \& Epstude, 2013). The practice session also allowed me to screen participants' sensitivity to simulation sickness by comparing the scores of simulation sickness test before and after the practice session even though there has been no simulation sickness reported with this low-fidelity simulator. After the practice session, in the no-anger no-music condition, participants drove with the neutral affective state without listening to music. Participants in the angry conditions spent 12 minutes writing about an angry experience they could vividly remember (e.g., Jeon, Yim, \& Walker, 2011). Then, to assess different aspects of the emotional event, they filled out the Answer Alternative questionnaire (Scherer et al., 1989) for 5 minutes. After the mood induction procedure, they rated their emotion check survey for the second time. Next, they had two minutes to pick a music piece from YouTube or cellphone playlist. This music was played on repeat from the experimental computer during the whole driving in the experimental scenario. Participants in the nomusic condition did not listen to any music for the drive. Participants were instructed to obey all the traffic rules that they normally do on the road. The driving session lasted approximately 15 minutes.

Driving performance data were collected manually in real-time by a trained experimenter who was present at all times. During the drive, the experimenter recorded the number of all driving errors. Following the driving portion, participants answered to CognitiveAffective Response Test-Music (CART-M), Differential Emotions Scale (DES), DAS, NASA-TLX, and demographic questions. Figure 5.1 shows the experimental procedure. 


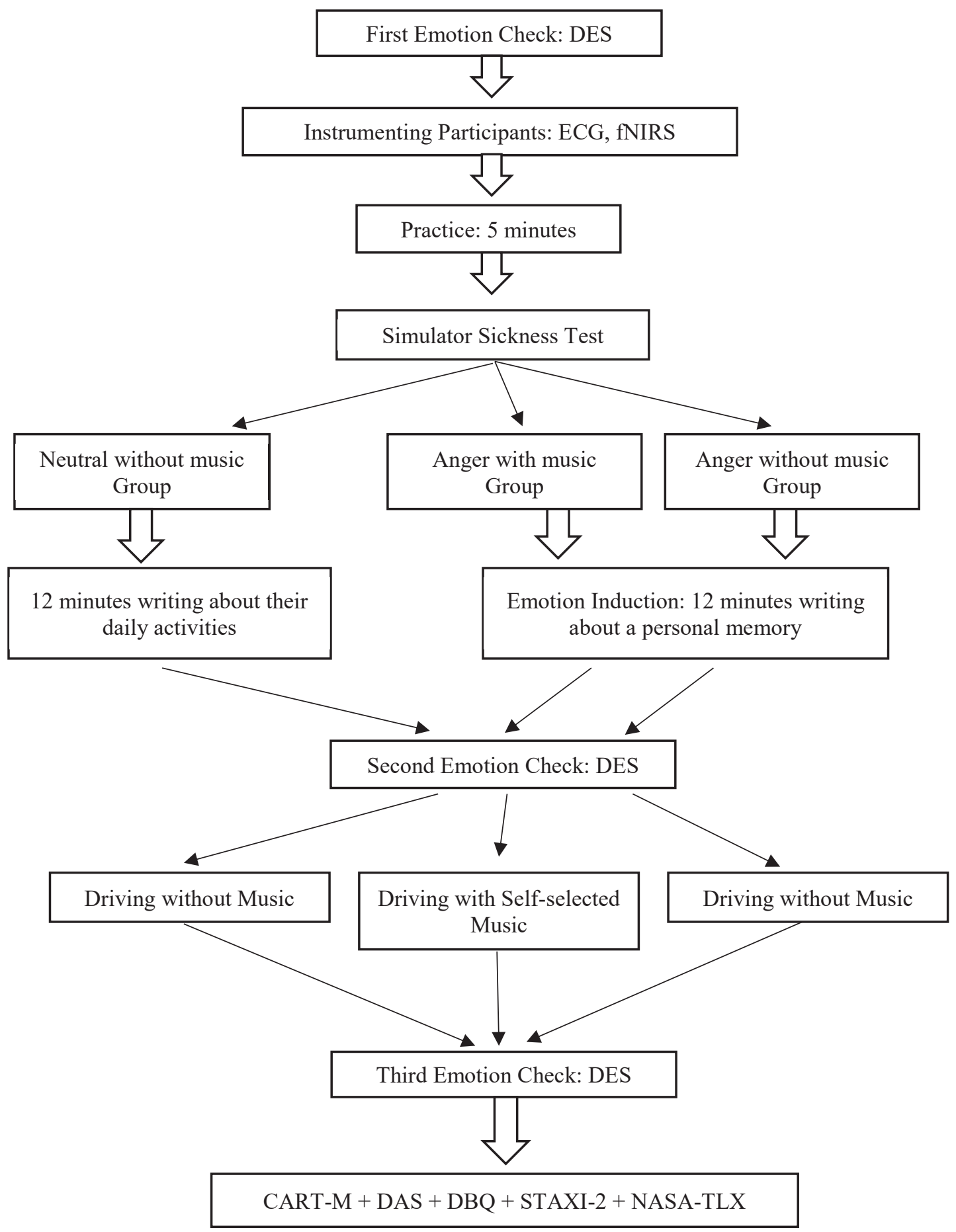

Figure 15.1. Experimental procedure in Experiment 1. 


\section{Results of Experiment 1}

\subsection{Subjective Results: Emotion Manipulation Check}

In this experiment two out of the three groups went through the emotion induction procedure. During the procedure, participants were supposed to remember and write a memory that makes them angry. Participants in Neutral without music group wrote about a normal daily activity to stay neutral. The idea behind this grouping is to see how much angry drivers' behaviors are different from neutral drivers and if music can help angry drivers or not. Then, drivers' emotion was checked via self-report questionnaires three times through the experiment:

1. when participants entered the lab (Anger 1)

2. after emotion induction procedure (Anger 2)

3. at the end of the experiment before they left the lab (Anger 3)

Figure 6.1 shows the patterns of groups' self-report anger through the experiments. Results of a one-way repeated measures ANOVA showed significant differences in Anger without music group $\left(F(2,16)=21, p=.000, \eta_{\mathrm{p}}{ }^{2}=.72\right)$ and Anger with music group $\left(F(2,15)=15, p=.000, \eta_{\mathrm{p}}{ }^{2}=.67\right)$ among the three self-report questionnaires. As expected, participants in neutral group did not report the same changes.

Several paired samples t-tests were used to make post hoc comparisons between the reports. Paired samples t-test indicated that participants in Anger with and without music 
to the time when they entered the lab and after the experiment (before leaving the lab)

(table 6.1). Tables 6.2 and 6.3 show the $t$ and $p$ values from the t-tests.

Table 6.1. Mean of self-report anger in each group.

\begin{tabular}{llll}
\hline Groups & Anger 1 & Anger 2 & Anger 3 \\
\hline Natural without music & 1.70 & 1.52 & 1.35 \\
\hline Anger with music & 1.47 & 3.70 & 1.94 \\
\hline Anger without music & 1.50 & 3.61 & 1.94 \\
\hline
\end{tabular}

Table 6.2. Paired samples t-test of self-report anger scores of before and after emotion induction.

\begin{tabular}{lll}
\hline Groups & t Value Anger 1,2 & $\boldsymbol{p}$ Value \\
\hline Natural without music & .71 & .484 \\
\hline Anger with music & -5.26 & .000 \\
\hline Anger without music & -5.71 & .000 \\
\hline
\end{tabular}

Table 6.3. Paired samples t-test of self-report anger scores after emotion induction and before leaving the lab.

\begin{tabular}{lll}
\hline Groups & $\mathbf{t}$ Value Anger 2, 3 & $\boldsymbol{p}$ Value \\
\hline Natural without music & .67 & .227 \\
\hline Anger with music & 6.51 & .000 \\
\hline Anger without music & 5.39 & .000 \\
\hline
\end{tabular}



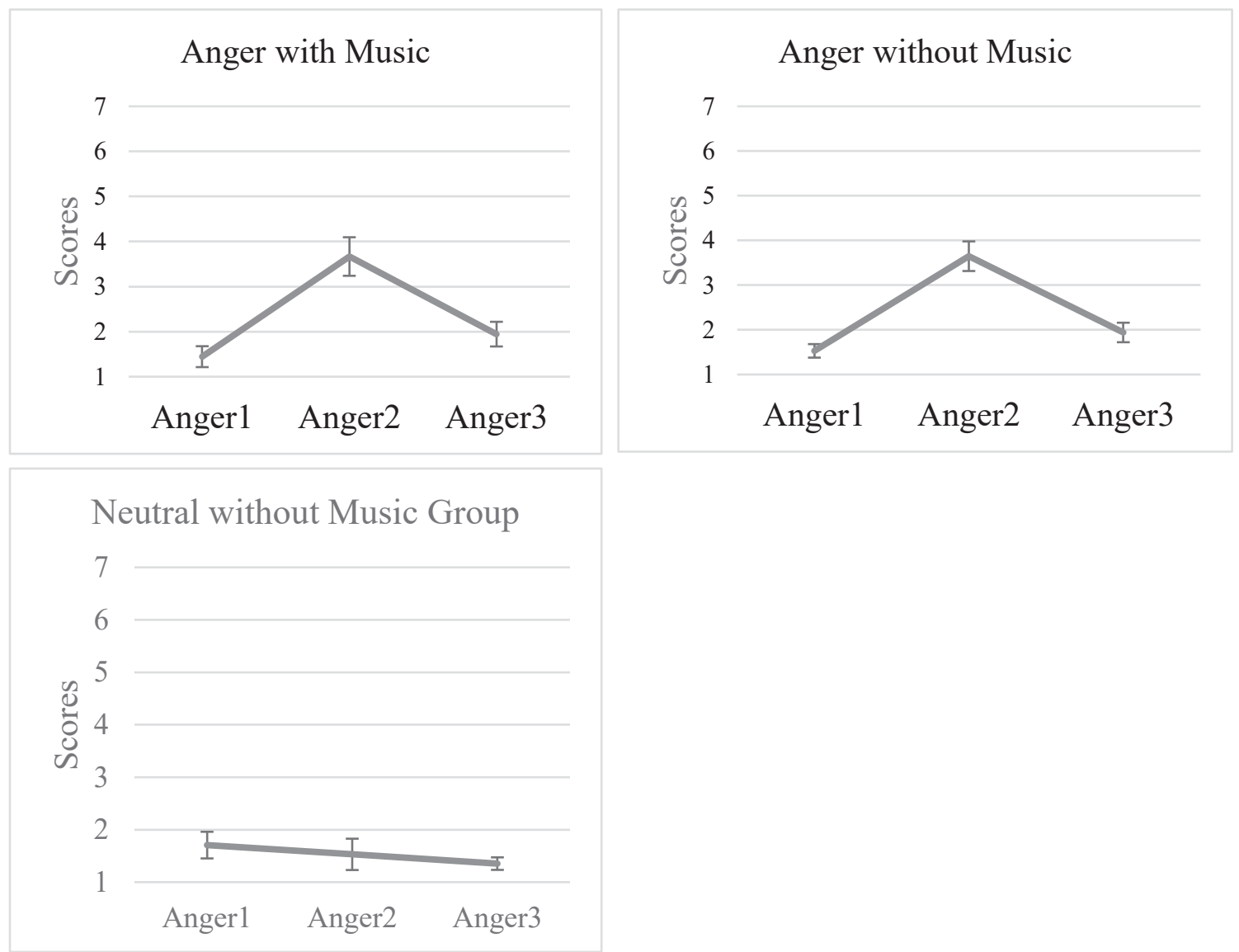

Figure 6.1. Participants anger score before and after emotion induction and before leaving the lab in the groups on a Likert scale from 1 (not at all) to 7 (very intense). Error bars represent standard errors.

\subsection{Physiological data}

\subsubsection{ECG}

To analyze all ECG data, values more than 1.5 interquartile range (IQR's) in each group were labeled as outliers and were eliminated from the statistical analysis. 1.5 IQR is common practice for identifying outliers. Second, after visualizing the data, individuals outside of this range were off of the average and standard error ranges. Tables 6.4 and 6.5 
show the total number of participants, how many of them were removed as outliers, and the number of participants in each group that were considered in HR and HRV analysis.

\subsubsection{Between group comparisons}

ECG data were analyzed based on two statistical values: mean of heart rate (HR) and standard deviation of heart rate variability (HRV).

Table 6.4. Number of total participants, outliers, and participants in HR analysis.

\begin{tabular}{llll}
\hline Groups & $\begin{array}{l}\text { Total Number of } \\
\text { Participants }\end{array}$ & $\begin{array}{l}\text { Number of } \\
\text { Outliers }\end{array}$ & $\begin{array}{l}\text { Number of } \\
\text { Participants in } \\
\text { the Analysis }\end{array}$ \\
\hline Natural without music & 17 & 2 & 15 \\
\hline Anger with music & 17 & 2 & 15 \\
\hline Anger without music & 18 & 2 & 16 \\
\hline
\end{tabular}

ECG (HR): To compare drivers' HR data during the driving sessions, a one-way ANOVA was performed on drivers' mean of HR. Results show that the mean $(F(2,45)=$

$\left.3.71, \mathrm{p}=.032, \eta_{\mathrm{p}}^{2}=.14\right)$ of HR during the driving sessions are different among the groups. In other words, angry drivers' HR who did not listened to music $(M=85.09, S D$ $=9.06)$ was significantly higher than angry drivers who listened to self-selected music $(M$ $=76.38, S D=12.22)$, and neutral drivers' $\mathrm{HR}(M=76.66, S D=8.99)$ (Figure 6.2).

Drivers in both intervention groups were angry based on their self-report results. Therefore, lower heart rate in the music group can be attributed to the role of music in changing and decreasing angry drivers' arousal level back to the normal or neutral state. 


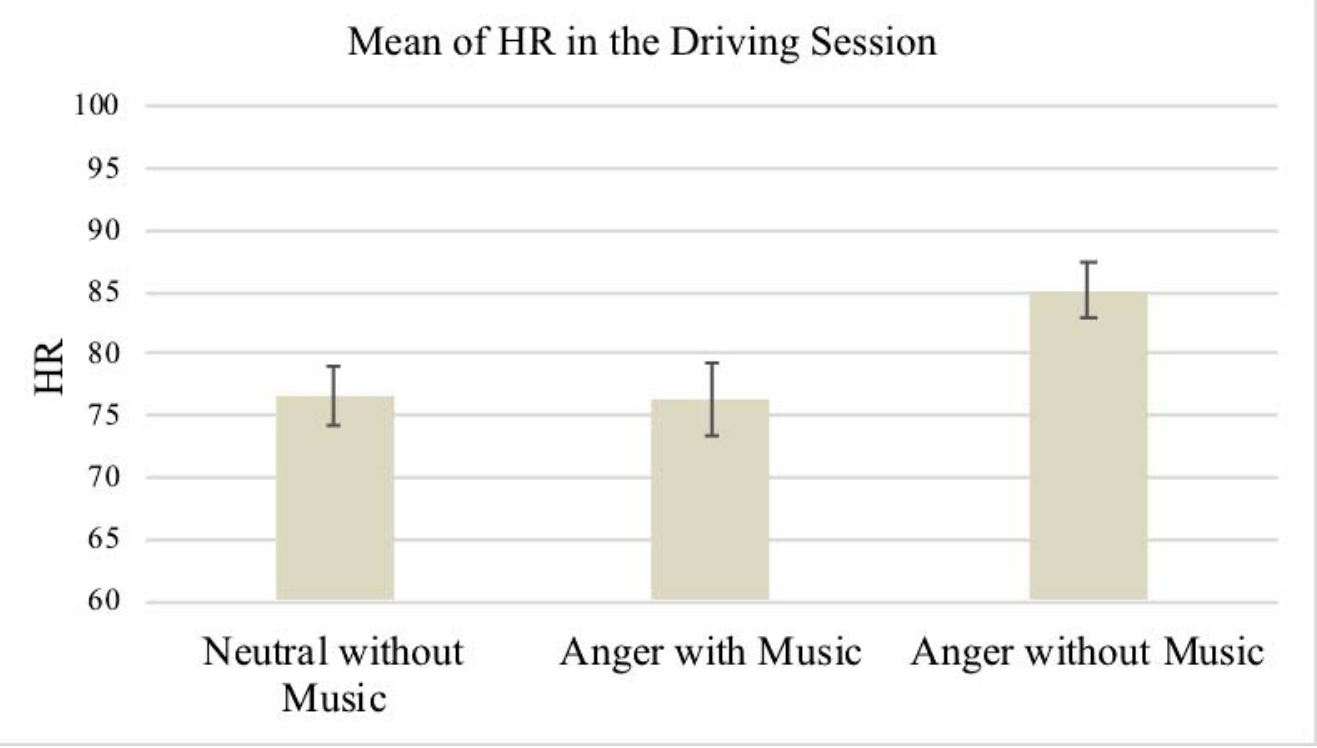

Figure 6.2. Mean of drivers' HR during the driving session among the groups. Error bars represent standard errors.

Table 6.5. Number of total participants, outliers, and participants in HRV analysis.

\begin{tabular}{llll}
\hline Groups & $\begin{array}{l}\text { Total Number of } \\
\text { Participants }\end{array}$ & $\begin{array}{l}\text { Number of } \\
\text { Outliers }\end{array}$ & $\begin{array}{l}\text { Number of } \\
\text { Participants in } \\
\text { the Analysis }\end{array}$ \\
\hline Natural without music & 17 & 1 & 16 \\
\hline Anger with music & 17 & 0 & 17 \\
\hline Anger without music & 18 & 1 & 17 \\
\hline
\end{tabular}

ECG (HRV): Drivers' HRV during the driving session was compared among the groups (Table 6.6). Results did not show any differences among the groups $(F(2,47)=.38, p=$ $\left..607, \eta_{\mathrm{p}}^{2}=.02\right)($ Figure 6.3). 


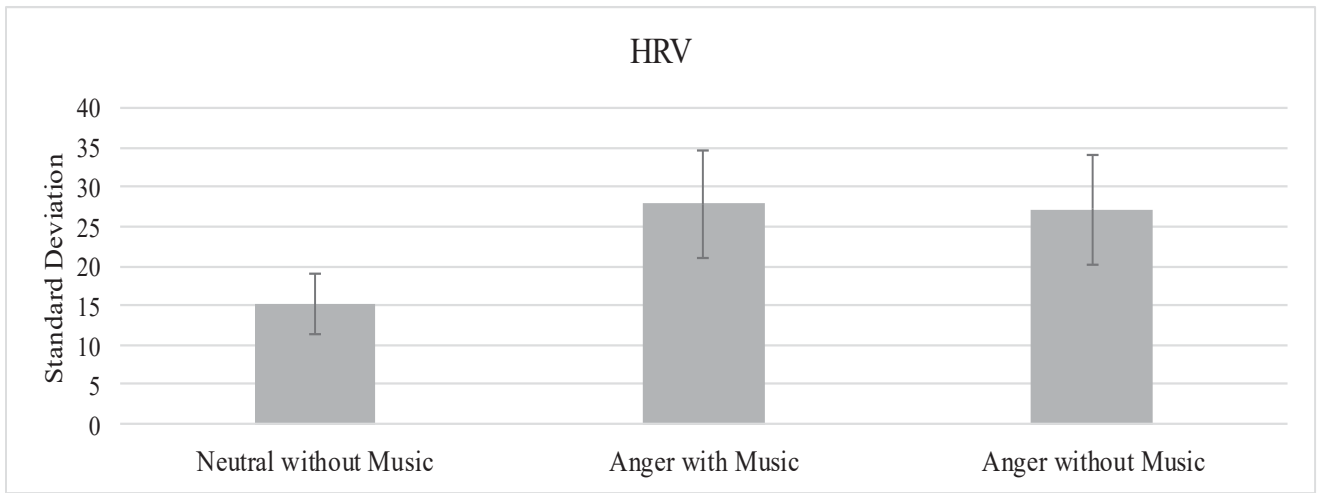

Figure 6.3. Drivers' HRV during the driving session among the groups. Error bars represent standard errors.

Table 6.6. Means, standard deviations, and standard errors of HRV in the three groups.

\begin{tabular}{llll}
\hline Groups & Mean & Std. Deviation & Std. Error \\
\hline Neutral without music & 59.52 & 15.11 & 3.77 \\
\hline Anger with music & 59.26 & 27.83 & 6.74 \\
\hline Anger without music & 58.88 & 27.16 & 7.01 \\
\hline
\end{tabular}

\subsubsection{Within group comparisons}

When it comes to physiological data, individual differences should be considered. To reduce the influence of individual differences in this between subject design experiment, heart rate (Figure 6.4) and hear rate variability (Figure 6.5) data were analyzed through the different phases (practice and driving). In other words, I compared each person's ECG data when he or she was in different phases of the experiment. This would give us a better understanding of the changes in each individual during the experiment.

\subsubsection{1 (ECG) HR}

Neutral without music group: Paired samples t-test indicated that mean of HR in driving $(M=77.23, S D=7.33)$ session is significantly less than practice session $(M=81.57, S D$ $=9.97), t(12)=3.74, p=.003$. 
Anger with music group: Paired samples t-test indicated that mean of HR in driving session $(M=76, S D=12.51)$ is not significantly different from the practice session $(M=$ 78.67, $S D=11.46), t(15)=1.5, p=.153$.

Anger without music group: Paired samples t-test indicated that mean of HR in driving $(M=84.82, S D=12.27)$ is significantly higher than practice session $(M=81.58, S D=$ 14.26), $t(17)=-3.94, p=.001$.

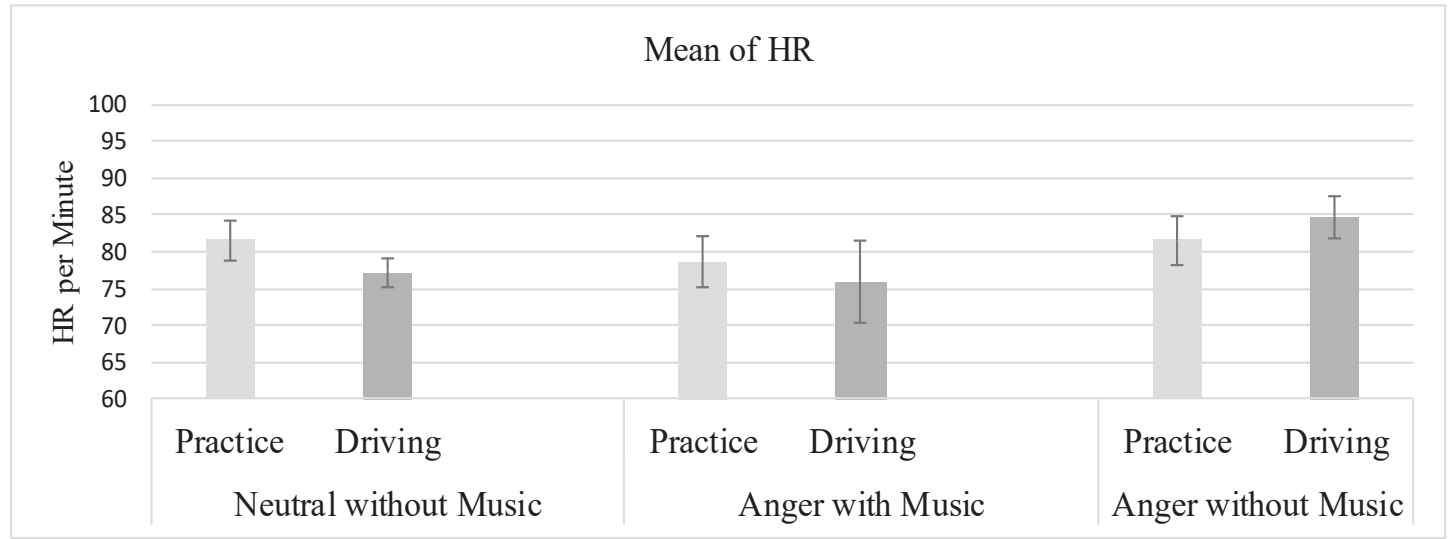

Figure 6.4. Mean of HR during different sessions among the groups. Error bars represent standard errors.

\subsection{ECG (HRV)}

Neutral without music group: Paired samples t-test indicated that SD of HRV in driving $(M=57.76, S D=13.84)$ session is not significantly different from practice session $(M=$ $59.72, S D=20.19), t(14)=.66, p=.519$.

Anger without music group: Paired samples t-test indicated that SD of HRV in driving ( $M$ $=73.46, S D=17.74)$ is not significantly different from the practice session $(M=50.48$, $S D=74.60), t(15)=-1.27, p=.221$. 
Anger with music group: Paired samples t-test indicated that SD of HRV in driving ( $M=$ $58.84, S D=27.61)$ session is not significantly different from the practice session $(M=$ $66.81, S D=50.58), t(14)=.71, p=.488$.

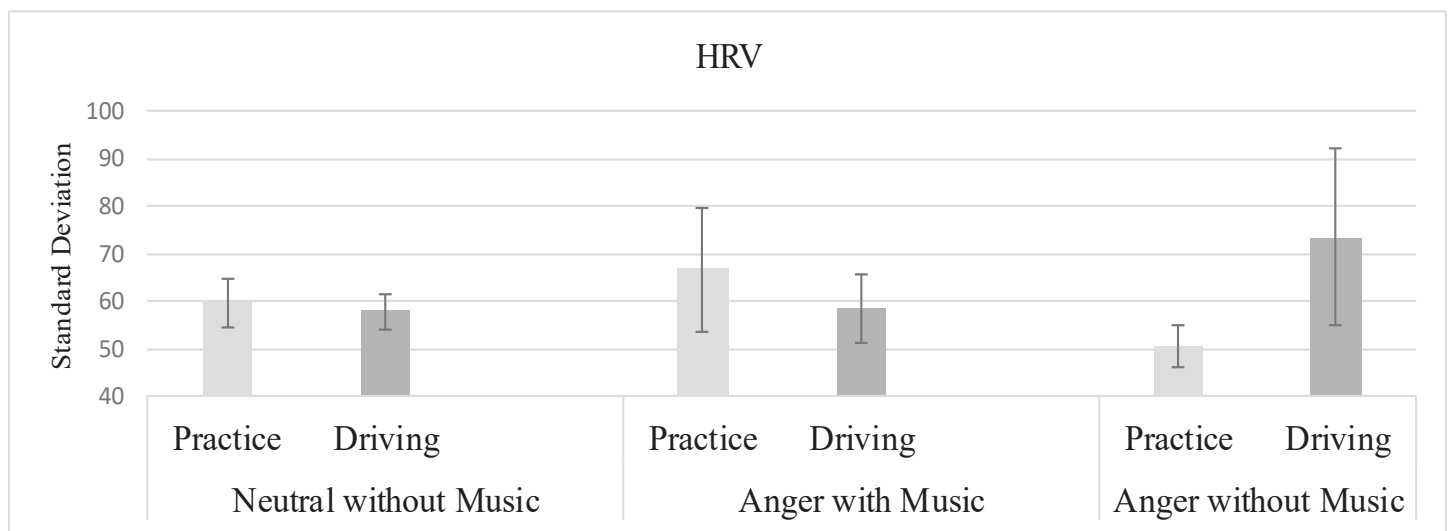

Figure 6.5. Drivers' HRV during practice and driving sessions among the groups. Error bars represent standard errors.

\subsection{2 fNIRS}

Results from fNIRS are based on the oxygenation $(\mathrm{O} 2 \mathrm{Hb})$ of PFC from both hemispheres. Results did not show any patterns regarding deoxygenatin $(\mathrm{HHb})$ and asymmetrical patterns of hemispheres in positive and negative emotions.

To analyze all fNIRS data, values more than 1.5 interquartile range (IQR's) in each group were labeled as outliers and were eliminated from the statistical analysis. Table 6.7 shows the total number of participants, how many of them were removed as outliers, and the number of participants in each group that were considered in $\mathrm{O} 2 \mathrm{Hb}$ analysis.

Table 6.7. Number of total participants, outliers, and participants in HRV analysis.

\begin{tabular}{llll}
\hline Groups & $\begin{array}{l}\text { Total Number of } \\
\text { Participants }\end{array}$ & $\begin{array}{l}\text { Number of } \\
\text { Outliers }\end{array}$ & $\begin{array}{l}\text { Number of } \\
\text { Participants in } \\
\text { the Analysis }\end{array}$ \\
\hline
\end{tabular}




\begin{tabular}{llll}
\hline Natural without music & 18 & 0 & 18 \\
\hline Anger with music & 17 & 0 & 17 \\
\hline Anger without music & 18 & 3 & 15 \\
\hline
\end{tabular}

\subsubsection{Between group comparisons}

Participants' hemodynamic changes of PFC (oxygenation and deoxygenation level) during the driving session were tested with a one-way ANOVA to see if there are any differences among drivers who listened to music and those who did not with different emotional states. Results showed that the oxygenation $(\mathrm{O} 2 \mathrm{Hb})$ levels are not significantly different among the groups $\left(F(2,44)=1.39, p=.260, \eta_{\mathrm{p}}^{2}=.02\right)$ (Figure 6.6).

\subsubsection{Within group comparisons}

Like ECG data, fNIRS results might be sensitive to the individual differences. Therefore, I checked the $\mathrm{O} 2 \mathrm{Hb}$ and $\mathrm{HHb}$ changes of $\mathrm{PFC}$ during the phases (practice and driving) for each participant in a group. Results of HHb did not show any patterns; however, $\mathrm{O} 2 \mathrm{Hb}$ changes are in line with the expectations:

Neutral without music group: Paired samples t-test indicated that average O2HB (meandriving $=3.76$, mean-practice $=1.89, t(16)=2.19, p=.043)$ increased significantly from practice to the driving session.

Anger without music group: Paired samples t-test indicated no changes from practice to the driving session $(t(14)=-.43, p=.627)$. 
Anger with music group: Paired samples t-tests between practice and driving sessions showed that average $\mathrm{O} 2 \mathrm{HB}$ (mean-driving $=4.38$, mean-practice $=1.51, t(14)=3.17, p=$ .007) increased significantly from practice to driving session.

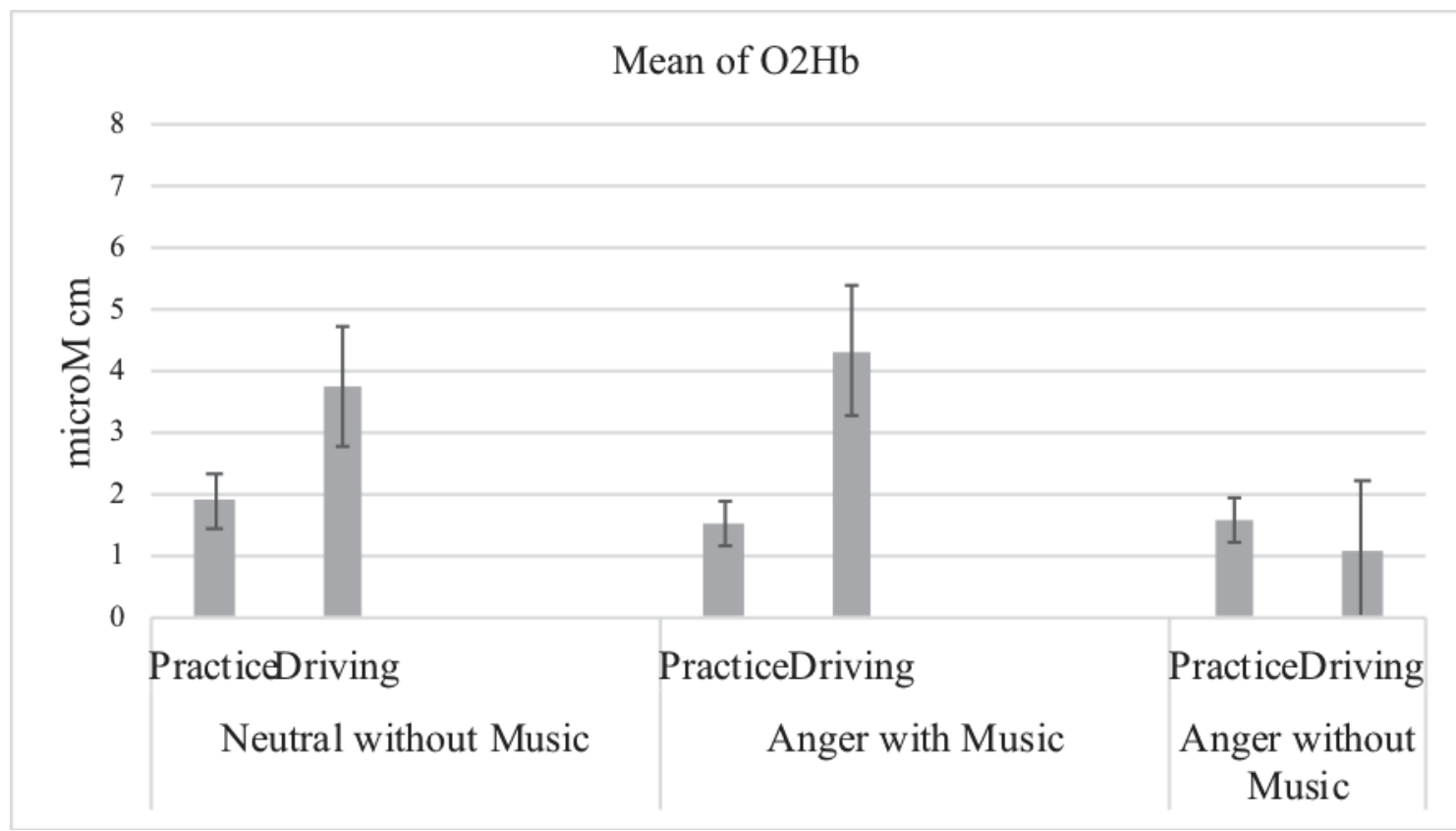

Figure 6.6. Mean of oxygenation during practice and driving sessions among the groups. Error bars represent standard errors.

\subsection{Behavioral Data: Driving Errors}

Drivers' lane departure, speeding, fuel-efficient driving, number of crashes, passing redlight, and passing stop sign were observed manually by the experimenter. All the variables were checked in two ways. First, each variable was checked across the conditions (e.g. sum of the time that drivers sped in easy, medium, and hard levels). Second, each variable was considered based on the difficulty level. Results showed that fuel-efficient driving is different among the groups. A one-way repeated measures ANOVA was performed on drivers' fuel-efficient driving performance among the 
groups. Results show that drivers of different groups performed significantly different in fuel-efficient driving behavior $\left(F(2,47)=3.94, p=.026, \eta_{\mathrm{p}}^{2}=.14\right)$ (Figure 6.7). Post hoc analysis with least significant difference (LSD) shows that angry drivers who did not listen to any music $(M=210, S D=163.18)$ had worse fuel-efficient driving performance than the drivers in the neutral $(M=96.25, S D=50.44, p=.007)$ group. This means that drivers in this group drove longer with worse fuel-efficient driving behavior.

Drivers' performance based on the difficulty levels of the scenarios showed significant results. Results from several one-way repeated measures ANOVA showed that drivers fuel-efficient driving behavior in the hard scenario (foggy and snowy road) is significantly different among the groups $\left(F(2,47)=4.34, p=.019, \eta_{\mathrm{p}}^{2}=.15\right)$. Post hoc analysis with LSD shows that angry drivers who did not listen to any music $(M=45, S D$ $=34.34)$ had significantly worse fuel-efficient driving performance than Neutral without music $(M=22.35, S D=14.8, p=.008)$ and Angry with music groups $(M=26, S D=$ $17.64, p=.031)($ Figure 6.8). 


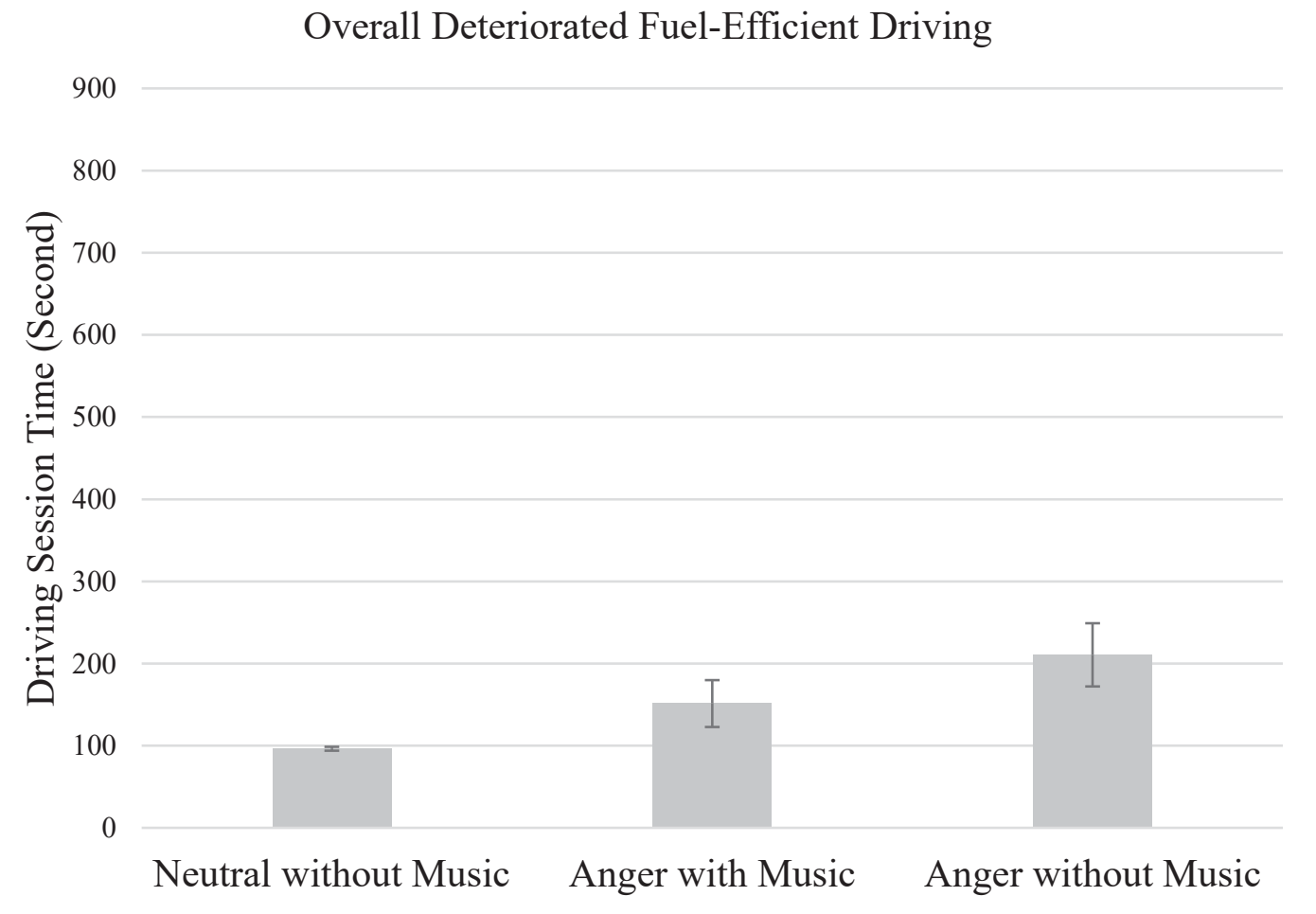

Figure 6.7. The amount of time that drivers in different groups showed deteriorated fuelefficient driving behavior based on seconds during the 15-minute drive. Error bars represent standard errors.

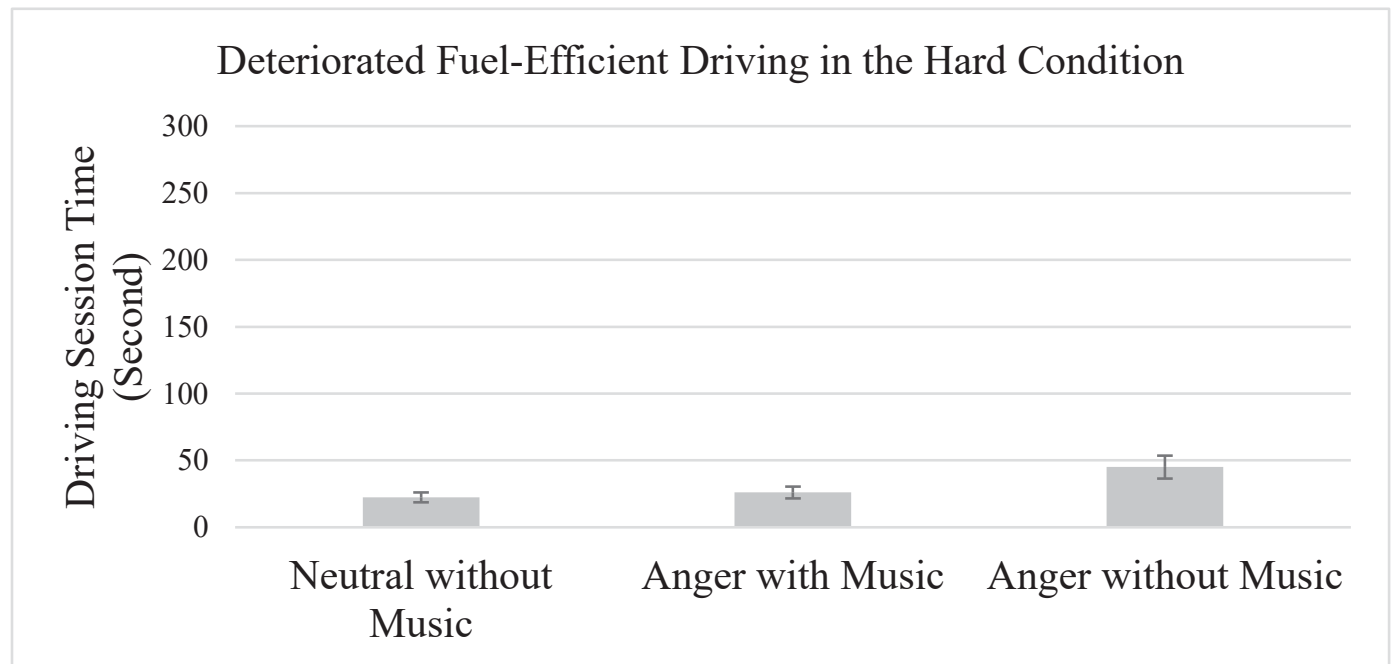

Figure 6.8. The amount of time that drivers in different groups showed deteriorated fuelefficient driving behavior based on seconds in the fogy and snowy road. Error bars represent standard errors. 
Moreover, results showed that drivers speeding in the hard scenario is significantly different among the groups $\left(F(2,45)=6.55, p=.003, \eta_{\mathrm{p}}^{2}=.22\right)$.

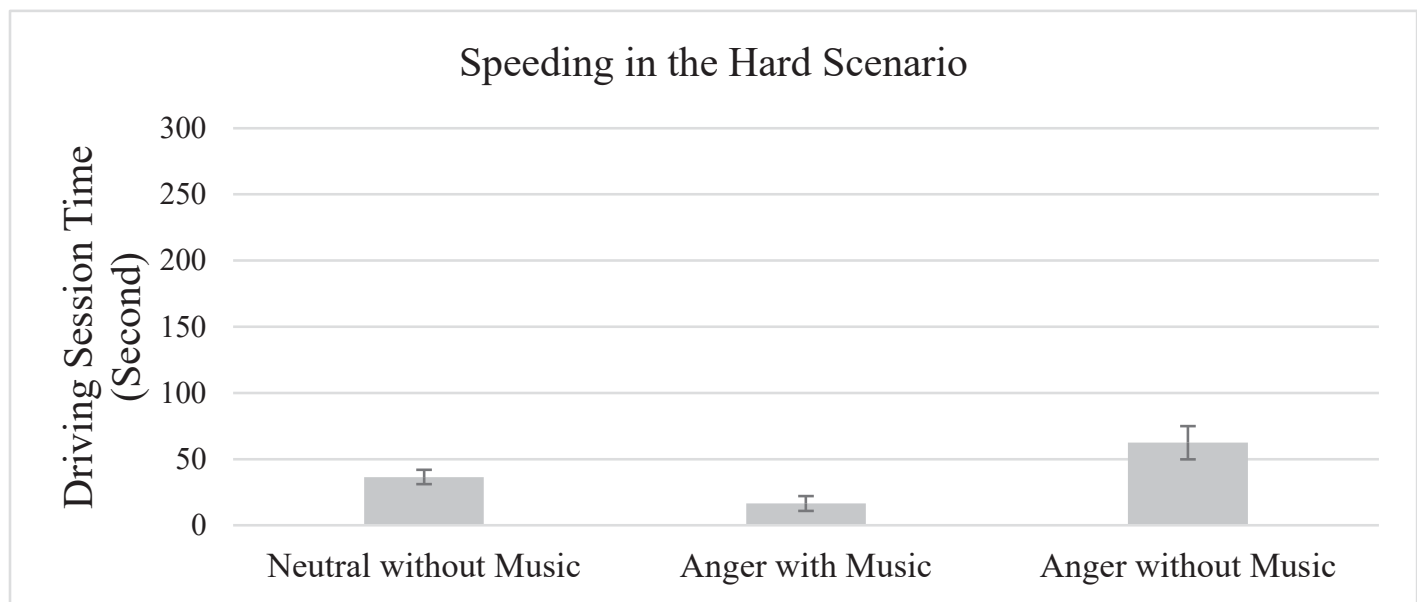

Figure 6.9. The amount of time that drivers in different groups sped based on seconds in the foggy and snowy road. Error bars represent standard errors.

Post hoc analysis with LSD shows that angry drivers who did not listen to any music ( $M$ $=62.35, S D=51.78, p=.003)$ significantly sped more than neutral drivers $(M=36.47$, $S D=22.34, p=.039)$ and Angry with music group $(M=16.43, S D=20.97, p=.001)$ in the snowy and foggy road (Figure 6.9).

\subsection{Questionnaires}

\subsubsection{Workload}

Considering workload for designing any in-vehicle system is important. In this study, finding how much an in-vehicle auditory display can add or reduce drivers' workload would be helpful. A one-way ANOVA was performed on workload factors to find if there are any differences among the groups. Results showed that workload-perform $(F(2$, 
$\left.43)=6.15, p=.004, \eta_{\mathrm{p}}^{2}=.03\right)$ and workload-effort $(F(2,46)=4.48, p=.017, \eta \mathrm{p} 2=.01)$ are significantly different among the groups (Figure 6.10).

Workload-perform: Post Hoc tests with LSD shows that angry drivers who did not listen to any music $(M=.18, S D=.07)$ rated their driving performance significantly worse than those angry drivers who drove with self-selected music $(M=.24, S D=.06, p=.021)$ and neutral drivers who drove without music $(M=.26, S D=.05, p=.001)$.

Workload-effort: Post Hoc tests with LSD shows that that angry drivers who drove with music $(M=.18, S D=.09)$ showed significantly less workload-effort than angry drivers who did not listen to any music $(M=.26, S D=.06, p=.006)$ and drivers in the neutral group $(M=.24, S D=.05, p=.039)$.

\subsubsection{DAS, DBQ, CART, STAXI}

Results of DAS, CART, and DBQ were not correlated with any of the driving errors. However, results from anger expression-out subscale were correlated with worse fuelefficiency driving behavior. It means that drivers with more anger expression-out style behavior had worse fuel- efficient driving performance $(\mathrm{r}=.3, p=.004)$. 


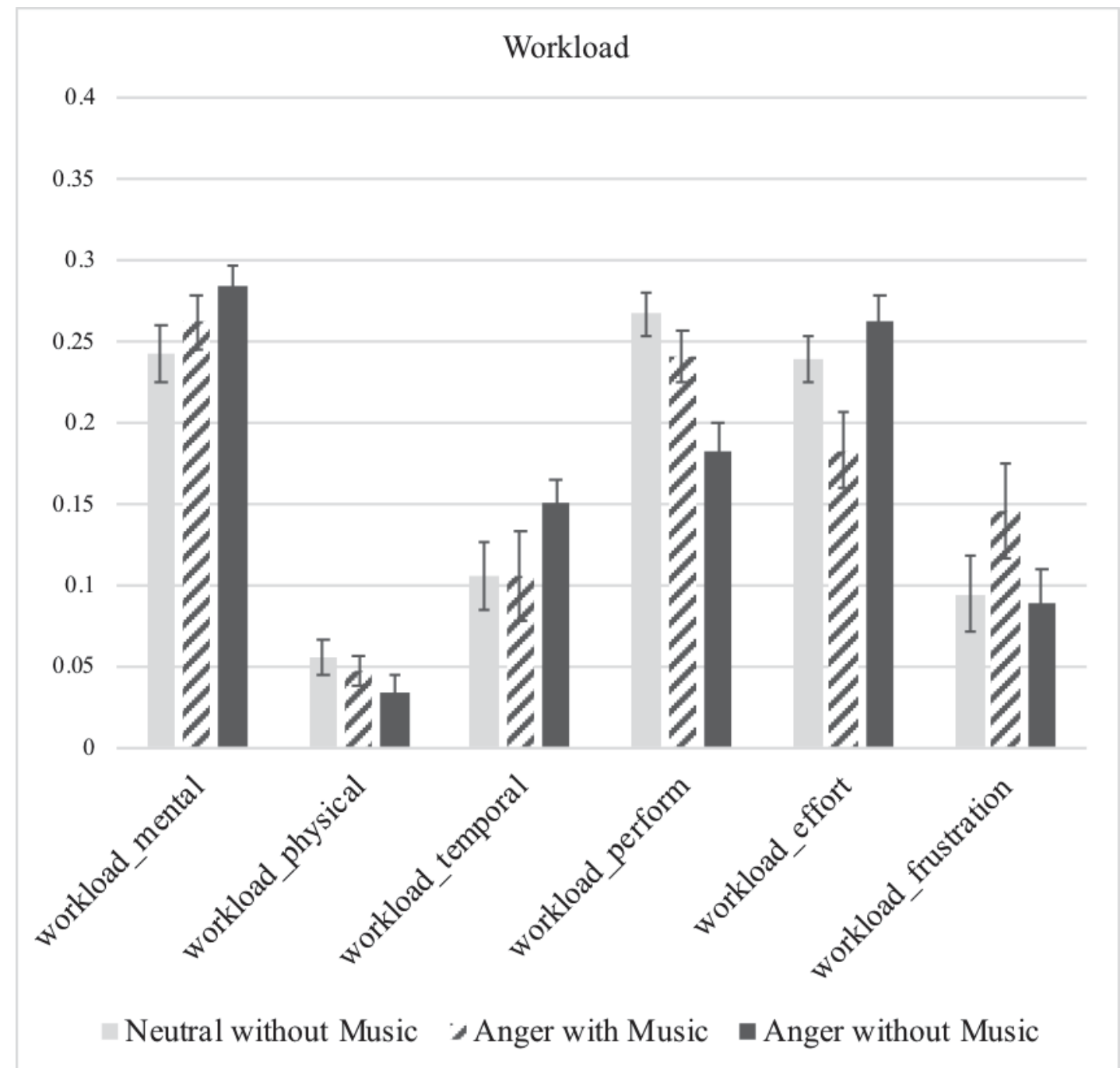

Figure 6.10. Scores of groups for each workload subscale. Error bars represent standard errors. 


\section{Discussion of Experiment 1}

Safe traffic conditions mostly depend on the driver rather than the vehicle or other environmental factors (AAA, 2009; NHTSA, 2015; Stanojević, Sullman, Jovanović, \& Stanojević, 2018). Any changes in the drivers' internal state can influence their driving behavior (Roidl, Frehse, \& Höger, 2014). In this study, anger was investigated as one of the most common, impactful, and negative emotions in the driving context. Results of this experiment showed consistent patterns in drivers' performance, self-report data, and physiological reactions.

Results from drivers' self-report anger showed the anger induction procedure was successful. Participants who were supposed to be angry reported significantly higher anger after the recall and writing procedure. This result reveals one aspect of emotion i.e., subjective feeling (Scherer, 2001; Thayer, Hansen, Saus-Rose, \& Johnsen, 2009).

Based on Hypothesis 3, angry drivers' self-report of anger in music and no-music groups were compared to find if anger decrements from after emotion induction procedure to the end of the experiment are different or not. This comparison was made to see if angry drivers in the music group reported more anger decrement than the drivers in the no music group. The results show no difference among angry drivers' self-report. Selfreported emotion is a Likert-based scale questionnaire that may not be sensitive to small changes and may not be able to reflect these patterns.

Consistent with the previous studies (Bachoo, Bhagwanjee, \& Govender, 2013; Fakhrhosseini, Landry, Tan, Bhattarai, \& Jeon, 2014; Jeon, Yim, \& Walker, 2011; Roidl, 
Frehse, \& Höger, 2014; Stephens, \& Groeger, 2009), in this experiment angry drivers showed more deteriorated driving behavior than the neutral drivers. This finding supports the first hypothesis that angry drivers will show worse driving performance than nonangry drivers. Regarding the type of behavior, this difference is shown on fuel-efficient driving behavior and driving speed. Angry drivers who did not listen to any music had worse fuel-efficient driving performance than the emotion-neutral drivers. As mentioned, poor fuel-efficient driving behavior is defined as flooring the gas and brake pedals recognized by the driving simulator. Poor fuel-efficient driving was counted as risky driving behavior, as has been done in related studies (Jeon, 2016; Haworth, \& Symmons, 2001). Haworth and Symmons (2001) in their paper discussed the safety benefits of EcoDrive training programs and their role on fuel efficiency and costs. In the nine principles of EcoDriving, they discussed that "drivers should look and plan ahead and coast to traffic lights or intersections so that there is no unnecessary braking and the timing is such that the vehicle does not need to come to a complete stop." For example, Reinhardt (1999) found 35\% fewer accidents with improvement in ecodriving behaviors. Johannson (1999) showed a significant decrease in fuel consumption and a reduction in costs associated with accidents. As shown in this and previous studies, fuel-efficient driving behavior is a valuable indicator of risky driving behavior.

When the driving difficulty was considered, in hard driving condition (foggy and snowy roads) angry drivers who did not listen to any music showed more speeding and worse fuel-efficient driving performance than both the neutral drivers and angry drivers who listened to music. The results from this study is in line with the results of previous 
research (e.g. Cassidy \& Macdonald, 2009) that self-selected music decrease distraction and anxiety, increase enjoyment, and regulate driver aggression in high demanding rides (Wiesenthal et al., 2003).

American Automobile Association in 2009 reported that impaired driving behavior and aggressive driving have been attributed to around 56 percent of fatal crashes. Therefore, it is important to find what factors can lead to unsafe driving behaviors and in what ways. It has been shown that emotional states impact on information processing (Nabi, 1999; Tiedens, \& Linton, 2001), reasoning, and decision making (Bechara, Damasio, \& Damasio, 2000; Blanchette, \& Richards, 2010; Schwarz, 2000). Consequently, any changes in drivers' emotional states can impact their driving performance. In a study by Jeon and Walker (2011) among nine affective states related to driving safety (fear, happiness, anger, sadness, confusion, embarrassment, urgency, boredom, and relief), it was shown that anger leads to negative outcomes and risky driving behaviors which is consistent with the results of this experiment.

Drivers' performance in different driving conditions (difficulty level) showed some unexpected patterns. Previous research suggests the effect of music on driving is partly determined by the primary task difficulty (Beh \& Hirst, 1999; Consiglio, Driscoll, Witte, \& Berg, 2003; Oron-Gilad, Ronen, \& Shinar, 2008; Ünal, Steg, \& Epstude, 2012; Ünal, Platteel, Steg, and Epstude, 2013; Wang, Jimison, Richard, \& Chuan, 2015). They suggested that if a driving task is very demanding, music may deteriorate driving performance. However, the results of this study showed that angry drivers who did not listen to music sped more and had worse fuel-efficient driving behavior mostly in the 
demanding driving situations than angry drivers who listened to music. On the other hand, angry drivers who listened to music showed relatively better performance. Some of the previous research (e.g., Groene \& Barrett, 2012) showed the influence of music on drivers' stress and reducing negative effects of emotional states on performance. It seems that music is even helpful in the demanding situations when drivers are angry by mitigating drivers' emotion or distracting drivers from their emotion.

Since emotional states can vary from moment to moment for different reasons, designing an in-vehicle system in cars to reduce the negative consequences of emotion via music would be helpful. Listening to music is a common and favorite activity in cars (Dalton \& Behm, 2007; Dibben \& Williamson, 2007; Sloboda, O’Neill \& Vivaldi, 2001; Stutts, 2003). Music creates emotions (Juslin, \& Laukka, 2004) or changes emotional states in its listeners (Kawakami, Furukawa, Katahira, \& Okanoya, 2013). Although the results of driving behavior among the two angry drivers' groups did not show any significant differences (rejection of Hypothesis 2: angry drivers in the music group will show better driving performance than angry drivers in the no music group), the trend is consistent with this hypothesis. The trend shows worse fuel-efficient driving behavior in the angry drivers group who did not listen to music than those who listened to self-selected music. On the other side, there is no difference between music group and neutral drivers in terms of driving performance. This means angry drivers' performance in the music group is at the similar level as neutral driver' performance. Similar results were found by (Ünal, de Waard, Epstude, \& Steg, 2013) that self-selected music could improve driving performance. The music in this experiment was drivers' self-selected music. They were 
asked to pick a music piece after the emotion induction procedure and were told that they would listen to that music while driving session. There was no control over the musical features and the emotions of the music. Studies showed different effects of music mood on mitigating driver anger (Fairclough, van der Zwaag, Spiridon, \& Westerink, 2014; Fakhrhosseini, Landry, Tan, Bhattarai, \& Jeon, 2014).

An in-vehicle auditory system for angry drivers should not be based on self-reported data alone. This system should be able to estimate drivers' emotional states indirectly via sensing and interpreting physiological data. To this aim, drivers' physiological data were recorded and analyzed. Hypothesis 4 predicted that angry drivers in the music group will show a different pattern in their physiological data than those in the no music group. To test this hypothesis, I compared the ECG and fNIRS data. Results showed that angry drivers who drove without listening to any music showed significantly higher HR than neutral drivers (who did not listen to music) and angry drivers (who listened to selfselected music). This difference can be related to drivers' anger and arousal level. As previous studies showed (Jallais, \& Gilet, 2010; Novaco, 1976; Russell, \& Mehrabian, 1974) anger is an emotion with negative valance and high arousal. High arousal is usually associated with higher HR (Cox, 2008; Potegal, \& Spielberger, 2010; Scherer, \& Wallbott 1994; Spielberger, 1999). Since we did not see the same pattern in Anger with music group, we can conclude that self-selected music helped angry drivers and changed the arousal level back to the neutral state. In this experiment HRV did not show any difference among the groups. 
Analyzing drivers' cardiovascular activity was not limited to between comparisons. To reduce individual differences, drivers' cardiovascular activity was compared during the practice and the driving phases. Results showed that drivers' HR significantly increased from practice to driving sessions in Anger without music groups and significantly decreased in neutral drivers. No significant changes were seen in the music group. These patterns imply that angry drivers who did not listen to music stayed angry during the driving session. However, angry drivers who listened to music during the driving had the same level heart rate as the practice session (before emotion induction), which shows the influence of music on drivers' HR data and regulating their arousal level. In other words, self-selected music kept drivers' arousal level the same as the neutral situation. The significant decrement in neutral drivers' HR data from practice to driving can be attributed to the driving task itself. It has been shown that more than 70 percent of drivers listen to music more than two thirds of their driving time (Dibben, \& Williamson, 2007) and their main reasons are maintaining an optimal level of arousal and avoiding boredom. Therefore, boring driving tasks can lead to lower arousal level.

Recording and testing drivers' hemodynamic changes of PFC were another aspect to assess drivers' emotional changes. Comparing the results of oxygenation and deoxygenation of PFC among the three groups did not show any significant differences. Although one benefit of fNIRS over fMRI is that fNIRS is less sensitive to motion (Cui, Bray, Bryant, Glover, \& Reiss, 2011), it may not be zero. Individual differences and body movements may have added noise to the data. Therefore, like cardiovascular data, results of fNIRS were tested within the groups during the practice and driving sessions to 
eliminate individual differences. Results showed that in Neutral without music and Anger with music groups the average $\mathrm{O} 2 \mathrm{Hb}$ increased significantly from practice to driving session. However, $\mathrm{O} 2 \mathrm{Hb}$ level did not change significantly from practice to the driving session in Anger without music group. Higher $\mathrm{O} 2 \mathrm{Hb}$ level represents higher activity of PFC (Leon-Carrion, Damas, Izzetoglu, Pourrezai, Martín-Rodríguez, y Martin, \& Dominguez-Morales, 2006) and higher activity in PFC is usually associated with emotional processing (both experiencing and regulating emotion) (Balconi, Grippa, \& Vanutelli, 2015) and cognitive controls (Koechlin, Ody, \& Kouneiher, 2003). Results from fNIRS showed that drivers in Neutral without music and Anger with music groups had higher $\mathrm{O} 2 \mathrm{Hb}$ level in the driving session than the practice one. Based on the result of driving behavior and cardiovascular activity, it seems that the higher activation of PFC in Neutral without music and Anger with music groups are related to cognitive controls and emotion regulation. Drivers in these two groups drove safer and did not show high arousal patterns associated with anger. Therefore, drivers in Anger with music group could regulate their anger to some extent via music and have similar PFC activity to neutral drivers. However, drivers in Anger without music group showed aggressive driving patterns which may be related to less concentration on the road and driving behavior in line with less PFC activity in the driving phase.

In the driving context the role of individual differences and some personality characteristics should be considered. Aggressive driving has been attributed to some personality characteristics (Constantinou, Panayiotou, Konstantinou, Loutsiou-Ladd, \& Kapardis, 2011; Dahlen, Edwards, Tubré, Zyphur, \& Warren, 2012; Krahé, \& Fenske, 
2002). Bogdan et al. (2016) discussed the relationship between driver anger and aggressive driving behavior and how much angry driving is associated with risky behaviors and less constructive responses. In this study, it was hypothesized that drivers who have anger-expression-out style and scored higher in driving anger scale will show worse driving performance (behavioral level) than other drivers (Hypothesis 5). Results supported half of the above notion. DAS was not correlated with any of the driving errors. This can be related to the driving scenario. In this study the hazards on the road are not similar to the hazards that were described in DAS items. However, anger expression-out was correlated with how much drivers showed fuel-efficient driving behavior. Drivers who had higher anger expression-out had worse performance in fuelefficiency driving. This finding supports my interpretation that worse fuel-efficient driving behavior is related to anger and anger expression style.

To add a new system to cars for drivers, it is important to find how much it influences drivers' workload in any direction. Implementing an in-vehicle auditory display for angry drivers means adding something to the driving environment. The balance between being distracted from dangerous emotions like anger through music and not being distracted from the road via music is a thin boundary. Although in this study drivers' performance, music perception, and emotional changes were checked, measuring workload would give us more information especially when we need to generalize this simulation study results to a real driving context in which drivers may drive for hours and miles. Experiment 1 showed that angry drivers who did not listen to music rated their performance worse than the other groups. Moreover, they reported more effort to accomplish the driving task. It 
seems that being distracted with anger adds to workload and music can reduce this workload by redirecting or to some extent regulating drivers' emotion.

In conclusion, this study found the contributing factors that influence driver anger. Results showed the benefits of music (self-selected) for angry drivers. However, selfselected music is only one of the important variables. For the idea of having an in-vehicle auditory display, the system should be able to detect and play a wide variety of music for different users with different interests and preferences. In line with the goals of this study, to find what kinds of music can benefit angry drivers the most, different types of emotional music have been considered in the next experiment. 


\section{Experiment 2}

In Experiment 1, results showed that listening to music would help angry drivers. The goal of Experiment 2 is to see how different types of music (positive vs. negative, selfselected vs. experimenter-selected) would help angry drivers. Different types of emotional music played for angry drivers. For each kind of emotional music (happy and sad) I compared two conditions: experimenter-selected and self-selected music. The selection of happy and sad music for angry drivers are based on emotional appraisal theory. Emotional appraisal theory states that emotions are experienced as a result of appraisals of our circumstances. The appraisal theory of emotion allows us to distinguish between negative valence emotions on the basis of appraisal dimensions like pleasantness, anticipated effort, attentional activity, certainty, human agency, and situational control (Ellsworth \& Smith, 1988). Scores on these scales reveal that anger has a kind of "signature", characterized by high perceptions of "other-agency" and "other situational control". That is, appraisals that result in anger tend to arise from situations where the person views another agent as being the source of a problem or obstacle to a goal. By this theory, the introduction of new stimuli (music) may force a re-appraisal of personal circumstances. If the re-appraisal can effectively cause the person to view the same circumstances in a new way with less certainty of "other-agency" and less "other situational control", then it may be possible to manage negative emotional impacts on driving by introducing new stimuli that cause reappraisal of driver circumstances.

Furthermore, having both self-selected and experimenter-selected conditions for each type of emotional music provides an opportunity to analyze the impact of different types 
of music more deeply. To discriminate emotion from other affective phenomena, Scherer (2005) mentioned people generally get emotional about things that they care about. In addition, the influence of self and experimenter selected music might be more important than the valence of each music piece. Therefore, I assigned participants in five groups:

1. Self-selected happy music group

2. Experimenter-selected happy music group

3. Self-selected sad music group

4. Experimenter-selected sad music group

5. Anger without music group

\subsection{Hypotheses}

Here is a list of hypotheses that will be tested in Experiment 2:

Hypothesis 1: Angry drivers in the music group will show better driving performance than angry drivers in the no music group.

Hypothesis 2a: Angry drivers with sad music will show better driving performance than drivers who will drive with happy music.

Hypothesis 2b: Angry drivers with happy music will show better driving performance than drivers who will drive with sad music.

For Hypotheses $2 \mathrm{a}$ and $2 \mathrm{~b}$, there are a few explanations. Based on the emotional appraisal theory, each emotion creates a mental model, which guides people's judgment and decision making. It has been shown that angry people are more optimistic about the 
outcome and tend to blame others for the issues (Lerner \& Tiedens, 2006). This type of information processing may be part of reasons that can be attributed to the issues with angry and aggressive drivers. Therefore, music with a different emotion may be able to change drivers' emotion, mental model, and consequently, their behavior.

Another explanation would be based on the two-dimensional theory of emotion. Happy music with high arousal/positive affect, or sad music with low/negative arousal affect can probably change arousal and valance level of drivers' anger and consequently their emotion to some extent.

Hypothesis 3: Angry drivers with self-selected music will perceive the music as being more intense (both emotionally and cognitively). This will be assessed by the scores of each group on Cognitive-Affective Response Test-Music.

Hypothesis 4: Angry drivers with self-selected music will show relatively better driving performance than drivers with experimenter-selected music (based on familiarity. i.e., they do not need to process lots of new information.).

Hypothesis 5: Self-selected music will decrease drivers' anger more than experimenterselected music (based on the fact that their own music is more important to them, probably they more intensely perceive the music emotionally).

Hypothesis 6: Drivers who scored higher in anger-out expression style subscale and driving anger questionnaire will show worse driving performance than other drivers. 


\subsection{Method}

Before conducting the experiment, I submitted the study protocol to the Michigan Technological University Human Subjects review board for the approval. There was no more than minimal risk associated with participating in this study.

\subsubsection{Participants}

All participants in this experiment were recruited from the MTU community population and the introductory psychology subject pool. I recruited 91 participants (male $=72$, female $=19$, mean age $=22.33, \mathrm{SD}$ of age $=2.61)$ in the MTU laboratory at Meese building. Participants will receive one credit for each half-hour of participation time, as an optional part of their class requirements. The entire experiment took one hour. The number of participants is shown in Table 8.1.

Table 8.1. Number of participants in each group.

\begin{tabular}{ll}
\hline Groups & N \\
\hline Self-selected happy music & 18 \\
\hline Experimenter-selected happy music & 20 \\
\hline Self-selected sad music & 19 \\
\hline Experimenter-selected sad music & 18 \\
\hline Anger without music & 16 \\
\hline
\end{tabular}

\subsubsection{Apparatus}

\subsubsection{Driving simulator}

A medium-fidelity simulator, Advanced Driving Simulator (NADS) MiniSim version 2.1 was used for Experiment 2. The simulation software runs on a single computer. Three Panasonic TH-42PH2014 42" plasma displays, each with a 1280x800 pixel resolution, allow for a total of 130 degree field of view in front of the seated participant. The center 
monitor is 28 inches from the center of the steering wheel and the left and right monitors are 37 inches from the center of the steering wheel. The MiniSim also includes a real steering wheel, adjustable car seat, gear-shift, and gas and brake pedals, as well as a Toshiba Ltd. WXGA TFT LCD monitor with a 1280x800 resolution to display the speedometer, etc.

A driving scenario was created using the Interactive Scenario Authoring Tool (ISAT) software, which comes with the NADS MiniSim. The scenario includes city, rural, and highway roads with different speed limits. The scenario also contains various road signs, vehicles, traffic signals, and pedestrians commonly seen in an actual driving environment. Different hazardous events were created in the scenario to extract different responses from drivers.

\subsubsection{Electrocardiogram (ECG)}

This section is the same as Experiment 1.

\subsubsection{Functional Near-Infrared Spectroscopy (fNIRS)}

This section is the same as Experiment 1.

\subsubsection{Materials}

This section is the same as Experiment 1. 


\subsubsection{Stimuli}

\subsubsection{Music}

Out of the five groups of angry drivers, four groups listened to music while driving. Two groups listened to self-selected music. Participants in the self-selected music conditions were told to spend a few minutes on YouTube or their cellphone to find a happy or sad (depending on the group that they were assigned to) music.

Table 8.2. Validated songs for the experimenter-selected conditions.

\begin{tabular}{ll}
\hline Happy Music & Sad Music \\
\hline Mark Ronson- Uptown Funk & Naruto Sad Song Collection \\
\hline Zac Brown Band- Quiet Your Mind & Rascal Flatts- Why \\
\hline Colony House- Silhouettes & Martina McBride- Concrete Angel \\
\hline Shania Twain- You're Still the One & Alan Jackson- Remember When \\
\hline
\end{tabular}

For the experimenter-selected music groups, eight music pieces were selected from the happy and sad (four for each) music list that was gathered from the self-selected conditions in experiment 1 (Table 8.2). These eight music pieces were selected based on a pilot study with nine college students. I asked them to rate all the music based on their emotion and intensity. Those music pieces with the highest agreements were used for experimenter-selected conditions in Experiment 2.

\subsubsection{Driving Scenario}

The driving scenario is a 12-minutes' drive. It starts with a city road and then after 5 minutes, drivers turn in an intersection that goes to a rural road. After 3 minutes driving in the rural road, they go to a highway with the right entrance. In all of these environments, there are a few hazards (overall 10 hazards). These hazards were 
implemented to simulate various driving conditions and how drivers in different emotional situations may react differently.

1. Swerving Car

2. Motorcycle

3. Traffic Signal

4. U-turn

5. Running Boy

6. Pulling out Car

7. Truck in HWY Entrance

8. Construction \& Lane Merge

9. Two Deer

10. Cutting off Car

\subsubsection{Design and Procedure}

In Experiment 2, I had five between-subjects conditions: Self-selected happy music, Selfselected sad music, Experimenter-selected happy music, Experimenter-selected sad music, and No-music group. In all five groups, participants self-induced anger. After completing the consent procedure, I asked participants to rate their current affective state using Differential Emotions Scale and fill out state-trait anger expression inventory. Participants practiced driving for 5 minutes to familiarize themselves with the driving simulator. This also allows me to screen participants sensitive to simulation sickness by comparing the scores of simulation sickness test before and after the practice session. After the practice session, participants of all the groups spent 12 minutes writing about an angry experience they could vividly remember (Jeon, Yim, \& Walker, 2011). Then, to 
assess different aspects of the emotional event, they filled out the Answer Alternative questionnaire created by Scherer et al. (1989) for 5 minutes. After the mood induction procedure, the participants rated their emotional states for the second time.

For the self-selected music conditions, I asked participants to give me a happy or sad music piece (depending on the group that they were assigned). They were told that music intensity for that specific emotion should be over 8 in a Likert from 1 (not feel at all) to 10 (strongly feel). Then, for the experimenter-selected music, I chose four music pieces out of the sad and happy music the participants gave me for self-selected conditions in experiment 1. Participants in the control group (no-music) did not listen to any music while driving. All participants were instructed to obey all the traffic rules that they normally do. The driving session lasted approximately 12 minutes. Errors, such as lane deviation, brake acceleration force, speeding, steering wheel angel, brake pedal force, and collisions were automatically saved by the simulator. Following the driving portion, participants answered to CART-M, DES, DAS, NASA-TLX, and demographic questions. Figure 8.1 shows the experimental procedure. 


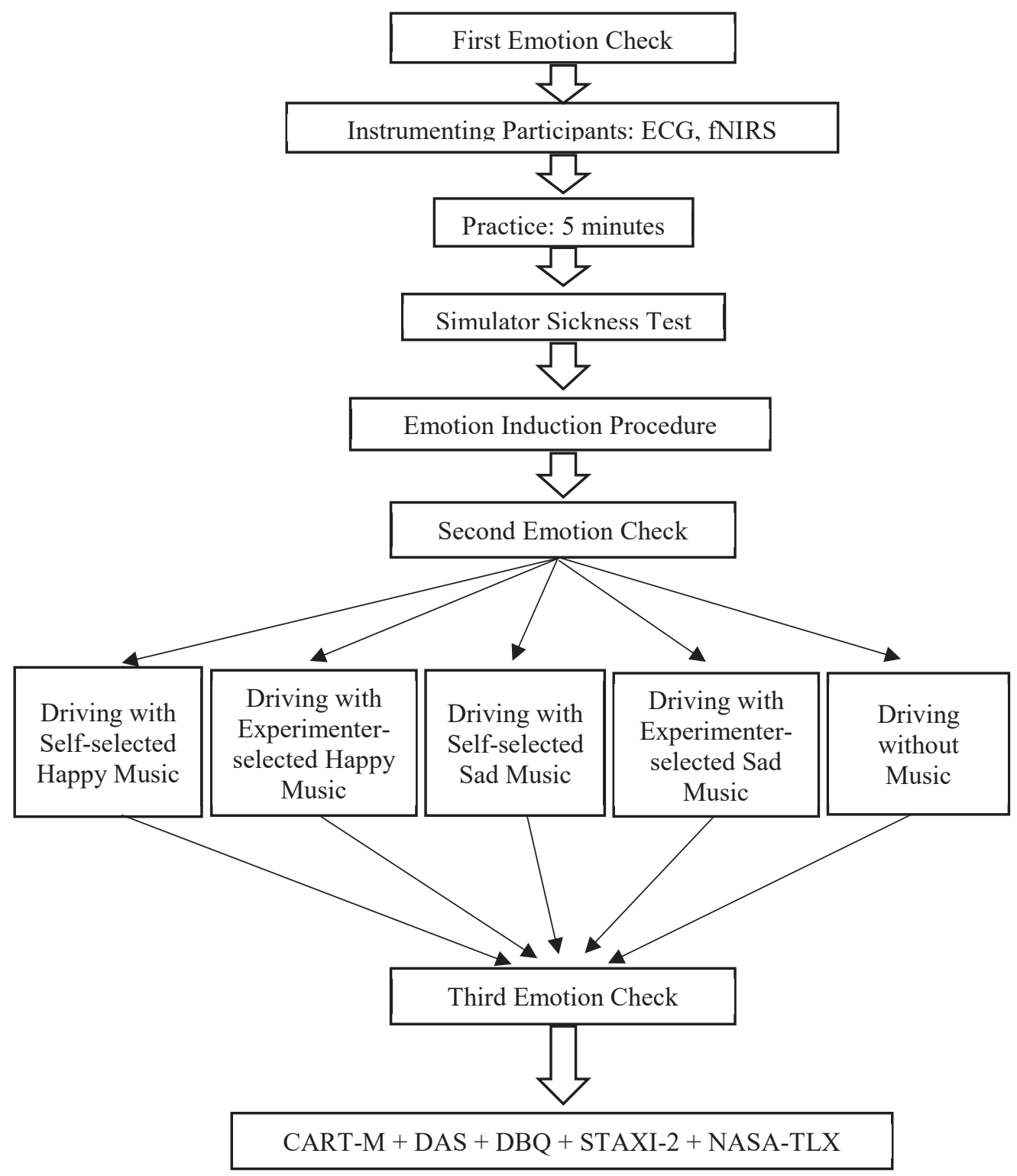

Figure 8.1. Experimental procedure in Experiment 2. 


\section{Results of Experiment 2}

\subsection{Subjective Results: Emotion Manipulation Check}

The goal of the emotion induction method was to induce anger. All participants from different groups went through the emotion induction procedure in order to feel angry. Figure 9.1 shows the patterns of self-report anger among the groups. Through the experiment we asked participants three times to report and rate their emotions. Several one-way repeated measures ANOVAs were conducted to compare their self-report emotions through the experiment. They reported their affective states three times:

1. when participants entered the lab (Anger 1)

2. after emotion induction procedure (Anger 2)

3. and at the end of the experiment before they left the lab (Anger 3)

Results of several one-way repeated measures ANOVAs showed significant differences in participants' anger through the experiment for Self-selected happy music group $(F(2$, $\left.14)=15, p=.000, \eta_{\mathrm{p}}^{2}=.69\right)$, Experimenter-selected happy music group $(F(2,17)=18$, $\left.p=.000, \eta_{\mathrm{p}}^{2}=.68\right)$, Self-selected sad music group $\left(F(2,17)=16, p=.000, \eta_{\mathrm{p}}{ }^{2}=.66\right)$, Experimenter-selected sad music group $\left(F(2,16)=9, p=.002, \eta_{\mathrm{p}}{ }^{2}=.54\right)$, and Anger without music group $\left(F(2,13)=14, p=.000, \eta_{\mathrm{p}}{ }^{2}=.69\right)$ (Figure 9.1). Results of post hoc comparisons with paired samples t-tests show the differences of Anger1, Anger2, and Anger3 in each group (Tables 9.1, 9.2, 9.3). 
Table 9.1. Mean of self-report anger in each group.

\begin{tabular}{llll}
\hline Groups & Anger 1 & Anger 2 & Anger 3 \\
\hline Self-selected happy music & 1.81 & 4 & 2.56 \\
\hline Experimenter-selected happy music & 1.42 & 3.5 & 1.68 \\
\hline Self-selected sad music & 1.84 & 3.89 & 2.26 \\
\hline Experimenter-selected sad music & 1.33 & 2.94 & 2.11 \\
\hline Anger without music & 1.2 & 3.66 & 2.2 \\
\hline
\end{tabular}

Table 9.2. Paired samples t-test of self-report anger scores before and after emotion induction.

\begin{tabular}{lll}
\hline Groups & $\begin{array}{l}\mathbf{t} \text { Value Anger } \\
\mathbf{1 , 2}\end{array}$ & $\boldsymbol{p}$ Value \\
\hline Self-selected happy music & -5.77 & .000 \\
\hline Experimenter-selected happy music & -5.66 & .000 \\
\hline Self-selected sad music & -5.66 & .000 \\
\hline Experimenter-selected sad music & -4.44 & .000 \\
\hline Anger without music & -5.67 & .000 \\
\hline
\end{tabular}

Table 9.3. Paired samples t-test of self-report anger scores after emotion induction and before leaving the lab.

\begin{tabular}{lll}
\hline Groups & $\begin{array}{l}\mathbf{t} \text { Value Anger } \\
\mathbf{1 , 2}\end{array}$ & $\boldsymbol{p}$ Value \\
& 4.55 & .000 \\
\hline Self-selected happy music & 4.58 & .000 \\
\hline Experimenter-selected happy music & 4.52 & .000 \\
\hline Self-selected sad music & 2.29 & .000 \\
\hline Experimenter-selected sad music & 3.29 & .000 \\
\hline Anger without music &
\end{tabular}

\subsection{Physiological data}

ECG data were analyzed based on two statistical values: mean of heart rate and standard deviation of HRV. All the analyses were based on three types of grouping of participants. The first type was based on the five groups that all the participants we randomly assigned. The second type was determined based on the type of music regardless of the 


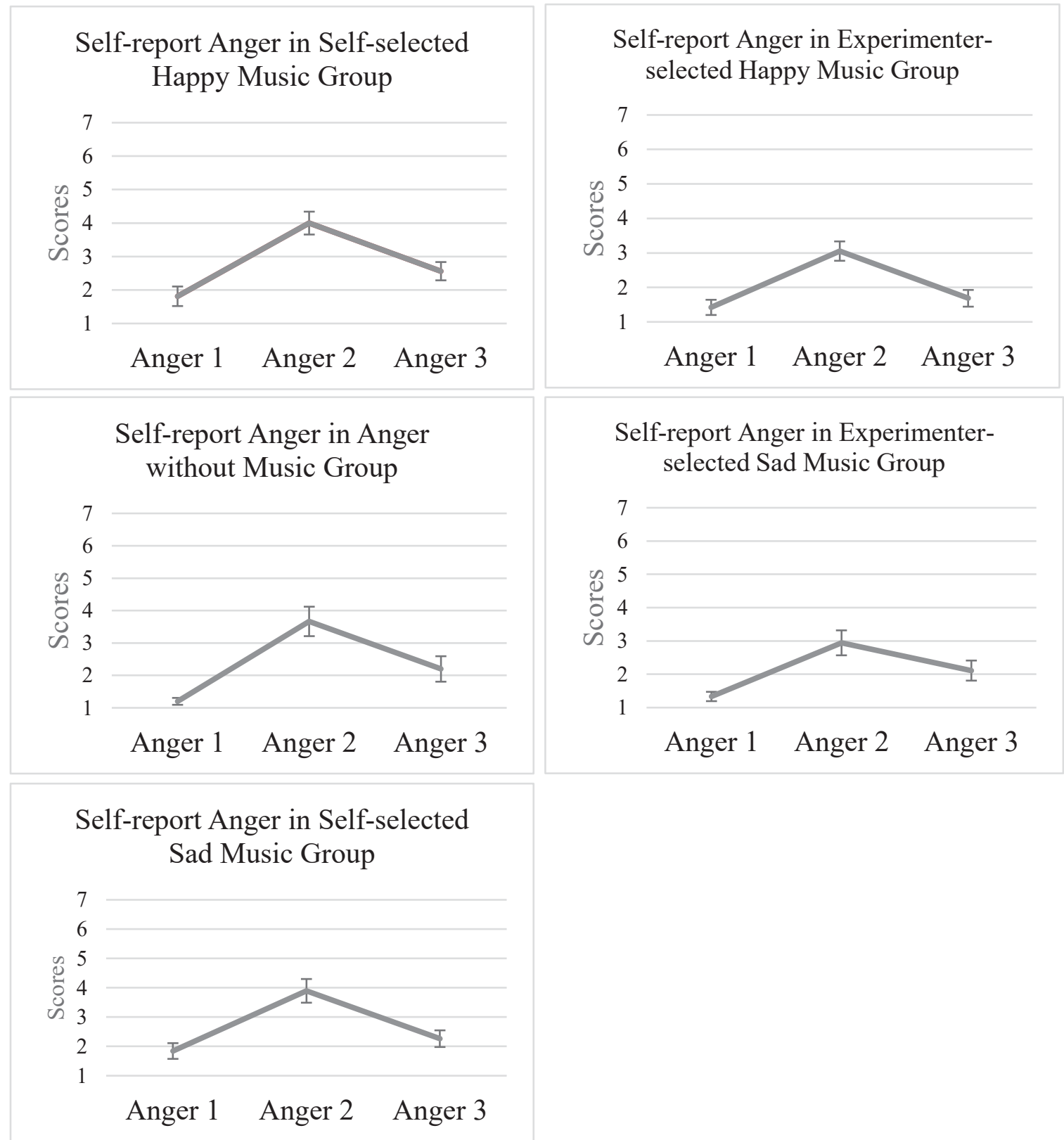

Figure 9.1. Changes in self-report anger scores in the groups in a Likert scale from 1 (not at all) to 7 (very intense). Error bars represent standard errors. 
selection way (either it is self or experimenter-selected). Finally, participants' data were grouped based on the selections way without considering the type of the music (happy and sad music).

\subsubsection{ECG}

To analyze all ECG data, values more than 1.5 interquartile range (IQR's) in each group were labeled as outliers and were eliminated from the statistical analysis. Tables 9.4 and 9.6 show the total number of participants, how many of them were removed as outliers, and the number of participants in each group that were considered in HR and HRV analysis.

\subsubsection{Between Group Comparisons}

\subsection{ECG $(\mathrm{HR})$}

Table 9.4. Number of total participants, outliers, and participants in HR analysis.

\begin{tabular}{llll}
\hline Groups & $\begin{array}{c}\text { Total Number of } \\
\text { Participants }\end{array}$ & $\begin{array}{l}\text { Number of } \\
\text { Outliers }\end{array}$ & $\begin{array}{l}\text { Number of } \\
\text { Participants } \\
\text { in the } \\
\text { Analysis }\end{array}$ \\
\hline Self-selected happy music & 18 & 1 & 17 \\
\hline $\begin{array}{l}\text { Experimenter-selected happy } \\
\text { music }\end{array}$ & 20 & 4 & 16 \\
\hline Self-selected sad music & 19 & 0 & 19 \\
\hline Experimenter-selected sad music & 18 & 1 & 17 \\
\hline Anger without music & 16 & 0 & 16 \\
\hline
\end{tabular}

\section{HR Five Groups Comparisons}

A one-way ANOVA was performed on the mean of Heart rate during the driving session. Results show that mean of Heart rate is not significantly different among the groups $(F(4$, $80)=.76, p=.554, \eta_{\mathrm{p}}^{2}=.03$ ) (Figure 9.5). 
Table 9.5. Descriptive statistic results of five groups' HR data.

\begin{tabular}{lllll}
\hline Groups & N & Mean & $\begin{array}{l}\text { Std. } \\
\text { Deviation }\end{array}$ & Std. Error \\
\hline Self-selected happy music & 17 & 81.68 & 17.95 & 4.35 \\
\hline $\begin{array}{l}\text { Experimenter-selected happy } \\
\text { music }\end{array}$ & 16 & 82.91 & 17.49 & 4.37 \\
\hline Self-selected sad music & 19 & 85.90 & 9.40 & 2.15 \\
\hline $\begin{array}{l}\text { Experimenter-selected sad } \\
\text { music }\end{array}$ & 17 & 88.37 & 11.73 & 2.84 \\
\hline Anger without music & 16 & 88.54 & 15.20 & 3.80 \\
\hline
\end{tabular}

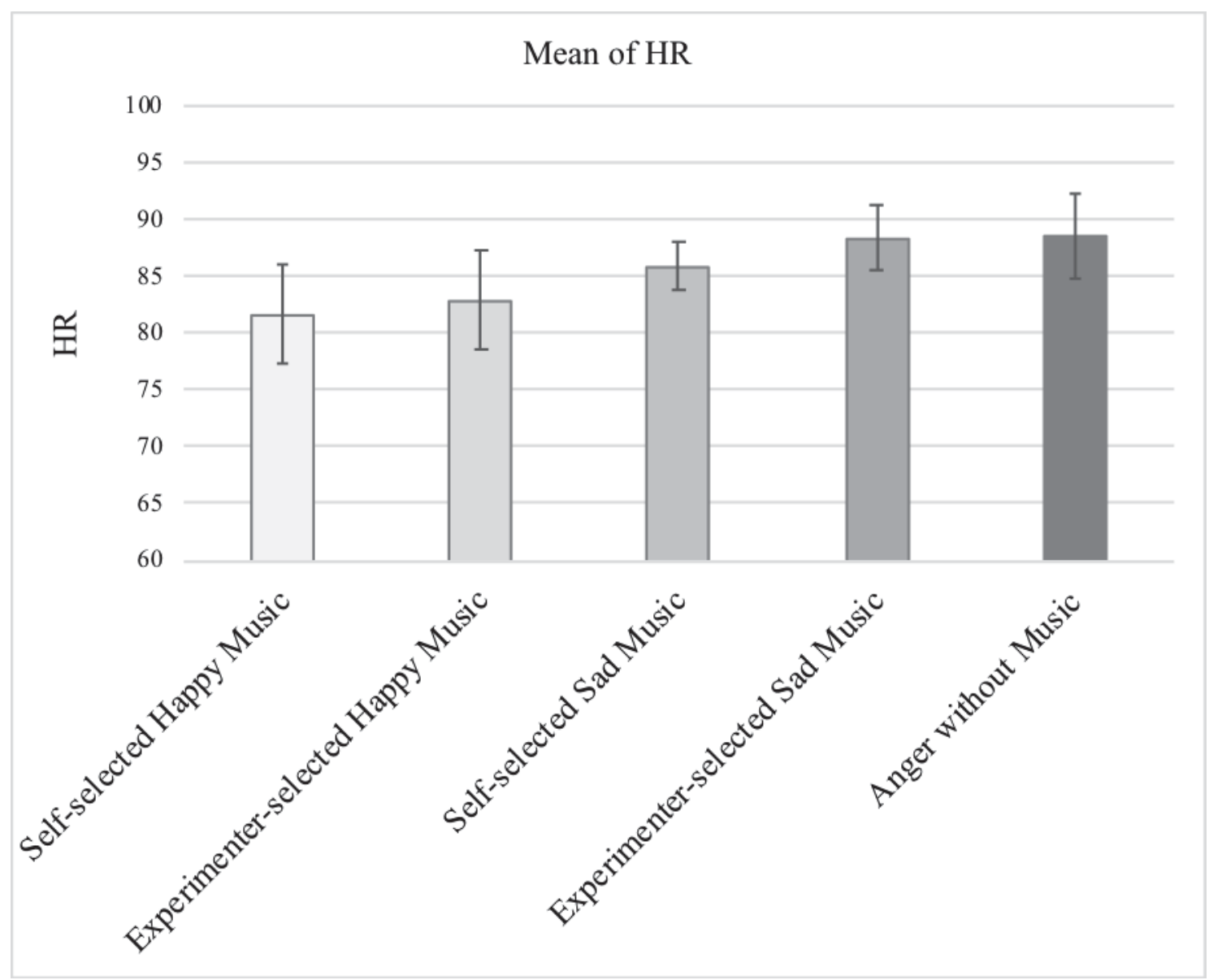

Figure 9.2. Drivers' HR during the driving session for each group. Error bars represent standard errors.

HR Music Choice Comparisons 
To find out how much the types of the music influenced angry drivers' heart rate data, a one-way ANOVA was performed. Results did not show any difference among the groups in terms of mean of $\operatorname{HR}\left(F(2,82)=.56, p=.569, \eta_{\mathrm{p}}{ }^{2}=.01\right)$.

\subsection{ECG (HRV)}

HRV Five Groups Comparisons

Regarding heart rate variability, the standard deviation of heart rate variability is significantly different $\left(F(4,77)=2.91, p=.027, \eta_{\mathrm{p}}{ }^{2}=.03\right)$ among the groups. Post hoc analysis with LSD shows that drivers' heart rate variability who were in Anger without music group significantly varied more than all the other groups (Figure 9.3).

Table 9.6. Number of total participants, outliers, and participants in HRV analysis.

\begin{tabular}{llll}
\hline Groups & $\begin{array}{l}\text { Total Number of } \\
\text { Participants }\end{array}$ & $\begin{array}{l}\text { Number of } \\
\text { Outliers }\end{array}$ & $\begin{array}{l}\text { Number of } \\
\text { Participants } \\
\text { in the } \\
\text { Analysis }\end{array}$ \\
\hline Self-selected happy music & 18 & 2 & 16 \\
\hline $\begin{array}{l}\text { Experimenter-selected happy } \\
\text { music }\end{array}$ & 20 & 5 & 15 \\
\hline Self-selected sad music & 19 & 0 & 19 \\
\hline Experimenter-selected sad music & 18 & 2 & 16 \\
\hline Anger without music & 16 & 0 & 16 \\
\hline
\end{tabular}




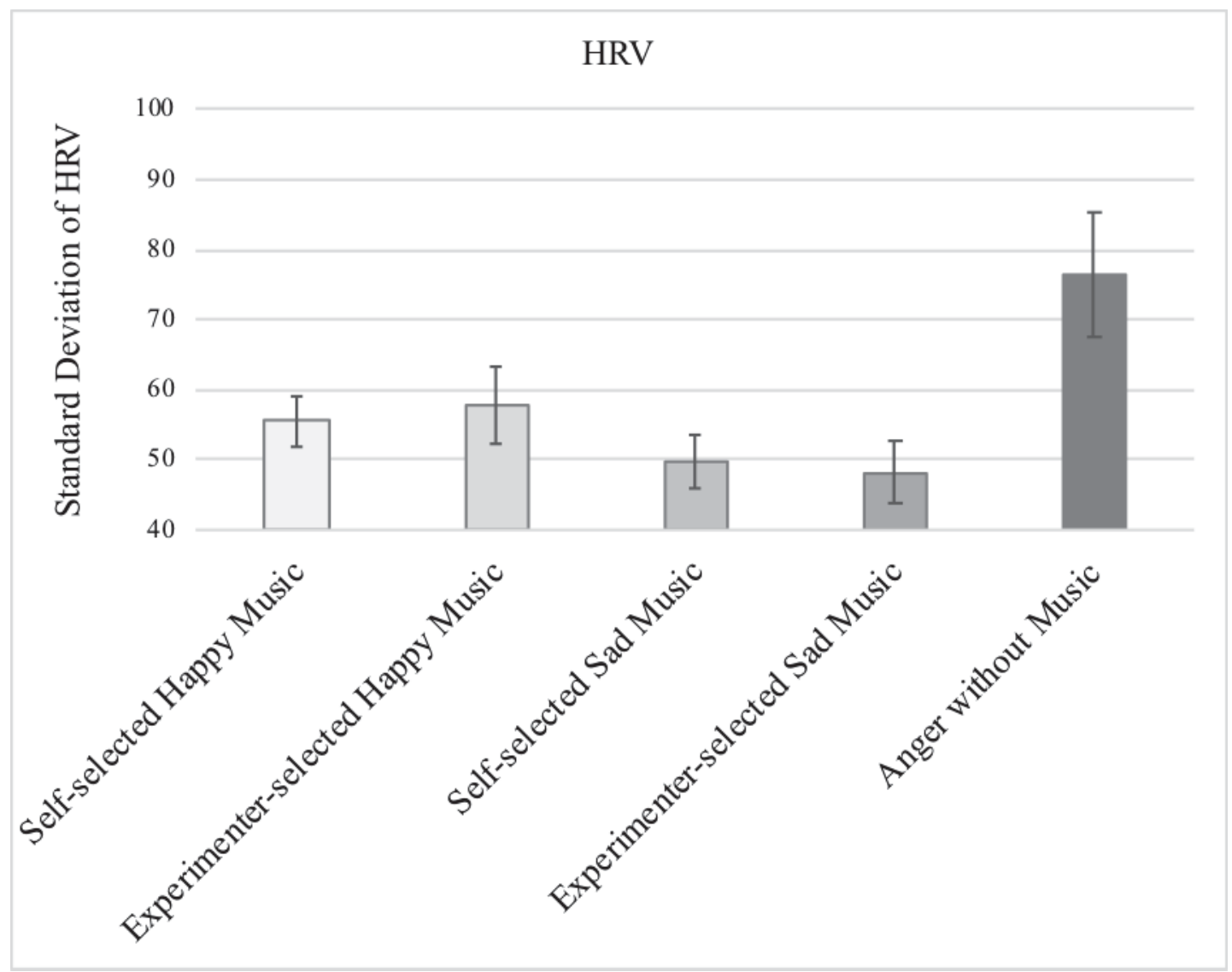

Figure 9.3. Drivers' HRV during the driving session for each group. Error bars represent standard errors.

\section{HRV Music Type Comparisons}

Standard deviation of heart rate variability were significantly different among the groups during the driving session $\left(F(2,79)=5.60, p=.005, \eta_{\mathrm{p}}{ }^{2}=.12\right)$. Post hoc analysis showed consistent result regarding standard deviation of heart rate variability for the Anger without music group (Figure 9.4). 


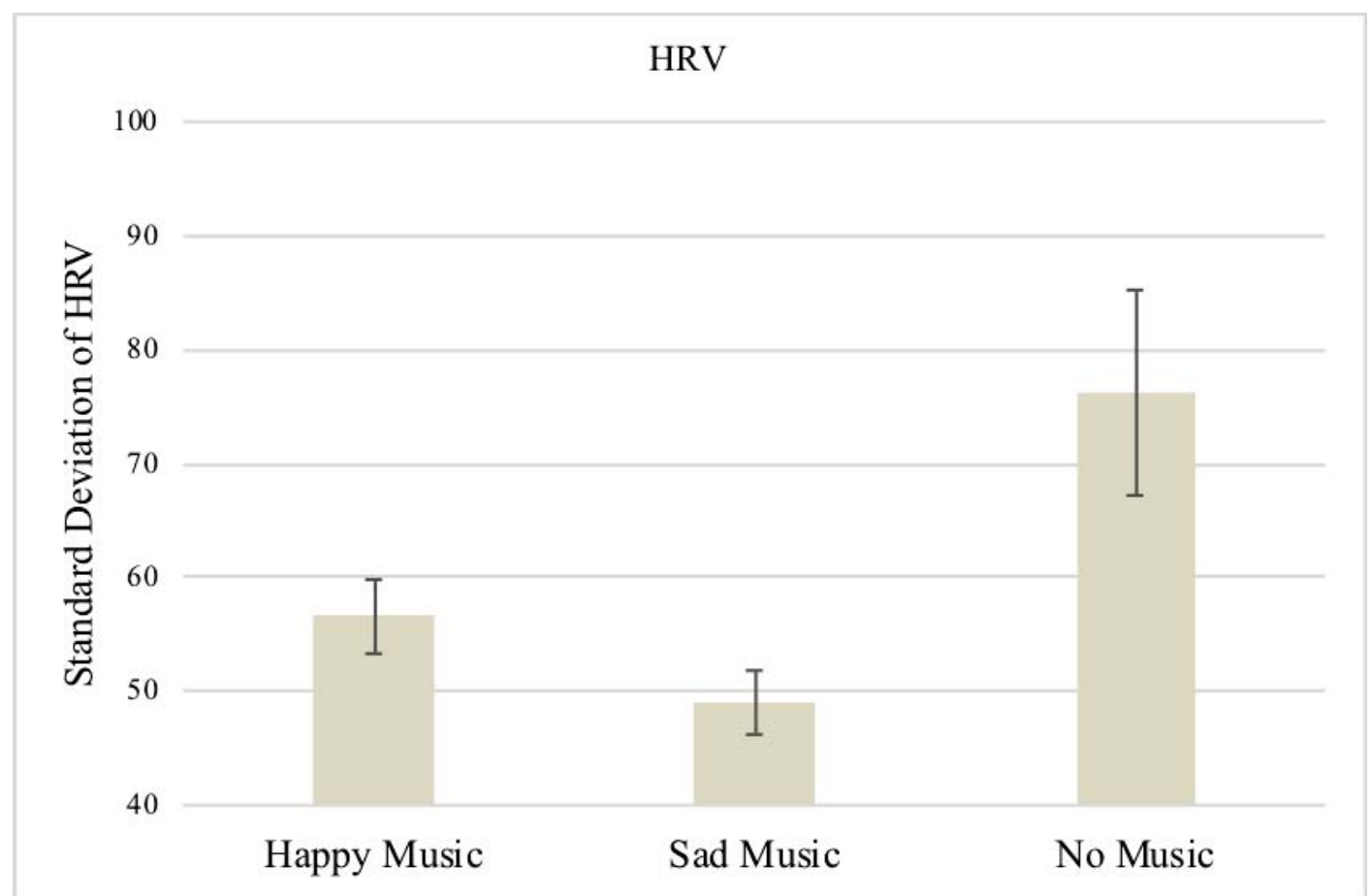

Figure 9.4. Drivers' HRV during the driving session based on the type the music. Error bars represent standard errors.

In other words, angry drivers' heart rate variability varies significantly more when they don't listen to any music in comparison to drivers who listened to happy and sad music regardless of the selection way (self vs experimenter selected music) (Table 9.7).

Table 9.7. Descriptive statistic results of five groups' HRV data.

\begin{tabular}{lllll}
\hline Groups & N & Mean & $\begin{array}{l}\text { Std. } \\
\text { Deviation }\end{array}$ & Std. Error \\
\hline Self-selected happy music & 16 & 55.50 & 13.97 & 3.60 \\
\hline $\begin{array}{l}\text { Experimenter-selected happy } \\
\text { music }\end{array}$ & 15 & 57.71 & 21.25 & 5.48 \\
\hline $\begin{array}{l}\text { Self-selected sad music } \\
\begin{array}{l}\text { Experimenter-selected sad } \\
\text { music }\end{array}\end{array}$ & 19 & 49.73 & 16.22 & 3.72 \\
\hline Anger without music & 16 & 48.22 & 25.21 & 4.57 \\
\hline
\end{tabular}


HRV Music Choice Comparisons

Results of a one-way ANOVA showed that the standard deviation of RR in the driving session is the highest in the control group $F(2,79)=5.66, p=.005, \eta_{\mathrm{p}}{ }^{2}=.12$ ) (Figure 9.5).

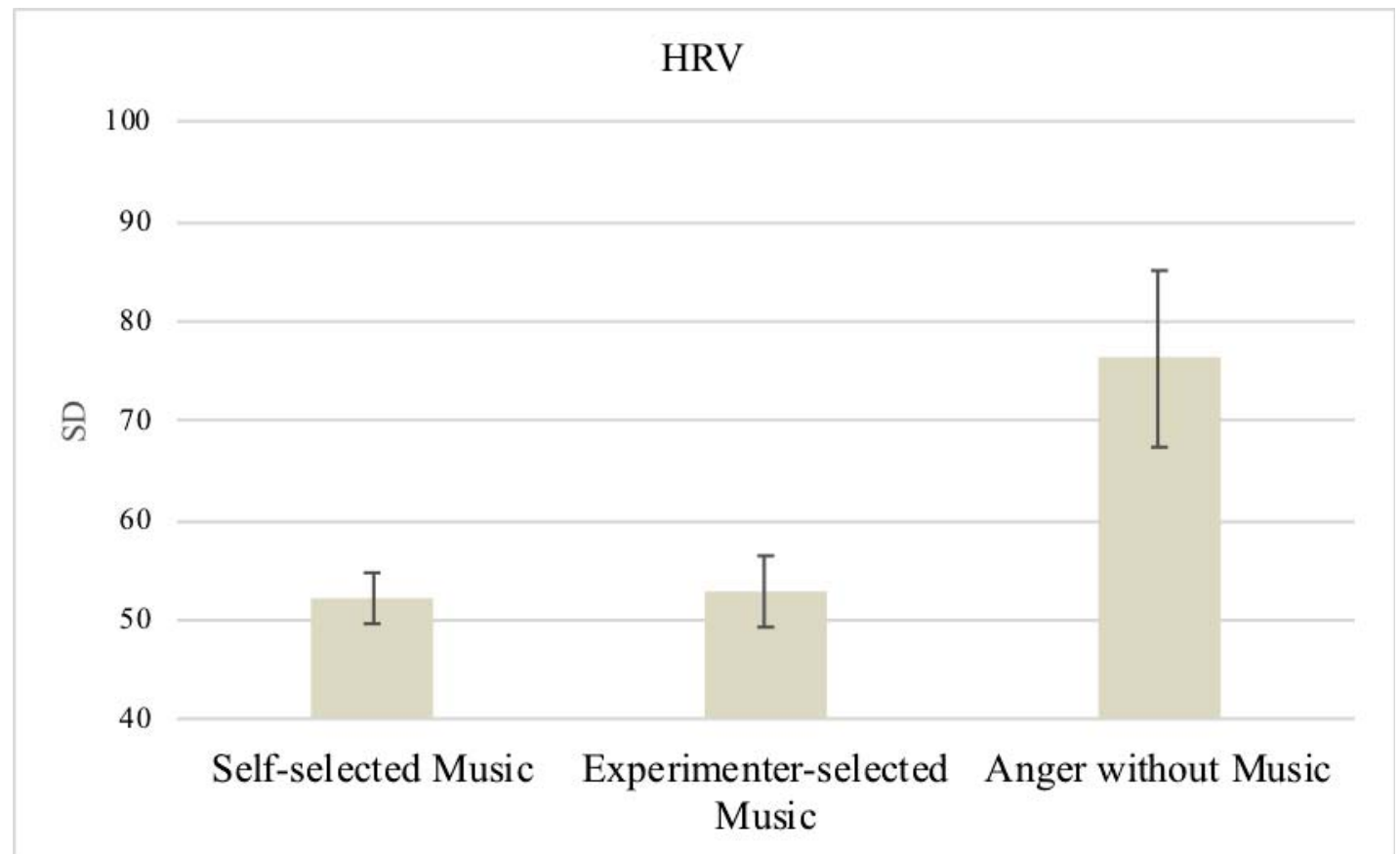

Figure 9.5. Drivers' HRV during the driving session based on the selection of the music. Error bars represent standard errors.

\subsubsection{Within Group Comparisons}

\subsection{ECG (HR)}

Since there are large individual differences in physiological responses, heart rate data and heart rate variability were analyzed through the sessions (practice and driving) that each participant went through. This would give us a better understanding of the changes during the experiment. Several paired samples t-tests were conducted to compare the mean of HR and SD of HRV among practice and driving conditions. Results show that the mean 
of HR in experimenter-selected sad music decreased significantly $(t(16)=2.18, p=.044)$ from practice $(M=92.51, S D=15.63)$ to the driving sessions $(M=88.37, S D=11.73)$.

\subsection{ECG (HRV)}

The SD of HRV in experimenter-selected sad music decreased significantly $(t(16)=$ $2.84, p=.012)$ from practice $(M=39.90, S D=15.55$ to the driving sessions $(M=55.84$, $S D=27.19)$.

\subsection{2 fNIRS}

All the results are based on mean of $\mathrm{O} 2 \mathrm{Hb}$ and $\mathrm{HHb}$ changes. Values more than 1.5 interquartile range (IQR's) in each group were labeled as outliers and were eliminated from the statistical analysis (Tables 9.8 and 9.9).

Table 9.8. Number of total participants, outliers, and participants in $\mathrm{O} 2 \mathrm{Hb}$ analysis.

\begin{tabular}{llll}
\hline Groups & $\begin{array}{l}\text { Total Number of } \\
\text { Participants }\end{array}$ & $\begin{array}{l}\text { Number of } \\
\text { Outliers }\end{array}$ & $\begin{array}{l}\text { Number of } \\
\text { Participants } \\
\text { in the } \\
\text { Analysis }\end{array}$ \\
\hline Self-selected happy music & 18 & 1 & 17 \\
\hline $\begin{array}{l}\text { Experimenter-selected happy } \\
\text { music }\end{array}$ & 20 & 2 & 18 \\
\hline Self-selected sad music & 19 & 2 & 17 \\
\hline Experimenter-selected sad music & 18 & 2 & 16 \\
\hline Anger without music & 15 & 2 & 13 \\
\hline
\end{tabular}

\subsubsection{Between Group Comparisons}

Five Groups Comparisons

Several one-way ANOVAs were run to see if participants' $\mathrm{O} 2 \mathrm{Hb}$ and $\mathrm{HHb}$ levels are different during the driving sessions. Results showed no difference among the groups based on these variables. 
9.9. Number of total participants, outliers, and participants in $\mathrm{O} 2 \mathrm{Hb}$ analysis.

\begin{tabular}{llll}
\hline Groups & $\begin{array}{l}\text { Total } \\
\text { Number of } \\
\text { Participants }\end{array}$ & $\begin{array}{l}\text { Number of } \\
\text { Outliers }\end{array}$ & $\begin{array}{l}\text { Number of } \\
\text { Participants } \\
\text { in the } \\
\text { Analysis }\end{array}$ \\
\hline Self-selected happy music & 18 & 2 & 16 \\
\hline $\begin{array}{l}\text { Experimenter-selected happy } \\
\text { music }\end{array}$ & 20 & 3 & 17 \\
\hline Self-selected sad music & 19 & 2 & 17 \\
\hline Experimenter-selected sad music & 18 & 1 & 17 \\
\hline Anger without music & 15 & 1 & 14 \\
\hline
\end{tabular}

Music Type Comparisons

Several one-way ANOVAs were run to see if participants' hemodynamic changes during the driving session is different among the groups or not. Results showed no difference among the groups.

Music Choice Comparisons

Several one-way ANOVAs were run to see if participants' hemodynamic changes during the driving session is different among the groups or not. Results showed no difference among the groups for $\mathrm{O} 2 \mathrm{Hb}$ and $\mathrm{HHb}$.

\subsubsection{Within Group Comparisons}

$\mathrm{HHb} \& \mathrm{O} 2 \mathrm{Hb}$

There were no significant patterns for $\mathrm{HHb}$ changes. However, results of paired samples t-tests shows that the $\mathrm{O} 2 \mathrm{Hb}$ increase significantly from practice to the driving conditions in all groups (Figure 9.6) (Table 9.10). 
9.10. Paired samples t-tests between practice and driving sessions in each group.

\begin{tabular}{lll}
\hline Groups & t Value & $\boldsymbol{p}$ Value \\
\hline Self-selected happy music & 18 & .039 \\
\hline Experimenter-selected happy music & 20 & .002 \\
\hline Self-selected sad music & 19 & .027 \\
\hline Experimenter-selected sad music & 18 & .000 \\
\hline Anger without music & 15 & .002 \\
\hline
\end{tabular}

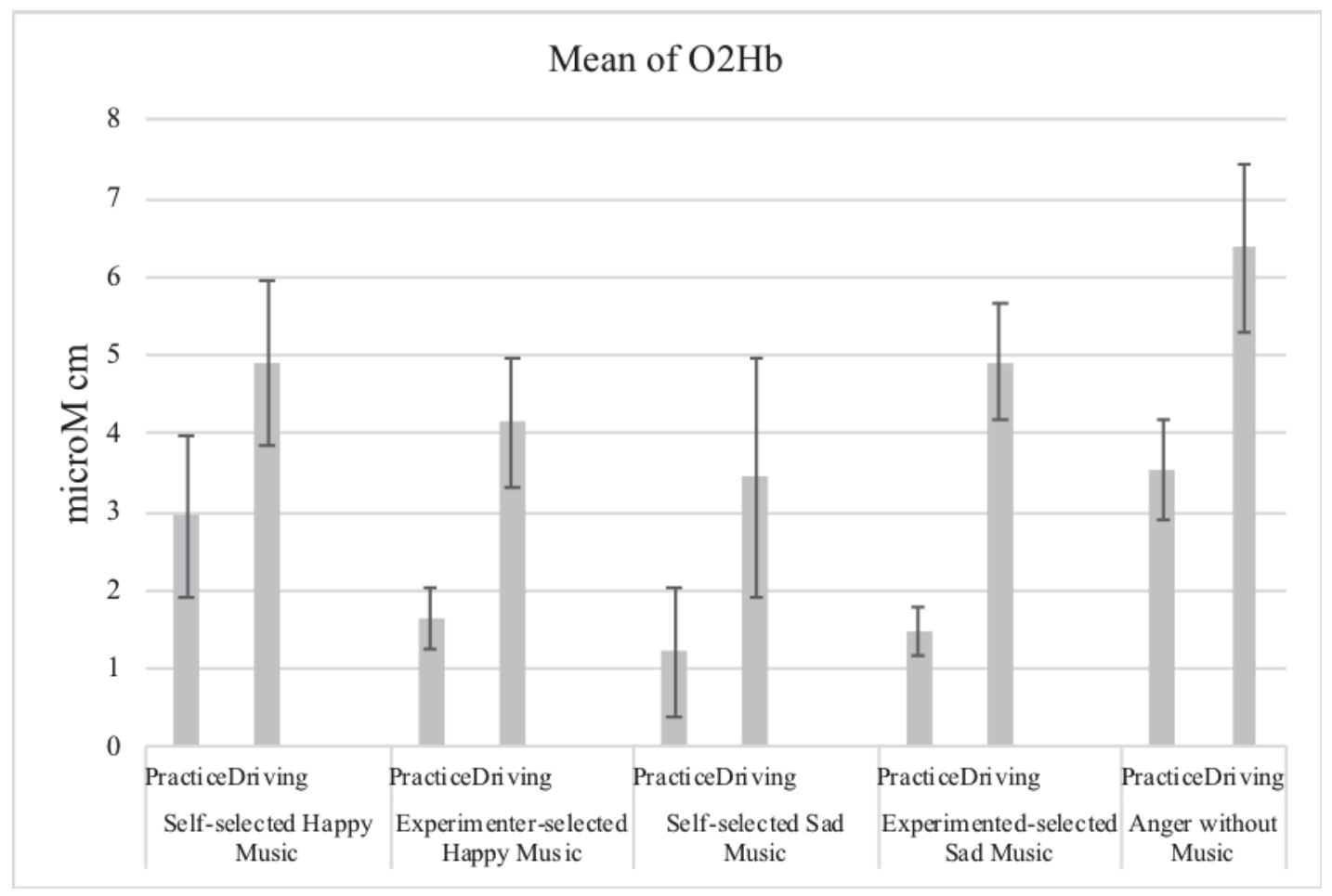

Figure 9.6. Mean of $\mathrm{O} 2 \mathrm{Hb}$ during the practice and driving sessions in each group. Error bars represent standard errors.

\subsection{Behavioral Data: Driving Errors}

Five Groups Comparisons

Several one-way repeated measures ANOVAs were performed to find drivers in which group made more errors. Number of crashes, lane departure, accelerator pedal position, 
brake pedal force, lane deviation, and speed were the considered variables for this section. Results showed that there were no differences among the groups $(\mathrm{p}>.05)$.

\section{Music Choice Comparisons}

To test whether self or experimenter selected music make a difference on driving behavior, participants were grouped based on the music selection way. Results showed there were no significant differences among the groups for any of those driving errors.

\subsection{Questionnaires}

\subsubsection{Workload}

Values more than 1.5 interquartile range (IQR's) in each group were labeled as outliers and were eliminated from the statistical analysis (Table 9.11).

9.11. Number of total participants, outliers, and participants in workload analysis.

\begin{tabular}{llll}
\hline Groups & $\begin{array}{l}\text { Total Number of } \\
\text { Participants }\end{array}$ & $\begin{array}{l}\text { Number of } \\
\text { Outliers }\end{array}$ & $\begin{array}{l}\text { Number of } \\
\text { Participants } \\
\text { in the } \\
\text { Analysis }\end{array}$ \\
\hline Self-selected happy music & 18 & 2 & 16 \\
\hline $\begin{array}{l}\text { Experimenter-selected happy } \\
\text { music }\end{array}$ & 20 & 0 & 20 \\
\hline Self-selected sad music & 19 & 1 & 18 \\
\hline Experimenter-selected sad music & 18 & 0 & 18 \\
\hline Anger without music & 15 & 0 & 15 \\
\hline
\end{tabular}

Workload Five Groups Comparisons

Several one-way ANOVAs were performed on workload factors to find out how much participants in the groups experienced workload differently. Results showed that 
workload-mental $\left(F(4,81)=2.69, p=.036, \eta_{\mathrm{p}}^{2}=.11\right)$ and workload-frustration $(F(4,83)$ $=2.68, p=.037, \eta_{\mathrm{p}}^{2}=.11$ were significantly different among the groups (Figure 9.7).

Workload-mental: Post Hoc tests with LSD showed that drivers who drove with selfselected happy music $(M=.24, S D=.06)$ reported significantly less workload-mental than drivers who drove with experimenter-happy music $(M=.29, S D=.04)$ and selfselected sad music $(M=.29, S D=.03)$. Also, drivers in experimenter-happy music $(M=$ $.29, S D=.04)$ mentioned significantly higher mental workload than participants in experimenter-sad music group $(M=.25, S D=.06)$.

Workload-frustration: Post Hoc tests with LSD showed that angry drivers' workloadfrustration who drove without music (Anger without music group) $(M=.22, S D=.1$ ) were significantly higher than those who drove with self-selected happy $(M=.14, S D=$ $.1)$ and self-selected sad music group $(M=.11, S D=.09)$. Moreover, self-selected-sad music $(M=.11, S D=.09)$ reduced frustration significantly more than experimenterhappy music $(M=.18, S D=.1)$. 


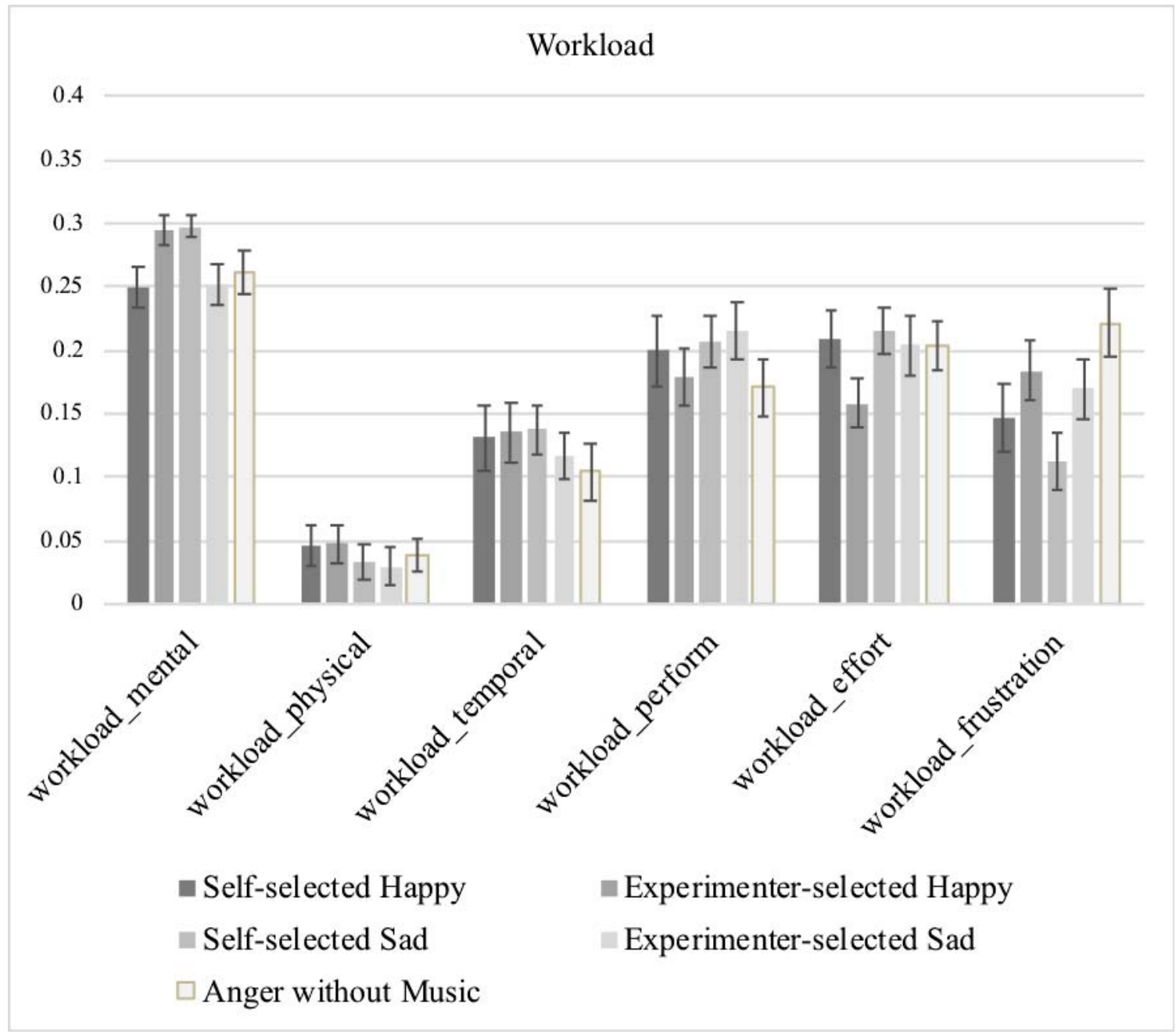

Figure 9.7. Drivers' workload scores for each subscale in each group. Error bars represent standard errors.

Workload Music Type Comparisons

Several one-way ANOVA were performed on workload factors to find if there are any differences among the groups. Results show that workload-frustration $(F(2,85)=3.26$, $\left.\eta_{\mathrm{p}}^{2}=.07\right)$ is different among the groups $(p=.043)$. 
Workload-frustration: Post Hoc tests with LSD showed that drivers in the control condition $(M=.22, S D=.1)$ showed significantly more frustration than drivers who listened to happy $(M=.16, S D=.1)$ and $\operatorname{sad}(M=.14, S D=.1)$ music.

Workload Music Choice Comparisons

Several one-way ANOVAs were performed on workload factors to find if there are any differences among the groups. Results showed that workload-frustration $(F(2,85)=4.85$, $\left.p=.010, \eta_{\mathrm{p}}{ }^{2}=.10\right)$ reported differently among the groups .

Workload-frustration: Post Hoc tests with LSD showed that drivers with self-selected music $(M=.12, S D=.1)$ showed significantly less frustration $(p<.05)$ than experimenter-selected music $(M=.17, S D=.1)$ and the control group $(M=.22, S D=.1)$ significantly more $(p<.05)$ frustration than happy $(M=.16, S D=.1)$ and $\operatorname{sad}(M=.14$, $S D=.1)$

\subsubsection{DAS, DBQ, CART, STAXI}

DAS, DBQ, CART and anger-expression-out subscale were not correlated with any of the driving errors $(p>.05)$. CART measures how participants perceived the music (either cognitively or emotionally). This questionnaire has 24 items on a scale from 1 to 7 . Half of the items measures drivers' cognitive perception of the songs and the other 12 items measure emotional perception of the song. Since most of the answers were in the same range, we need more participants to find a pattern between listeners' perception of a song and their behavioral reactions. 


\section{Discussion of Experiment 2}

There has been a lot of research about the effects of music and negative emotions on driving performance; however, the impact of different types of music on driving performance for drivers under anger emotion is not clear yet. This experiment aimed to explore the effects of emotional and musical factors on driving performance. Five groups of angry drivers drove while listening to different types of music in a pre-determined scenario with various hazards on the road. Drivers' reactions to hazards, errors, and overall performance were compared based on the music they listened to and their emotional states.

Results of drivers' self-report anger showed the anger induction procedure was successful. Most of the participants in all the five groups reported significantly higher scores on the anger scale after the recall and writing procedure. This result shows one aspect of emotion i.e., subjective feeling (Scherer, 2001, 2005; Thayer, Hansen, SausRose, \& Johnsen, 2009).

The results of this experiment did not show that the angry drivers in the music group had better driving performance than the angry drivers in the no music group. When participants were grouped based on the music emotion i.e., they listened to (happy and sad), and music selection (self vs experimenter selected), no significant difference was found in their driving performance as well. To understand why drivers' performance was not different among the groups, we need to look at other layers of data. 
Results of drivers' physiological data are consistent with their performance. Heart rate did not show any significant patterns among the groups. This means that angry drivers in the no music condition did not show higher arousal than the music groups as it was seen in the first experiment. Regarding HRV, the control group showed significantly higher HRV than all the other groups. Previous studies have shown that an increase in HRV is associated with regulating one's emotion (Thayer, Åhs, Fredrikson, Sollers, \& Wager, 2012). With HRV results the inconsistent pattern in drivers' performance between Experiments 1 and 2 is clearer. We can cautiously infer that angry drivers in the no music condition might try to regulate their emotion for themselves (because there was no external help, music) and so did not have worse driving performance than the drivers in the music groups. Participants' different emotion regulation patterns among the two experiments may be related to different types of driving simulators in the two experiments. Unlike the first experiment with a low fidelity simulator and a video game like scenario, the second experiment was conducted with a medium fidelity simulator, which had a more realistic environment. It is possible that participants in the higher fidelity driving simulator considered the driving task more seriously and made a bigger effort to drive as usual and regulate their emotions than in the lower fidelity simulator.

When drivers HR and HRV was compared in each group in practice and the driving sessions, drivers in Experimenter-selected sad music group showed significantly different patterns. Decreased HR and HRV from practice to the driving session in drivers who listened to self-selected sad music can be related to the interaction of some factors (minor key and self-selection) in music that can have major physiological impacts. 
Oxygenation patterns of PFC supported the behavioral data and the pattern of cardiovascular activity to some extent. As the same as Experiment 1, between group comparisons of $\mathrm{O} 2 \mathrm{Hb}$ did not show any patterns. However, within group comparisons showed that $\mathrm{O} 2 \mathrm{Hb}$ increased significantly from practice to the driving sessions in all five groups. Since PFC is responsible for higher level cognition and integrating thoughts, actions, and emotions (Miller, \& Cohen, 2001), higher levels of $\mathrm{O} 2 \mathrm{Hb}$ in the driving session (than the practice session) can be attributed to emotion, listening to music, and encountering the hazards.

Drivers' subjective feelings implied that they got angry after emotion induction procedure in all five groups; however, their physiological data were not consistent. Based on anger response style model of Stemmler (1993), the combination of weak physiological and behavioral and strong experience response is called low denial. Low denial is characterized by only an experiential reaction. This might happen when a person pretends to be angry. Therefore, the results of self-report anger might be biased towards the experimental demands where participants had to report their anger level after asking them to recall a memory that makes you angry. Conversely, drivers might overcome their anger and regulate their emotion for the driving task, which to some extent was supported with the physiological data.

Drivers' perception of the music was analyzed through a self-report questionnaire (CART-M). This questionnaire was used to find how much emotionally or cognitively drivers listened to music and whether the music selection way could influence on their perception of the music or not. Results of CART showed that the selection way was not 
correlated with the music perception intensity neither cognitively nor emotionally. This is consistent with drivers' behavioral data when they were grouped based on the music selection way. Self-selected and experimenter-selected music had similar influences on driving performance which implies the rejection of Hypothesis 4 (Angry drivers with self-selected music will show relatively better driving performance than drivers with experimenter-selected music). However, results from workload showed that drivers who drove with self-selected music reported less frustration.

Although CART-M did not show any difference among music perception, workload data showed that angry drivers' frustration levels were higher when they listened to a music piece that was not their choice or when they did not listen to any music at all.

Results of this study did not show any differences in terms of physiological and behavioral data related to the type of music emotion. In other words, angry drivers who listened to sad and happy music showed similar patterns. Even if the music pieces the experimenter selected as sad and happy were based on previous studies and our pilot results, people got different feelings when listening to the same music. Since the number of participants in each group is relatively low for this kind of generalization, more research is required to show the effects of different emotion of music.

To consider the role of personality characteristics in the story of driving with anger and listening to music, which indicates the motivational component in the emotional assessment, drivers' anger-expression style and their scores on DAS were tested in regards to their driving performance. Unlike the first experiment, results from DAS and 
anger expression style were not correlated with any of the driving errors (Hypothesis 6a). As discussed earlier, driving performance in this experiment did not show any patterns. Driving performance might be influenced by the type of the music. Since music is very personal and people's opinion, feeling, and preferences are different about different songs, and the songs in each group were selected based on two characteristics/variables (music emotion and selection way), larger groups of participants are required for smaller variances and clearer patterns. 


\section{General Discussion}

Designers and researchers try to balance drivers' workload for optimum performance by adding active in-vehicle systems. Driving is a dynamic process of continuous monitoring, perception, and responding under the influence of a wide range of variables such as drivers' personality characteristics, driving environment, types of vehicle, etc. In the driving context, any changes in emotional states may have negative consequences with its influences on cognition and behavior. Among all types of emotion, anger has been recognized as a dangerous emotion in the driving context. Deffenbacher, Lynch, Oetting, and Swaim (2002) argued that driver anger leads to aggressive driving. Since the vehicle is a limited environment, possible methods of emotional intervention are limited as well. In this regard music would be an easy, simple, and applicable approach to driver emotion mitigation. Music has been the target of many psychological and medical experiments for its ability to influence people's mood and body. Therefore, this study aimed to explore the idea of an in-vehicle auditory display that can estimate drivers' anger and play the most appropriate song for angry drivers.

There has been a lot of research and debate on the nature of emotions. Most researchers consider emotion as multidimensional and multifaceted processes (Appelhans, \& Luecken, 2006; Scherer, 2005; Thayer, 2006). Sechere (2005) and Thayer et al. (2009) claimed that to understand any emotional processes, changes in peripheral and central nervous systems, behavioral tendencies, and cognitive processing should be considered. Based on these approaches, this study was designed and conducted to understand angry drivers' emotional reactions. In two experiments, a total of 143 participants were 
recruited and randomly assigned to different groups. Groups were defined based on the types of music, who selected the music, and the emotion induction procedure. Results from self-report anger in both experiments showed that the emotion induction procedure was successful. In other words, results of self-report from the groups with anger induction procedure showed significantly higher levels of anger after the emotion induction procedure. Drivers mentioned that they were angrier after the 12-minute anger induction period through the recall and writing of personal memories in both studies. However, based on Sherer (2005), emotion is a multidimensional process and the subjective feeling is just one of the dimensions. Therefore, checking drivers' physiological data is the next logical step.

Among all the physiological changes, cardiovascular and PFC activities are considered to be important for emotional changes. To measure cardiovascular activity, HR and HRV were recorded during the experiment. In the first experiment, angry drivers who drove without listening to any music showed significantly higher HR than neutral drivers who did not listen to music and angry drivers who listened to self-selected music. This difference is most likely related to drivers' anger. As previous studies showed, anger is an emotion with negative valance and high arousal. High arousal is usually associated with higher HR. Moreover, HR increased significantly from practice to the driving session in angry drivers who did not listen to music and neutral drivers. In other words, music helped angry drivers' HR to come back to the practice level (before emotion induction). This can be interpreted as music changed angry drivers' HR and arousal level. In the Neutral without anger group, self-reported anger did not show that participants in this 
group became angry in any sessions but their HR decreased significantly which can be attributed to other variables. For example, they may have gotten bored or irritated from the experimental demands or writing about their daily activities.

In the second experiment, instead of HR, HRV showed clearer patterns. Regardless of the grouping method (based on the five groups, music type, or selection type), HRV was significantly higher in the control group. Previous studies showed that an increase in HRV is associated with regulating one's emotions (Thayer, Åhs, Fredrikson, Sollers, \& Wager, 2012). Appelhans and Luecken (2006) mentioned "HRV is a measure of the continuous interplay between sympathetic and parasympathetic influences on heart rate that yields information about autonomic flexibility and thereby represents the capacity for regulated emotional responding." The assumption was that higher HRV should be found in the music groups because music can be a tool to help angry drivers regulate their emotions. A possibility is that drivers in the control group actively mitigated their Anger without any external help (e.g., music) to overcome the driving demands, and so their HRV was higher than other music groups.

The cardiovascular system is responsible for providing sufficient blood flow to organs and the brain. Any environmental changes including emotional situations lead to changes in the blood flow and blood pressure by an intricate system. To regulate the changes in blood pressure, parasympathetic and sympathetic activations of autonomic nervous system will be involved. Therefore, there is a two-way connection between heart and the brain (Thayer, Åhs, Fredrikson, Sollers, \& Wager, 2012). Autonomic nervous system (ANS) is a key to generate physiological arousals. The autonomic nervous system 
(sympathetic and parasympathetic branches) is connected to the sinoatrial node of the heart. The sinoatrial node generates action potentials causing heart muscle contractions (heartbeat). Activation of sympathetic fibers leads to increment in HR and parasympathetic activation inhibit activity of the sinoatrial node to decrease HR. Consequently, faster heart rates mean shorter interbeat intervals and vice versa (Appelhans, \& Luecken, 2006). Thus, ANS effects on the timing of the heart beats. The sympathetic branch of ANS effects are slow, on the time scale of seconds, whereas the parasympathetic branch generates rapid changes in the beat to beat timing of the heart (Thayer, Åhs, Fredrikson, Sollers, \& Wager, 2012). Higher arousal is related to higher sympathetic activation and heart rate, and vice versa. The transition between high and low arousal states is related to the ANS's adjustments to heart rate. This adjustment (changing physiological arousal on a momentary basis) (Gross, 1998) is emotion regulation.

In the first experiment, the results of oxygenation level among the three groups (angry drivers who drove with and without music and neutral drivers) did not show any differences among the groups. However, when we compared the changes of each person through the sessions, Neutral drivers without music and Angry drivers with music had significantly higher $\mathrm{O} 2 \mathrm{Hb}$ level in the driving session in comparison to the practice one. Since PFC is responsible for coordinating thoughts and body, higher $\mathrm{O} 2 \mathrm{Hb}$ level can be related to better performance, emotion regulation, and cognitive controls in Neutral drivers without music and angry drivers with music groups. 
In the second experiment, the results of oxygenation level increased significantly from practice to the driving session in all groups. Among half of the previous studies (50\% of all studies) on brain region activated by emotional tasks, no specific part was recognized that activates across individual emotions. However, the medial prefrontal cortex (MPFC) was the only region that was commonly activated regardless of specific emotion or induction method (Phan, Wager, Taylor, \& Liberzon, 2002). Therefore, the same changes in all the groups may be related to the existence of emotion rather than implying a specific type of emotion.

In addition, workload measurement was added to figure out how much the perception of workload was different among the groups and whether it is related to drivers' emotion and the music they listened to. In Experiment 1, angry drivers who drove without music reported higher workload-effort. Drivers who listened to self-selected music perceived less workload-effort. Workload-effort refers to the amount of work (mentally and physically) requires to accomplish a task. Less perceived effort in the music group means that the driving task was perceived easier and simpler by angry drivers in comparison to drivers who drove in the same scenario without any music regardless of their emotional states.

In the same line, in Experiment 2, drivers who did not listen to any music reported higher frustration. Interestingly, when drivers listened to experimenter-selected music, they also showed higher frustration than control and self-selected music groups. It seems that music familiarity, preference, and self-selection help to reduce some aspects of workload regardless of the kind of the emotion that the music has. 
Anger can be expressed in different ways. Whether people's anger expression style is adaptive or maladaptive, it can be a good predictor of their driving behavior while they are angry. Results of the first study showed that drivers with anger expression-out style who tend to express their anger outwardly in a negative way had more reckless driving behavior. In this study, one of the goals is finding factors that can help an in-vehicle auditory system to understand drivers. Therefore, any information related to personality characteristics of the driver can be used for system customization purposes.

Overall, angry drivers' performance was worse than neutral drivers and this difference was significant when angry drivers did not listen to any music. Drivers in Anger without music group showed the worst fuel-efficiency performance in the first experiment. Drivers in this group reported that they felt angry after emotion induction, showed higher HR, less PFC activity, and less self-report success on driving performance. The patterns in line with lower performance on fuel-efficiency indicate drivers' emotional status. Lower PFC activity in this group in comparison to other groups is probably related to less activation of this part of brain, which is associated with complex information processing and higher-level decision making.

Drivers' performance in the second study did not show any differences among the groups. Although the result did not support our hypothesis that angry drivers who did not listen to music may have worse driving performance, physiological data (Higher HRV and $\mathrm{O} 2 \mathrm{Hb}$ level) uncovered the reasons behind it. 
Humans are multimodal information processing machines. Based on multiple resource theory (MRT), for two ongoing tasks, performance on both may be maintained if the tasks are in separate processing stages, or involve different processing modalities (Wickens, 2002). Although attention allocation occurs automatically for the majority of the time, people may not be able to attend to all the important information (e.g., while driving) when they are emotional. Results of this study showed that music by engaging different modalities (auditory modality vs visual modality) can mitigate drivers' anger and improve their driving performance. This is also in line with the theory of automaticity which suggests multiple processes can go on at the same time, when they are habitual and involve minimal conscious control (Iqbal, Ju, \& Horvitz, 2010). Therefore, based on MRT, this study showed that music can help angry drivers. Based on the results of this study, to design an in-vehicle auditory display for angry drivers, the below points should be considered:

1. The system should be able to monitor drivers' physiological reactions.

2. The system should be able to integrate subjective, behavioral, and physiological responses to a meaningful emotional state. For example, the system should be able to interpret higher HR as high arousal and if it is accompanied by other variables e.g., poor fuel-efficient driving behavior as anger.

3. The system should be sensitive to drivers' fuel-efficient driving behavior (e.g., speeding, abruptly flooring pedals). Results showed that other variables such as lane deviation, lane departure, etc. are not the main indicators of angry driving behavior. 
4. The system should play mostly self-selected music to reduce frustration.

5. The system should be customizable to some drivers' personality characteristics e.g., anger response style.

\subsection{Limitations and Future Work}

Although this study has a holistic approach on assessing and controlling the variables related to emotion and driving behavior, a few points remained that should be considered in future studies. To control the influence of a specific kind of music on drivers and physiological reactions, one song was played on repeat during the driving session. It is possible that some of the drivers got irritated from the repetition of the song and this irritation influenced on their emotional reactions. In real world, drivers usually listen to a list of music or they turn off the music player for certain situations and future studies should control these factors.

Another point is the source of emotion. The emotion induction procedure in this study was based on recall of a personal memory. Drivers' anger is sometimes related to events on the road rather than a personal issue (integral vs. incidental emotions). It will be interesting to find out the differences of physiological patterns, reactions, and music perception among them.

A similar study can be conducted with advanced neuroergonomic devices. For example, in the present dissertation, I used a 2 channel fNIRS. The device with more channels will provide more data about the location mapping, which will further disentangle the relationship between the emotional stimuli and drivers' responses. 
Finally, in this study the intensity of the emotion was not controlled. As shown in the self-report results, most of the participants reported average anger after emotion induction (around 3 or 4 out of 7). Next studies should consider the influence of anger intensity on physiological patterns, music perception, and performance.

This study uncovered some important points on music perception and emotional patterns. Result showed that music helps angry drivers in different ways. Music helps angry drivers to drive better and perceive less workload. However, not all kinds of music have the same influence. Self-selected music seems to help angry drivers more than experimented-selected music. It reduces frustration and improves driving behavior. Although this study did not show any strong relationships between specific kinds of emotional music and drivers' performance, overall positive influences of music on drivers' anger were supported. 


\section{Reference List}

AAA Foundation for Traffic Safety (2016). Prevalence of Self-Reported Aggressive Driving Behavior: United States, 2014. AAA Foundation for Traffic Safety.

Ambak, K., Shamsudini, S., Daniel, B. D., \& Ghani, A. R. A. (2017). Driver Anger Scale (DAS) Among Car Drivers: How Serious Are They? In MATEC Web of Conferences, 103, 08001. EDP Sciences.

Appelhans, B. M., \& Luecken, L. J. (2006). Heart rate variability as an index of regulated emotional responding. Review of General Psychology, 10(3), 229.

Bachoo, S., Bhagwanjee, A., \& Govender, K. (2013). The influence of anger, impulsivity, sensation seeking and driver attitudes on risky driving behaviour among post-graduate university students in Durban, South Africa. Accident Analysis \& Prevention, 55, 67-76.

Balconi, M., Grippa, E., \& Vanutelli, M. E. (2015). What hemodynamic (fNIRS), electrophysiological (EEG) and autonomic integrated measures can tell us about emotional processing. Brain and Cognition, 95, 67-76.

Balconi, M., \& Vanutelli, M. E. (2016). Hemodynamic (fNIRS) and EEG (N200) correlates of emotional inter-species interactions modulated by visual and auditory stimulation. Scientific Reports, 6, 23083.

Bartel, L. R. (1992). The development of the cognitive-affective response testMusic. Psychomusicology: A Journal of Research in Music Cognition, 11(1), 15. 
Bechara, A., Damasio, H., \& Damasio, A. R. (2000). Emotion, decision making and the orbitofrontal cortex. Cerebral Cortex, 10(3), 295-307.

Beck, K. H., Wang, M. Q., \& Mitchell, M. M. (2006). Concerns, dispositions and behaviors of aggressive drivers: What do self-identified aggressive drivers believe about traffic safety? Journal of Safety Research, 37(2), 159-165.

Beh, H.C., \& Hirst, R. (1999). Performance on driving-related tasks during music. Ergonomics 42(8), 1087-1098.

Berz, W. L. (1995). Working memory in music: A theoretical model. Music Perception, 353-364.

Blanchette, I., \& Richards, A. (2010). The influence of affect on higher level cognition: A review of research on interpretation, judgement, decision making and reasoning. Cognition \& Emotion, 24(4), 561-595.

Böddeker, I., \& Stemmler, G. (2000). Who responds how and when to anger? The assessment of actual anger response styles and their relation to personality. Cognition \& Emotion, 14(6), 737-762.

Brodsky, W. (2001). The effects of music tempo on simulated driving performance and vehicular control. Transportation Research Part F: Traffic Psychology and Behavior, $4(4), 219-241$. 
Brodsky, W. (2017). Driving with music: cognitive-behavioural implications. CRC Press.

Bodenhausen, G. V. (1993). Emotions, arousal, and stereotypic judgments: A heuristic model of affect and stereotyping. In Affect, Cognition and Stereotyping, 13-37.

Callahan, R. J. (2001). The impact of Thought Field Therapy on heart rate variability. Journal of Clinical Psychology, 57(10), 1153-1170.

Cassidy, G., \& Macdonald, R. (2009). The effects of music choice on task performance: A study of the impact of self-selected and experimenter-selected music on driving game performance and experience. Musicae Scientiae, 13(2), 357-386.

Cassidy, G. G., \& Macdonald, R. (2010). The effects of music on time perception and performance of a driving game. Scandinavian Journal of Psychology, 51(6), 455-464.

Chan, M., \& Singhal, A. (2015). Emotion matters: Implications for distracted driving. Safety Science, 72, 302-309.

Consiglio, W., Driscoll, P., Witte, M., \& Berg, W. P. (2003). Effect of cellular telephone conversations and other potential interference on reaction time in a braking response. Accident Analysis \& Prevention, 35(4), 495-500.

Cooper, C. K. (2013). The Impact of Emotional Content on Cognitive Performance and Self-Evaluations during Media Multitasking (Doctoral dissertation, The Ohio State University). 
Costin, R., Rotariu, C., \& Pasarica, A. (2012). Mental stress detection using heart rate variability and morphologic variability of EeG signals. In Electrical and Power Engineering (EPE), 2012 International Conference and Exposition on, 591-596. IEEE.

Cox, D. E. (2008). Neuropsychological and psychophysiological correlates of anger expression styles (Doctoral dissertation, Virginia Polytechnic Institute and State University).

Craft, R. H., \& Preslopsky, B. (2009). Driver distraction and inattention in the USA large truck and national motor vehicle crash causation studies. In 1st International Conference on Driver Distraction and Inattention (DDI 2009) Chalmers University of Technology, SwedenSAFER Vehicle and Traffic Safety CentreINRETS-ARCUEIL, FRANCE.

Cui, X., Bray, S., Bryant, D. M., Glover, G. H., \& Reiss, A. L. (2011). A quantitative comparison of NIRS and fMRI across multiple cognitive tasks. Neuroimage, 54(4), 28082821.

Cunningham, M. L., \& Regan, M. A. (2016). The impact of emotion, life stress and mental health issues on driving performance and safety. Road \& Transport Research: A Journal of Australian and New Zealand Research and Practice, 25(3), 40.

Dalton, B. H., \& Behm, D. G. (2007). Effects of noise and music on human and task performance: A systematic review. Occupational Ergonomics, 7(3), 143. 
Deffenbacher, J. L., Deffenbacher, D. M., Lynch, R. S., \& Richards, T. L. (2003). Anger, aggression, and risky behavior: a comparison of high and low anger drivers. Behaviour Research and Therapy, 41(6), 701-718.

Deffenbacher, J. L., Filetti, L. B., Lynch, R. S., Dahlen, E. R., \& Oetting, E. R., (2002). Cognitive-behavioral treatment of high anger drivers. Behaviour Research and Therapy, vol. 40, pp. 895-910.

Deffenbacher, J. L., Getting, E. R., \& Lynch, R. S. (1994). Development of a driving anger scale. Psychological Reports, 74(1), 83-91.

Deffenbacher, J. L., Huff, M. E., Lynch, R. S., Oetting, E. R., \& Salvatore, N. F. (2000). Characteristics and treatment of high-anger drivers. Journal of Counseling Psychology, $47(1), 5$.

Deffenbacher, J. L., Lynch, R. S., Oetting, E. R., \& Swaim, R. C. (2002). The Driving Anger Expression Inventory: A measure of how people express their anger on the road. Behaviour Research and Therapy, 40(6), 717-737. http://dx.doi.org/10.1016/S00057967(01)00063-8.

Deffenbacher, J. L., Lynch, R. S., Oetting, E. R., \& Yingling, D. A. (2001). Driving anger: Correlates and a test of state-trait theory. Personality and Individual Differences, 31(8), 1321-1331.

Dibben, N., \& Williamson, V. J. (2007). An exploratory survey of in-vehicle music listening. Psychology of Music, 35(4), 571-589. 
Easterbrook, J.A. (1959). The effects of emotion on cue utilization and the organization of behavior. Psychological Review, 66, 183-201.

Ehrlichman, H. (1987). Hemispheric asymmetry and positive-negative affect. In Duality and unity of the brain, 194-206. Palgrave Macmillan, London.

Ellis, H.C., \& Ashbrook, P.W. 1988. Resource allocation model of the effects of depressed mood states on memory. In Affect, Cognition and Social Behavior edited by K. Fiedler and J. Forgas: Toronto: Hogrefe: 25-43.

Ellsworth, P. C. (2013). Appraisal theory: Old and new questions. Emotion Review, 5(2), $125-131$.

Ellsworth, P. C., \& Smith, C. A. (1988). From appraisal to emotion: Differences among unpleasant feelings. Motivation and Emotion, 12(3), 271-302.

Eyben, F., Wöllmer, M., Poitschke, T., Schuller, B., Blaschke, C., Färber, B., \& NguyenThien, N. (2010). Emotion on the road-necessity, acceptance, and feasibility of affective computing in the car. Advances in human-computer interaction, 2010.

Fairclough, S. H., van der Zwaag, M., Spiridon, E., \& Westerink, J. (2014). Effects of mood induction via music on cardiovascular measures of negative emotion during simulated driving. Physiology \& Behavior, 129, 173-180.

FakhrHosseini, S., Jeon, M., \& Bose, R. (2015). Estimation of Drivers’ Emotional States Based on Neuroergonmic Equipment: An Exploratory Study Using fNIRS. Proceedings 
of the 7th International Conference on Automotive User Interfaces and Interactive Vehicular Applications (AutoUI'15), Nottingham, UK.

FakhrHosseini, M., Kirby, P., \& Jeon, M. (2015). Regulating Drivers’ Aggressiveness by Sonifying Emotional Data. In Proceedings of the 6th International Conference on Auditory Displays.

Fakhrhosseini, S. M., Landry, S., Tan, Y. Y., Bhattarai, S., \& Jeon, M. (2014, September). If you're angry, turn the music on: Music can mitigate anger effects on driving performance. In Proceedings of the 6th International Conference on Automotive User Interfaces and Interactive Vehicular Applications, 1-7. ACM.

Groene, R., \& Barrett, S. (2012). The Effect of Music and Suggestion on Defensive Driving Responses of High School Students: Implications for Music Therapy. Music Therapy Perspectives, 30(1), 56-64.

Haake, A. B. (2011). Individual music listening in workplace settings. An exploratory survey of offices in the UK. Musicae Scientiae, 15(1), 107-129.

Hancock, P. A. (1984). Environmental stressors. In J.S Warm (ed.), Sustained Attention in Human Performance (New York: Wiley), 112-128.

Hanoch, Y., \& Vitouch, O. (2004). When less is more information, emotional arousal and the ecological reframing of the Yerkes-Dodson law. Theory \& Psychology, 14(4), 427452. 
Harmon-Jones, E., \& Sigelman, J. (2001). State anger and prefrontal brain activity: evidence that insult-related relative left-prefrontal activation is associated with experienced anger and aggression. Journal of Personality and Social Psychology, 80(5), 797.

Harrison, W. A. (2009). Reliability of the Driver Behaviour Questionnaire in a sample of novice drivers.

Hart, S. G. (2006, October). NASA-task load index (NASA-TLX); 20 years later. In Proceedings of the human factors and ergonomics society annual meeting, 50(9), 904908). Sage CA: Los Angeles, CA: Sage Publications.

Haworth, N., \& Symmons, M. (2001). Driving to reduce fuel consumption and improve road safety. Monash University Accident Research Centre. http://www. rsconference. com/pdf/RS010036. pdf.

Hennessy, D. A. (2000). The Influence of Music on Driver Stress. Journal of Applied Social Psychology, 30(8), 1709-1719.

Hennessy, D. A., \& Wiesenthal, D. L. (1999). Traffic congestion, driver stress, and driver aggression. Aggressive Behavior, 25(6), 409-423.

Hughes, G. M., Rudin-Brown, C. M., \& Young, K. L. (2013). A simulator study of the effects of singing on driving performance. Accident Analysis \& Prevention, 50, 787-792. 
Iqbal, S. T., Ju, Y. C., \& Horvitz, E. (2010, April). Cars, calls, and cognition:

investigating driving and divided attention. In Proceedings of the SIGCHI Conference on Human Factors in Computing Systems (pp. 1281-1290). ACM.

Izard, C. E. (1992). Basic emotions, relations among emotions, and emotion-cognition relations. Psychological Review, 99(3), 561-565.

Jallais, C., Roge, J., Alexandra, F., \& Gabaude, C. (2013). Effects of anger and sadness on the drivers' useful visual field: toward a tunnel vision phenomenon? In $3 \mathrm{rd}$ International Conference on Driver Distraction and Inattention.

Jallais, C., \& Gilet, A. L. (2010). Inducing changes in arousal and valence: Comparison of two mood induction procedures. Behavior Research Methods, 42(1), 318-325.

Jansen, S., Westphal, A., Jeon, M., \& Riener, A. (2013). Detection of drivers' incidental and integral affect using physiological measures. In Adjunct Proceedings of the 5th AutomotiveUI Conference, Eindhoven, the Netherlands.

Jarašūniene, A., \& Jakubauskas, G. (2007). Improvement of road safety using passive and active intelligent vehicle safety systems. Transport, 22(4), 284-289.

Jeon, M. (2012, September). A systematic approach to using music for mitigating affective effects on driving performance and safety. In Proceedings of the 2012 ACM Conference on Ubiquitous Computing, 1127-1132. ACM.

Jeon, M. (2016). Don't cry while you're driving: sad driving is as bad as angry driving. International Journal of Human-Computer Interaction, 32(10), 777-790. 
Jeon, M., \& Walker, B. N. (2011). What to detect? Analyzing factor structures of affect in driving contexts for an emotion detection and regulation system. In Proceedings of the Human Factors and Ergonomics Society Annual Meeting, 55(1), 1889-1893). Sage CA: Los Angeles, CA: Sage Publications.

Jeon, M., Yim, J. B., \& Walker, B. N. (2011). An angry driver is not the same as a fearful driver: effects of specific negative emotions on risk perception, driving performance, and workload. In Proceedings of the 3rd International Conference on Automotive User Interfaces and Interactive Vehicular Applications, 137-142. ACM.

Johnson, D. R. (2009). Goal-directed attentional deployment to emotional faces and individual differences in emotional regulation. Journal of Research in Personality, 43(1), 8-13.

Juslin, P. N., \& Laukka, P. (2004). Expression, perception, and induction of musical emotions: A review and a questionnaire study of everyday listening. Journal of New Music Research, 33(3), 217-238.

Kahneman, D. (1973). Attention and effort. Englewood Cliffs, NJ: Prentice-Hall, 1063.

Kawakami, A., Furukawa, K., Katahira, K., \& Okanoya, K. (2013). Sad music induces pleasant emotion. Frontiers in Psychology, 4.

Koechlin, E., Ody, C., \& Kouneiher, F. (2003). The architecture of cognitive control in the human prefrontal cortex. Science, 302(5648), 1181-1185. 
Lajunen, T., Parker, D., \& Summala, H. (2004). The Manchester driver behaviour questionnaire: a cross-cultural study. Accident Analysis \& Prevention, 36(2), 231-238.

Lang, A., Park, B., Sanders-Jackson, A. N., Wilson, B. D., \& Wang, Z. (2007). Cognition and emotion in TV message processing: How valence, arousing content, structural complexity, and information density affect the availability of cognitive resources. Media Psychology, 10(3), 317-338

Lazarus, R. S. (1982). Thoughts on the relations between emotion and cognition. American Psychologist, 37(9), 1019.

Lazarus, R. S. (1991). Progress on a cognitive-motivational-relational theory of emotion. American Psychologist, 46(8), 819-834.

Lee, J. D. (2008). Fifty years of driving safety research. Human Factors: The Journal of the Human Factors and Ergonomics Society, 50(3), 521-528.

Lee, C., Yoo, S. K., Park, Y., Kim, N., Jeong, K., \& Lee, B. (2006, January). Using neural network to recognize human emotions from heart rate variability and skin resistance. In 2005 IEEE Engineering in Medicine and Biology 27th Annual Conference, 5523-5525, IEEE.

Lee, J. D., Young, K. L., \& Regan, M. A. (2008). Defining driver distraction. Driver distraction: Theory, Effects, and Mitigation, 31-40.

León-Carrión, J., \& León-Domínguez, U. (2012). Functional near-infrared spectroscopy (fNIRS): principles and neuroscientific applications. In Neuroimaging-Methods. InTech. 
Lerner, J. S., \& Tiedens, L. Z. (2006). Portrait of the angry decision maker: How appraisal tendencies shape angers influence on cognition. Journal of Behavioral Decision Making, 19(2), 115.

Lerner, J. S., \& Keltner, D. (2000). Beyond valence: Toward a model of emotion-specific influences on judgement and choice. Cognition \& Emotion, 14(4), 473-493.

Levenson, R. W., Ekman, P., \& Friesen, W. V. (1990). Voluntary facial action generates emotion-specific autonomic nervous system activity. Psychophysiology, 27, 363-384.

Lewis, E. (2002). The relationship of listening to classical music on first graders' ability to retain information (Thesis/Dissertation). Retrieved from Education Resources Information Center online library (ERIC No. ED471383).

Lisetti, C. L., \& Nasoz, F. (2005, July). Affective intelligent car interfaces with emotion recognition. In Proceedings of 11 th International Conference on Human Computer Interaction, Las Vegas, NV, USA.

Liu, Y., Singh, S., \& Subramanian, R. (2015). Motor vehicle traffic crashes as a leading cause of death in the United States, 2010 and 2011 (No. DOT HS 812 203).

Lynch, R. S., Deffenbacher, J. L., Filetti, L. B., \& Dahlen, E. R. (1999). Anger, aggression, and risk associated with driving anger. In 107th Annual Convention of the American Psychological Association, Boston, MA.

Makishita, H., \& Matsunaga, K. (2008). Differences of drivers' reaction times according to age and mental workload. Accident Analysis \& Prevention, 40(2), 567-575. 
Matthews, G., Quinn, C.E.J., \& Mitchell, K.J. (1998). Rock music, task-induced stress and simulated driving performance. Transport Research Laboratory, 20-32.

Mesken, J., Hagenzieker, M. P., Rothengatter, T., \& de Waard, D. (2007). Frequency, determinants, and consequences of different drivers' emotions: An on-the-road study using self-reports, (observed) behaviour, and physiology. Transportation Research Part F: Traffic Psychology and Behaviour, 10(6), 458-475.

Miller, E. K., \& Cohen, J. D. (2001). An integrative theory of prefrontal cortex function. Annual Review of Neuroscience, 24(1), 167-202.

Nabi, R. L. (1999). A cognitive-functional model for the effects of discrete negative emotions on information processing, attitude change, and recall. Communication Theory, 9(3), 292-320.

Neighbors, C., Vietor, N. A., \& Knee, C. R. (2002). A motivational model of driving anger and aggression. Personality and Social Psychology Bulletin, 28(3), 324-335.

Nilsson, U. (2009). Soothing music can increase oxytocin levels during bed rest after open-heart surgery: a randomized control trial. Journal of Clinical Nursing, 18(15), 21532161.

Nguyen, T. N., Nilsson, S., Hellström, A. L., \& Bengtson, A. (2010). Music therapy to reduce pain and anxiety in children with cancer undergoing lumbar puncture: a randomized clinical trial. Journal of Pediatric Oncology Nursing, 27(3), 146-155. 
North, A. C. \& Hargreaves, D. J. (1999). Music and driving game performance.

Scandinavian Journal of Psychology, 40, 285-92.

Novaco, R. W. (1976). The functions and regulation of the arousal of anger. American Journal of Psychiatry, 133(10), 1124-1128.

Oron-Gilad, T., Ronen, A., \& Shinar, D. (2008). Alertness maintaining tasks (AMTs) while driving. Accident Analysis \& Prevention, 40(3), 851-860.

Pratto, F., \& John, O. P. (1991). Automatic vigilance: the attention-grabbing power of negative social information. Journal of personality and social psychology, 61(3), 380.

Pembrook, R. G. (1987). The effect of vocalization on melodic memory conservation. Journal of Research in Music Education, 35(3), 155-169.

Pêcher, C., Lemercier, C., \& Cellier, J. M. (2009). Emotions drive attention: Effects on driver's behaviour. Safety Science, 47(9), 1254-1259.

Phan, K. L., Wager, T., Taylor, S. F., \& Liberzon, I. (2002). Functional neuroanatomy of emotion: a meta-analysis of emotion activation studies in PET and fMRI. Neuroimage, 16(2), 331-348.

Potegal, G. S. M., \& Spielberger, C. (Eds.). (2010). International handbook of anger. 924. Springer New York.

Ranney, T. A., Mazzae, E., Garrott, R., \& Goodman, M. J. (2000, July). NHTSA driver distraction research: Past, present, and future. In Driver distraction internet forum, 2000. 
Reinhardt, E. (1999). EcoDrive in Switzerland: A success story of Energy 2000. EcoDrive Conference proceedings, Graz, Austria, 56-61.

Roidl, E., Frehse, B., \& Höger, R. (2014). Emotional states of drivers and the impact on speed, acceleration and traffic violations-A simulator study. Accident Analysis \& Prevention, 70, 282-292.

Russell, J. A., \& Mehrabian, A. (1974). Distinguishing anger and anxiety in terms of emotional response factors. Journal of consulting and clinical psychology, 42(1), 79.

Ryali, S., Supekar, K., Abrams, D. A., \& Menon, V. (2010). Sparse logistic regression for whole-brain classification of fMRI data. NeuroImage, 51(2), 752-764.

Saarikallio, S., \& Erkkilä, J. (2007). The role of music in adolescents' mood regulation. Psychology of Music, 35(1), 88-109.

Salamé, P., \& Baddeley, A. (1989). Effects of background music on phonological shortterm memory. The Quarterly Journal of Experimental Psychology, 41(1), 107-122.

Schaefer, A., Nils, F., Sanchez, X., \& Philippot, P. (2010). Assessing the effectiveness of a large database of emotion-eliciting films: A new tool for emotion researchers. Cognition and Emotion, 24(7), 1153-1172.

Scherer, K. R. (2005). What are emotions? And how can they be measured? Social Science Information, 44(4), 695-729. 
Scherer, K. R., \& Wallbott, H. G. (1994). Evidence for universality and cultural variation of differential emotion response patterning. Journal of Personality and Social Psychology, 66, 310-328.

Schoeneburg, R., \& Breitling, T. (2005). Enhancement of active and passive safety by future PRE-SAFE systems. In 2005 ESV Conference, Washington DC Paper, 05-0080.

Schwarz, N. (2000). Emotion, cognition, and decision making. Cognition \& Emotion, 14(4), 433-440.

Schwebel, D. C., Severson, J., Ball, K. K., \& Rizzo, M. (2006). Individual difference factors in risky driving: The roles of anger/hostility, conscientiousness, and sensationseeking. Accident Analysis \& Prevention, 38(4), 801-810.

Sendelbach, S. E., Halm, M. A., Doran, K. A., Miller, E. H., \& Gaillard, P. (2006). Effects of music therapy on physiological and psychological outcomes for patients undergoing cardiac surgery. Journal of Cardiovascular Nursing, 21(3), 194-200.

Sloboda, J.A., O’Neill, S.A., \& Vivaldi, A. (2001). Functions of music in everyday life: An exploratory study using the experience sampling method, Musicae Scientae 5, 9-32.

Spielberger, C. D. (1999). STAXI-2: State-trait anger expression inventory-2:

Professional manual. Odessa, FL: Psychological Assessment Resources.

Spielberger, C. D. (1988). Professional manual for the state-trait anger expression inventory (STAXI)(research ed.). Tampa, FL: Psychological Assessment Resources. Inc.(PAR). 
Stanojević, P., Sullman, M. J., Jovanović, D., \& Stanojević, D. (2018). The impact of police presence on angry and aggressive driving. Accident Analysis \& Prevention, 110, 93-100.

Stanovich, K. E. (2009). Distinguishing the reflective, algorithmic, and autonomous minds: Is it time for a tri-process theory. In two minds: Dual processes and beyond, 5588.

Stemmler, G. (1992). Differential psychophysiology: Persons in Situations. New York: Springer.

Stephens, A. N., \& Groeger, J. A. (2009). Situational specificity of trait influences on drivers' evaluations and driving behaviour. Transportation Research Part F: Traffic Psychology and Behaviour, 12(1), 29-39.

Stutts, J. C., Feaganes, J., Rodgman, E. A., Hamlett, C., Meadows, T., \& Reinfurt, D. W. (2003). Distractions in everyday driving (Report prepared for AAA Foundation for Traffic Safety). Washington, DC.

Suda, M., Morimoto, K., Obata, A., Koizumi, H., \& Maki, A. (2008). Emotional responses to music: towards scientific perspectives on music therapy. Neuroreport, 19(1), 75-78.

Tasca, L. (2000). A review of the literature on aggressive driving research. Ontario Advisory Group on Safe Driving Secretariat, Road User Safety Branch, Ontario Ministry of Transportation. 
Tefft, B. (2012). Motor Vehicle Crashes, Injuries, and Deaths in Relation to Driver Age: United States, 1995-2010. Project Summary Report. Washington, DC: AAA Foundation for Traffic Safety.

Teigen, K. H. (1994). Yerkes-Dodson: A law for all seasons. Theory \& Psychology, 4(4), 525-547.

Thayer, J. F., Åhs, F., Fredrikson, M., Sollers, J. J., \& Wager, T. D. (2012). A metaanalysis of heart rate variability and neuroimaging studies: implications for heart rate variability as a marker of stress and health. Neuroscience \& Biobehavioral Reviews, 36(2), 747-756.

Thayer, J. F., Hansen, A. L., Saus-Rose, E., \& Johnsen, B. H. (2009). Heart rate variability, prefrontal neural function, and cognitive performance: the neurovisceral integration perspective on self-regulation, adaptation, and health. Annals of Behavioral Medicine, 37(2), 141-153.

Tiedens, L. Z., \& Linton, S. (2001). Judgment under emotional certainty and uncertainty: the effects of specific emotions on information processing. Journal of Personality and Social Psychology, 81(6), 973.

Underwood, G., Chapman, P., Wright, S., \& Crundall, D. (1999). Anger while driving. Transportation Research Part F: Traffic Psychology and Behavior, 2(1), 55-68. 
Ünal, A. B., Platteel, S., Steg, L., \& Epstude, K. (2013). Blocking-out auditory distracters while driving: A cognitive strategy to reduce task-demands on the road. Accident Analysis \& Prevention, 50, 934-942.

Ünal, A. B., Steg, L., \& Epstude, K. (2012). The influence of music on mental effort and driving performance. Accident Analysis \& Prevention, 48, 271-278.

Vagg, P. R., \& Spielberger, C. D. (1979). State-Trait Anger Expression Inventory ${ }^{\mathrm{TM}}$ Interpretive Report (STAXI-2: IR $\left.{ }^{\mathrm{TM}}\right)$. Psychol. Assess. Resour. Inc, 6.

Van der Zwaag, M. D., Dijksterhuis, C., de Waard, D., Mulder, B. L., Westerink, J. H., \& Brookhuis, K. A. (2012). The influence of music on mood and performance while driving. Ergonomics, 55(1), 12-22.

Van der Zwaag, M. D., Fairclough, S., Spiridon, E., \& Westerink, J. H. (2011, October). The impact of music on affect during anger inducing drives. In International Conference on Affective Computing and Intelligent Interaction (pp. 407-416). Springer, Berlin, Heidelberg.

Vanutelli, M. E., \& Balconi, M. (2015). Perceiving emotions in human-human and human-animal interactions: Hemodynamic prefrontal activity (fNIRS) and empathic concern. Neuroscience Letters, 605, 1-6.

Wallbott, H. G., Scherer, R. (1989). Assessing emotion by questionnaire. Emotion, Theory, Research, and Experience, 4, 69-71. Academic Press. 
Wickens, C. D. (2002). Multiple resources and performance prediction. Theoretical Issues in Ergonomics Science, 3(2), 159-177.

Wickens, C. M., Toplak, M. E., \& Wiesenthal, D. L. (2008). Cognitive failures as predictors of driving errors, lapses, and violations. Accident Analysis \& Prevention, 40(3), 1223-1233.

Wiesenthal, D. L., Hennessy, D. A., \& Totten, B. (2003). The influence of music on mild driver aggression. Transportation Research Part F: Traffic Psychology and Behaviour, $6(2), 125-134$.

Yamada, M. (2002). The effect of music on the performance and impression in a racing video game. In C. Stevens., D. Burnham., G. McPherson, E. Schubert., \& J. Renwick (eds), Proc of the 7th International Conference on Music Perception \& Cognition. Causal Productions, Adelaide, 340-43.

Young, K., Regan, M., \& Hammer, M. (2007). Driver distraction: A review of the literature. Distracted Driving, 379-405. 


\section{A NASA-TLX}

Sharek, D. (2009). NASA-TLX Online Tool (Version 0.06) [Internet Application].

Research Triangle, NC. Retrieved from http://www.nasatlx.com

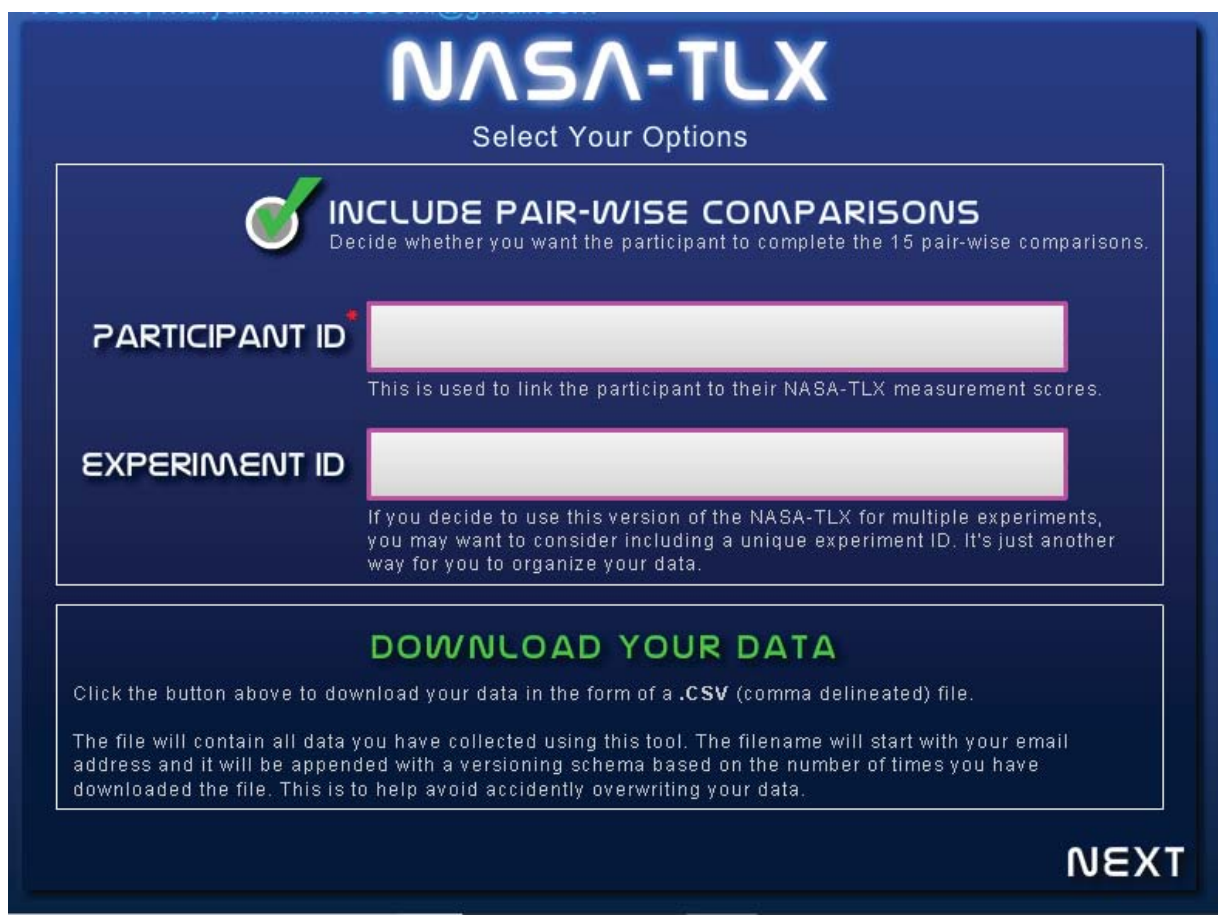




\section{NAS^-TLX WORKLOAD ASSESSMENT}

\section{Instructions}

The following assessment is used to measure your personal opinion on how much workload was required of you during the task you just completed.

In this assessment, you will first be asked to rate six workload measures.

After you have completed the ratings, you will be asked to compare which of two workload measures is more important than the other when considering the task you just completed. You will be asked to answer 15 of these pairings.

There is no right or wrong answer.

When you are ready, click the Start button to begin.

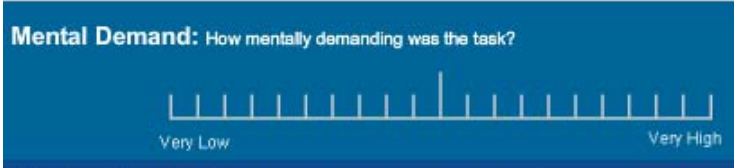

Physical Demand: How physically demanding was the task?

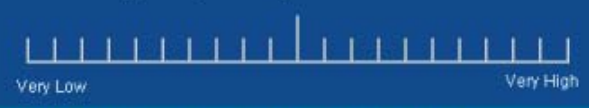

Temporal Demand: How hurried or rushed was the pece of the task?

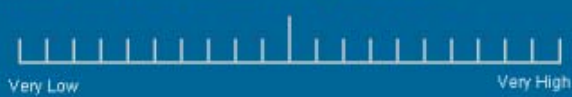

Performance: How successful were you in accomplishing what you were asked to do?

$\sqcup 111111|| 11111111$ Poor

Effort: How hard did you have to work to accomplish your level of performance?

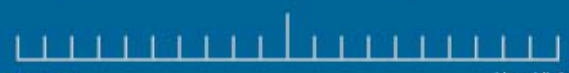

Very Low Very High

Frustration: How insecure, discouraged, irritated, stressed, and annoyed were you?

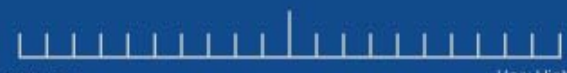

\section{INSTRUCTIONS:}

Please rate all six workload measures on the left by clicking a point on the scale that best represents your experience with the task you just completed.

Consider each scale individually and select your responses carefully. Mouse over the scale definitions for additional information.

Your ratings will play an important role in the evaluation being conducted. Your active participation is essential to the success of this experiment, and is greatly appreciated.

Click the Submit button when you have completed all six ratings.

Please note that the Performance scale goes from Poor on the left to Good on the right.

\section{SUENNIT}


Of the two workload measures below, which one contributed the most to the task you just completed?

\section{Temporal Demand}

or

\section{Effort}

\section{SUBMIT}

Of the two workload measures below, which one contributed the most to the

task you just completed?

\section{Performance}

or

\section{Frustration}

SUBMIT 
Of the two workload measures below, which one contributed the most to the task you just completed?

\section{Frustration}

or

\section{Mental Demand}

\section{SUBMIT}

Of the two workload measures below, which one contributed the most to the task you just completed?

\section{Physical Demand}

or

\section{Frustration}


Of the two workload measures below, which one contributed the most to the task you just completed?

\section{Mental Demand}

or

Effort

SUBMIT

Of the two workload measures below, which one contributed the most to the task you just completed?

Temporal Demand

or

Mental Demand

SUBMIT 
Of the two workload measures below, which one contributed the most to the task you just completed?

Mental Demand

or

Physical Demand

SUBMIT

Of the two workload measures below, which one contributed the most to the task you just completed?

Frustration

or

Effort

SUBNIT 
Of the two workload measures below, which one contributed the most to the task you just completed?

\section{Performance}

or

\section{Temporal Demand}

\section{SUBMIT}

Of the two workload measures below, which one contributed the most to the task you just completed?

Temporal Demand

or

\section{Frustration}

SUBMIT 
Of the two workload measures below, which one contributed the most to the task you just completed?

\section{Effort}

or

\section{Performance}

SUBMIT

Of the two workload measures below, which one contributed the most to the task you just completed?

\section{Effort}

or

\section{Physical Demand}


Of the two workload measures below, which one contributed the most to the task you just completed?

Physical Demand

or

Performance

SUBMIT

Of the two workload measures below, which one contributed the most to the task you just completed?

\section{Performance}

or

Mental Demand

SUBMIT 
Of the two workload measures below, which one contributed the most to the task you just completed?

\section{Physical Demand}

or

\section{Temporal Demand}

\section{THANK YOU VERY MUCH!}

Please let the experimenter know that you are done. 